EFEITO DA TEMPERATURA DE ENVELHECIMENTO SOBRE AS PROPRIEDADES MECÂNICAS E RESISTÊNCIA À CORROSÃO POR PITE DO AÇO INOXIDÁVEL MARTENSÍTICO ENDURECIDO POR PRECIPITAÇÃO UNS S46500

Dissertação de Mestrado apresentada à Escola Politécnica da Universidade de São Paulo para obtenção do título de Mestre em Ciências.

SÃO PAULO

2013 


\section{EFEITO DA TEMPERATURA DE ENVELHECIMENTO SOBRE AS PROPRIEDADES MECÂNICAS E RESISTÊNCIA À CORROSÃO POR PITE DO AÇO INOXIDÁVEL MARTENSÍTICO ENDURECIDO POR PRECIPITAÇÃO UNS S46500}

Dissertação de Mestrado apresentada à Escola Politécnica da Universidade de São Paulo para obtenção do título de Mestre em Ciências, dentro do Programa Engenharia Metalúrgica.

Área de Concentração:

Engenharia Metalúrgica e de Materiais

Orientadora:

Professora Dra. Neusa Alonso-Falleiros

SÃO PAULO

2013 
Este exemplar foi revisado e corrigido em relação à versão original, sob responsabilidade única do autor e com a anuência de seu orientador.

São Paulo, 17 de dezembro de 2013.

Assinatura do autor

Assinatura do orientador

FICHA CATALOGRÁFICA

Beraldo, Camila Haga

Efeito da temperatura de envelhecimento sobre as propriedades mecânicas e resistência à corrosão por pite do aço inoxidável martensítico endurecido por precipitação UNS S46500 / C.H. Beraldo. -versão corr. -- São Paulo, 2013.

p. 107

Dissertação (Mestrado) - Escola Politécnica da Universidade de São Paulo. Departamento de Engenharia Metalúrgica e de Materiais.

1. Aço inoxidável martensítico 2. Corrosão 3. Endurecimento por precipitação 4. Tratamento térmico 5. Cloreto 6. Sulfato I. Universidade de São Paulo. Escola Politécnica. Departamento de Engenharia Metalúrgica e de Materiais II. t. 
Dedico este trabalho aos meus amores,

Marcelo e Cecília. 


\section{AGRADECIMENTOS}

São muitas as pessoas que agradeço neste momento tão especial da minha vida: Primeiramente aos meus queridos pais, Maria Valderei e Silvio, por sempre me incentivarem nos estudos e ressaltar a importância do aprendizado para o nosso crescimento pessoal e profissional.

À minha Alma Gêmea, Marcelo, por sempre estar ao meu lado e compartilhar deste sonho em cada instante.

À Prof. Dra. Neusa Alonso-Falleiros por me receber com muita atenção e carinho e me orientar, na vida acadêmica e na vida pessoal.

À Embraer - ELEB, em especial ao Vladimir, ao Alessandro e a toda equipe da Engenharia de Materiais ELEB, por viabilizar a realização deste estudo.

A todos meus queridos amigos e família que torceram, pois me fortaleceram a cada dia.

Aos novos amigos, Wilmar, Duberney e Lívio, que estiveram comigo em cada etapa deste estudo.

Aos funcionários da biblioteca do PMT/USP, Sra Clélia de Lourdes Lara Meguerditchian e Sr. Gilberto Martins pelo apoio na busca de informações.

Ao Prof. Dr. Rodrigo Magnabosco e ao Departamento de Engenharia de Materiais do Centro Universitário da FEI por auxiliar e disponibilizar os recursos que possibilitaram o enriquecimento deste estudo.

A todos aqueles amigos que de alguma forma contribuíram para que este trabalho fosse realizado.

E, por fim, não com menor importância, agradeço a Deus por me dar forças, estar ao meu lado e me proporcionar esse momento tão feliz de realização e superação! 


\section{RESUMO}

Os aços inoxidáveis endurecidos por precipitação vêm sendo largamente empregados na indústria aeronáutica, por combinar resistência mecânica, tenacidade à fratura e resistência à corrosão. E deste modo, são materiais que possibilitam a substituição dos aços carbonos utilizados atualmente, que necessitam de tratamento superficial adicional, como o cádmio, para melhorar a resistência à corrosão. A utilização desses revestimentos traz desvantagens como o custo, a fabricação, a susceptibilidade à fragilização por hidrogênio além dos aspectos ambientais.

Neste contexto, o aço endurecido por precipitação UNS S46500, designado como Custom $465 \AA$ foi avaliado considerando o efeito da temperatura de envelhecimento sobre as propriedades mecânicas e a resistência à corrosão por pite. Amostras tratadas nas condições solubilizada e envelhecida a $510^{\circ} \mathrm{C}$ (H950) e 538ㅇ $\mathrm{C}(\mathrm{H} 1000)$ foram submetidas ao ensaio de tração, caracterização microestrutural e ensaios de polarização potenciodinâmica (PP) para determinar a resistência à corrosão por pite. Os exames microestruturais foram realizados com auxílio de microscopia óptica (MO), microscopia eletrônica de varredura $(\mathrm{MEV})$, espectroscopia de energia dispersiva (EDS) e difração de raios $X$. Também foram realizadas análises utilizando o software Thermo-Calc. A resistência à corrosão por pite foi avaliada em solução $0,6 \mathrm{M} \mathrm{NaCl}$ com adições crescentes de $\mathrm{Na}_{2} \mathrm{SO}_{4}$. Os resultados obtidos nos ensaios de PP nas duas condições de tratamento térmico foram comparados entre si e com resultados disponíveis na literatura (CALDERÓN-HERNANDEZ, 2012) para o aço inoxidável UNS S30403 (304L). Os exames e análises da microestrutura revelaram que o aço Custom 465® envelhecido apresenta uma matriz martensítica, precipitados de fase chi, austenita e precipitados $\mathrm{Ni}_{3} \mathrm{Ti}$. O tratamento H950 apresentou maior resistência mecânica e menor alongamento do que o tratamento H1000. Tal comportamento foi devido à produção de maior porcentagem de fase chi e menor porcentagem de austenita nesse tratamento de envelhecimento. Os diferentes tratamentos térmicos, condição solubilizada, H950 e H1000 apresentaram praticamente a mesma resistência à corrosão por pite. Por outro lado, o aço Custom $465 \AA$ apresentou ótima resposta à inibição da nucleação de pite com adições crescentes de sulfato em meio de $0,6 \mathrm{M} \mathrm{NaCl}$, sendo que a condição $\mathrm{H} 1000$ se sobressai sobre a H950 nessa questão. Além disso, através da adição de sulfato foi 
possível obter maior resistência a corrosão por pite do aço Custom $465 \AA$ comparativamente ao aço 304L. Tal comportamento foi discutido em termos da afinidade química entre níquel, cloreto e sulfato, levando a maior resistência à corrosão por pite quando o aço contém maior teor de níquel (que é o caso do aço Custom $465 \AA)$. Este trabalho indicou que o critério na escolha do tratamento de envelhecimento do aço Custom $465 \AA$ deve ser o das propriedades mecânicas almejadas, uma vez que a resistência à corrosão por pite mostrou-se praticamente independente do tratamento térmico.

Palavras-chave: corrosão por pite, aço inoxidável martensítico endurecível por precipitação, maraging, tratamento térmico, cloreto, sulfato. 


\begin{abstract}
The precipitation hardened stainless steels have been widely used in the aircraft industry to combine mechanical strength, fracture toughness and corrosion resistance. And therefore, are materials that enable replacement of the carbon steels used today, which require additional surface treatment, such as cadmium plating, to improve the corrosion resistance. The use of such coatings brings disadvantages such as cost, manufacturing, susceptibility to hydrogen embrittlement beyond environmental aspects.
\end{abstract}

In this context, the precipitation hardened steel UNS S46500, known as Custom $465 \AA$ were evaluated for the effect of aging temperature on the mechanical properties and the resistance to pitting corrosion. Treated samples in solubilized and aged condition at $510{ }^{\circ} \mathrm{C}(\mathrm{H} 950)$ and $538^{\circ} \mathrm{C}(\mathrm{H} 1000)$ were subjected to tensile strength test, microstructural characterization and potentiodynamic polarization (PP) tests to determine the pitting corrosion resistance. The microstructural studies were performed with the aid of optical microscopy (OM), scanning electron microscopy (SEM), energy dispersive spectroscopy (EDS) and X-ray diffraction. Analyzes were also performed using the Thermo -Calc software. The resistance to pitting corrosion was evaluated at $0.6 \mathrm{M} \mathrm{NaCl}$ solution with increasing additions of $\mathrm{Na}_{2} \mathrm{SO}_{4}$. The results obtained from tests of PP in both heat treatment conditions were compared with each other and with results available in the literature (CALDERÓN HERNANDEZ, 2012) to stainless steel UNS S30403 (304L). The analysis of the microstructure revealed that the steel aged Custom 465 ® presents a martensitic matrix, chi precipitates, $\mathrm{Ni}_{3} \mathrm{Ti}$ precipitates and austenite phase. The $\mathrm{H} 950$ age treatment had higher mechanical strength and lower elongation than the treatment H1000. Such behavior was due to the production of higher percentage of chi and a lower percentage of austenite phase in aging treatment. The different heat treatments, solubilized condition, H950 and $\mathrm{H} 1000$ showed almost the same pitting corrosion resistance. On the other hand, the Custom 465® showed good response to pitting inhibition with increasing nucleating additions of sulfate in $0.6 \mathrm{M} \mathrm{NaCl}$, with enhanced result for $\mathrm{H} 1000$ condition. Furthermore, by adding sulfate was possible to obtain greater pitting corrosion resistance of Custom $465 \AA$ compared to the $304 \mathrm{~L}$ steel. This behavior has been discussed in terms of the chemical affinity between nickel, chloride and sulphate, leading to higher pitting corrosion resistance when the steel contains a higher nickel 
content (which is the case of steel Custom $465 \AA$ ). This study indicates that the criterion in selecting the aging heat treatment of Custom $465 \AA$ steel must be the desired mechanical properties, since the pitting corrosion resistance was found to be substantially independent of heat treatment.

Key words: martensitic precipitation hardening stainless steel, aging, pitting, corrosion, chloride, sulphate, maraging. 


\section{LISTA DE FIGURAS}

Figura 1: Diagrama mostrando a relação entre processamento - microestrutura propriedades. (Modificado. WRIGHT; JUNG, 2011)

Figura 2: Isotermas do diagrama Fe-Cr-Ni a (a) $1300^{\circ} \mathrm{C}$, (b) $1200^{\circ} \mathrm{C}$, (c) $1100^{\circ} \mathrm{C} \mathrm{e} \mathrm{(d)}$ $1000^{\circ} \mathrm{C}$. (Modificado. RAYNOR; RIVLIN, 1988).

Figura 3: Isotermas do diagrama Fe-Cr-Ni a $900^{\circ} \mathrm{C}, 800^{\circ} \mathrm{C}$ e $650^{\circ} \mathrm{C}$. (Modificado. RAYNOR; RIVLIN, 1988)

Figura 4: Isotermas do diagrama Fe-Ti-Cr. (Modificado. RAGHAVAN, 1987). .29

Figura 5: Representação esquemática da composição das fases intermediárias no sistema ferro-cromo-molibdênio. (Modificado. BECHTOLD; VACHER, 1957). 30

Figura 6: Isotermas do diagrama de fases Fe-Cr-Mo-Ni da liga contendo $70 \% \mathrm{Fe}$. (BECHTOLD; VACHER, 1957).

Figura 7: Diagrama ilustrando o tratamento térmico dos aços endurecidos por precipitação. (Modificado. WRIGHT; JUNG, 2011).

Figura 8: Modelo proposto por SCHNITZER et al. (2010) para explicar a formação da austenita revertida. (Modificado. SCHNITZER et al., 2010) 37

Figura 9: Imagem de MET da amostra envelhecida a $575^{\circ} \mathrm{C}$ por $3 \mathrm{~h}$. Austenita revertida (marcada pelas setas) nos grãos da antiga austenita. Aço $13 \mathrm{Cr}-8 \mathrm{Ni}-\mathrm{Mo}$, contento Ni e Al. (SCHNITZER et al., 2010).

Figura 10: Efeito da quantidade de austenita sobre o limite de escoamento (LE) e limite de resistência (LR) do aço $\mathrm{PH}$ 17-4 (contém $\mathrm{Ni}$ e $\mathrm{Cu}$ ). (Modificado. NAKAGAWA; MIYAZAKI, 1999).

Figura 11: Temperatura solvus para compostos estabilizadores do tipo MX (onde $M$ é o metal e X é o C ou N). (Modificado. GATES; JAGO, 1987) Os valores indicados por círculos correspondem a nitreto e carboneto formados em Fe não-ligado. $\mathrm{O}$ ponto indicado por triângulo corresponde a nitreto de titânio formado na liga $\mathrm{Fe}$ $18 \% \mathrm{Cr}-2 \% \mathrm{Mo}$. Na presença de $\mathrm{Cr}$, o TiN forma-se em temperatura mais baixa porque o Cr aumenta a solubilidade do Ti no Fe. 
Figura 12: Curva de polarização em meio $0,1 \mathrm{M} \mathrm{HCl}+0,4 \mathrm{M} \mathrm{NaCl}$ a temperatura ambiente. Velocidade de varredura $0,1 \mathrm{mV} \cdot \mathrm{s}^{-1}$. (Modificado. WEGRELIUS; OLEFJORD, 1995) 42

Figura 13: Modelo da estrutura do filme passivo proposto por Okamoto (1973). .44

Figura 14: Modelo do mecanismo de penetração. (Modificado. MARCUS; OUDAR, 1995)

Figura 15: Pressão do filme passivo calculada como função da espessura do filme, considerando a superfície do filme com constante dielétrica $\varepsilon=10$, tensão superficial $\mathrm{V}=100$ dina. $\mathrm{cm}^{-1}$ e campo elétrico $\mathrm{E}=4 \times 10^{6}, 5 \times 10^{6}$ e $6 \times 10^{6} \mathrm{~V} . \mathrm{cm}^{-1}$. (Modificado. SATO, 1971)

Figura 16: Pressão do filme passivo calculada como função da espessura do filme, considerando a superfície do filme com constante dielétrica $\varepsilon=10$, tensão superficial $Y=100$ dina. $\mathrm{cm}^{-1}$ e campo elétrico $E=4 \times 10^{6} \mathrm{~V} \cdot \mathrm{cm}^{-1}$, e tensão superficial $\mathrm{Y}=10,50,100$ e 200 dina. $\mathrm{cm}^{-1}$. (Modificado. SATO, 1971)

Figura 17: Modelo do mecanismo da quebra mecânica do filme passivo. (Modificado. MARCUS; OUDAR, 1995)

Figura 18: Curva para aço inoxidável 18-8 em solução $\mathrm{H}_{2} \mathrm{SO}_{4}$, mostrando o efeito da adição de $\mathrm{Cl}^{-} \cdot 25^{\circ} \mathrm{C}, \mathrm{pH}=2,05$ e $\mathrm{EH}=+800 \mathrm{mV}, \mathrm{y}=$ tempo de indução (Modificado. HOAR; JACOB, 1967)

Figura 19: ĺons cloreto substituindo as moléculas de água: (b) inibição da formação da ponte de hidrogênio; (a') resultando na quebra do filme passivo.

Figura 20: Crescimento autocatalítico do pite na presença de cloreto. As setas tracejadas indicam o movimento dos elétrons. (EVANS, U. R. apud DAVISON; DEBOLD; JOHNSON, 1987)

Figura 21: Curvas de polarização em $0,1 \mathrm{M} \mathrm{NaCl}$ mostrando o aumento do potencial de pite com a adição de $\mathrm{Na}_{2} \mathrm{SO}_{4}, 2^{\circ} \mathrm{C}$. (Modificado. LECKIE; UHLIG, 1966). .... 55

Figura 22: Tratamento térmico do aço Custom $465 \AA$ 57

Figura 23: Corpo de prova de tração. (ASTM E8/E8M, 2011)..... 58

Figura 24: Representação esquemática da célula plana. (CORDEIRO, 2001). 59

Figura 25: Representação esquemática do potenciostato e célula utilizados. .60 
Figura 26: Propriedades mecânicas encontradas após ensaio de tração; os valores medidos são a média de 6 ensaios de tração.

Figura 27: Comparação das propriedades mecânicas nas condições H950 e H1000 obtidas no presente trabalho.

Figura 28: Curvas típicas de tração encontradas para o Custom $465 \AA$ nas condições (a) H950 (Área=28,56mm²; D=6,03mm; Lo=30 mm; Lf=33,04 mm; $\sigma_{R}=1859,35 \mathrm{MPa}$; $\sigma_{\mathrm{e}}=1836,7 \mathrm{MPa}$ ) e (b) H1000 (Área=28,18 mm²; $\mathrm{D}=5,99 \mathrm{~mm} ; \mathrm{L}_{0}=30 \mathrm{~mm} ; \mathrm{Lf}=33,13$ $\left.\mathrm{mm} ; \sigma_{\mathrm{R}}=1703,6 \mathrm{MPa} ; \sigma_{\mathrm{e}}=1697,16 \mathrm{MPa}\right)$.

Figura 29: Imagens em MO das amostras polidas até $1 \mu \mathrm{m}$ : (a) solubilizada; (b) H950 e (c) H1000, todas com aumento de 50x. .70

Figura 30: (a) Imagem de elétrons secundários da amostra na condição H950, polida, mostrando o precipitado; (b) e (c) resultados dos EDS's realizados no precipitado e na matriz.

Figura 31: Imagens em MO na condição (a) solubilizada; (b) H950 e (c) H1000; todas com aumento de $200 x$, ataque Vilella. As setas indicam os precipitados de TiN. 73

Figura 32: Imagens de elétrons secundários na condição solubilizada: (a) ataque com Vilella e (b) ataque com Fry. .75

Figura 33: Imagens de elétrons secundários na condição H950: (a) ataque com Vilella e (b) ataque com Fry. .76

Figura 34: Imagens de elétrons secundários na condição H1000: (a) ataque com Vilella e (b) ataque com Fry..... .77

Figura 35: Imagens de elétrons secundários nas condições: (a) H950 e (b) H1000, ataque com Vilella, mostrando a diferença na quantidade de precipitados observados e no tamanho de grão. .79

Figura 36: Imagem de elétrons secundários na condição solubilizada e análise por EDS, mostrando que o precipitado (indicado pela seta) é rico em Mo e Ti (ataque com Vilella). .80 
Figura 37: Imagem de elétrons secundários da amostra na condição H1000 e análise por EDS, mostrando que as partículas escuras são ricas em Ti (nitreto de titânio) (ataque com Vilella).

Figura 38: Espectro de difração de raios $X$ das amostras: (a) solubilizada; (b) H950 e (c) H1000. (fases: $\alpha=$ ferrita; $X=$ chi).

Figura 39: Resultado do Thermo-Calc para o Custom $465 \AA$ (composição química Tabela 4) mostrando as fases que podem ser encontradas no equilíbrio. As linhas tracejadas indicam as temperaturas de tratamento $\mathrm{H} 950\left(510^{\circ} \mathrm{C}\right)$ e $\mathrm{H} 1000\left(538^{\circ} \mathrm{C}\right)$.

Figura 40: Curvas típicas de polarização potenciodinâmica obtidas para o aço Custom 465® nas condições: (a) solubilizada; (b) H950 e (c) H1000; com adições crescentes de sulfato $\left(\mathrm{Na}_{2} \mathrm{SO}_{4}\right)$.

Figura 41: Potencial de pite médio (Ep): (a) para o aço Custom 465® e (b) para Custom $465 \AA$ e $304 \mathrm{~L}$. Os valores para o aço 304L pertencem ao trabalho CalderónHernández (2012). Teor fixo de 0,6M NaCl. .88

Figura 42: Imagens obtidas em MO da morfologia dos pites encontrados em ensaio de polarização potenciodinâmica, condições: (a) solubilizada; (b) H950 (c) H1000 em meio $0,6 \mathrm{M} \mathrm{NaCl}$. .90

Figura 43: Imagens obtidas em MO da morfologia dos pites encontrados em ensaio de polarização potenciodinâmica, condições: (a) solubilizada; (b) H950 (c) H1000 em meio $0,6 \mathrm{M} \mathrm{NaCl}+0,06 \mathrm{M} \mathrm{Na}_{2} \mathrm{SO}_{4}$. Aumento $100 x$. .92

Figura 44: Imagens de em MEV da morfologia dos pites encontrados em ensaio de polarização potenciodinâmica, condições: (a) $\mathrm{H} 950$ e (b) $\mathrm{H} 1000$ em meio $0,6 \mathrm{M} \mathrm{NaCl}$ $+0,06 \mathrm{M} \mathrm{Na}_{2} \mathrm{SO}_{4}$. 


\section{LISTA DE TABELAS}

Tabela 1: Composição química de aços inoxidáveis martensíticos endurecidos por precipitação. (AMS 5963, 2007; WASKO; AGGEN, 1993).

Tabela 2: Características das fases intermediárias no diagrama Fe-Cr-Mo-Ni. (BECHTOLD; VACHER, 1957).....

Tabela 3: Propriedades mecânicas típicas de aços inoxidáveis martensíticos endurecidos por precipitação. (AMS 5963, 2007; SEDRIKS, 1996). .35

Tabela 4: Composição química do aço inoxidável Custom 465® (\% em massa). ....56

Tabela 5: Dimensão do corpo de prova de tração. (ASTM E8/E8M, 2011) ................58

Tabela 6: Concentração dos eletrólitos estudados 61

Tabela 7: Composição química dos reagentes. (BENSCOTER, 1985) .62

Tabela 8: Média (de seis ensaios) dos resultados encontrados no ensaio de tração.

Tabela 9: Fases determinadas no Thermo-Calc. .85

Tabela 10: Resumo da caracterização do aço Custom $465 \AA$. .85

Tabela 11: Potenciais de pite do aço Custom 465® e 304L (V, Ag/AgCl). .86

Tabela 12: Regressão linear do $\mathrm{Ep}(\mathrm{y})$ em função do teor de $\mathrm{SO}_{4}^{-2}(\mathrm{x})$ - dados da Figura 41. 98 


\section{LISTA DE ABREVIATURAS E SIGLAS}

$\mathrm{Ag} / \mathbf{A g C l}$ - prata-cloreto de prata

$\mathrm{AL}$ - Alongamento

CDP - Corpo de prova

CST - Corrosão sob tensão

DRX - Difração de raios $X$

EDS - Espectroscopia de energia dispersiva

Ep - Potencial de pite

H1000 - Tratamento térmico de envelhecimento na condição $538^{\circ} \mathrm{C}\left(1000^{\circ} \mathrm{F}\right) / 4$ horas

H950 - Tratamento térmico de envelhecimento na condição $510^{\circ} \mathrm{C}\left(950^{\circ} \mathrm{F}\right) / 4$ horas

i crit - Densidade de corrente crítica para passivação

MET - Microscopia eletrônica de transmissão

MEV - Microscópio eletrônico de varredura

Mf - Temperatura de fim de transformação martensítica

MO - Microscópio ótico

Ms - Temperatura de início de formação martensítica

PP - Polarização Potenciodinâmica

PRE - Pitting Resistance Equivalence

SADP - Difração de elétrons de área selecionada

SCE - Eletrodo de Calomelano Saturado

TCC - Tetragonal de corpo centrado

WDS - Espectrometria por Dispersão de Comprimento de Onda

a-Fe - ferrita

$\mathrm{Y}$-Fe - austenita

$\varepsilon-$ Épsilon

$\eta-$ Eta

$\sigma_{e}-$ Limite de escoamento

$\sigma_{\mathbf{R}}-$ Limite de resistência

$\boldsymbol{\sigma}$ - Sigma

p-Rho

$\mathrm{X}$ - Chi 


\section{SUMÁRIO}

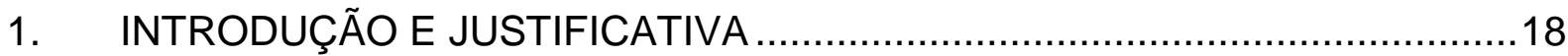

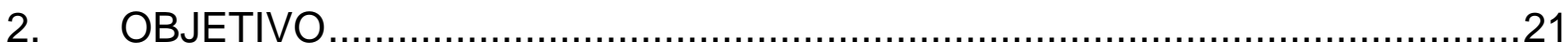

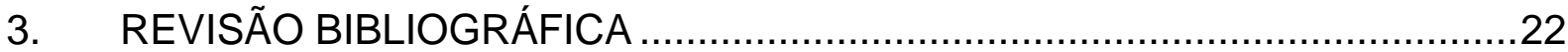

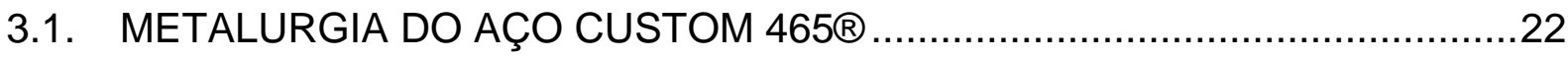

3.1.1. Aços inoxidáveis endurecidos por precipitação ...................................22

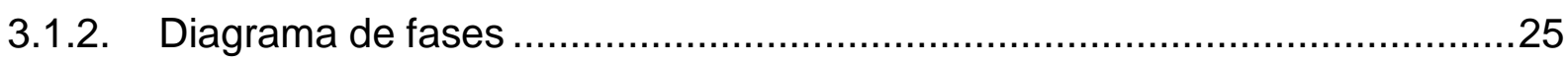

3.1.3. Tratamento térmico dos aços martensíticos endurecidos por precipitação..33

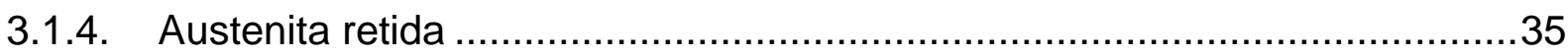

3.1.5. Influência dos elementos de liga ................................................ 39

3.2. CORROSÃO POR PITE EM AÇOS INOXIDÁVEIS ..................................43

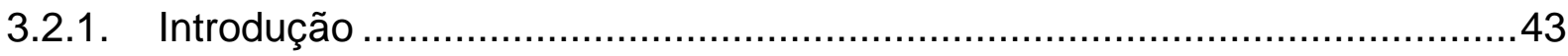

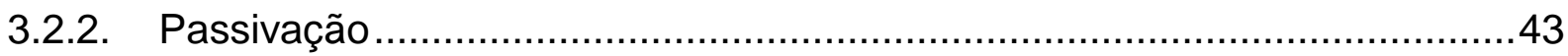

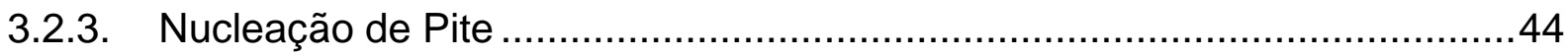

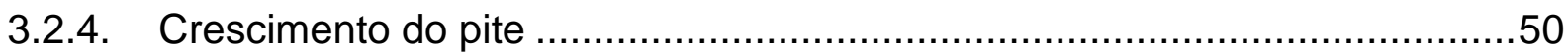

3.2.5. Resistência à corrosão dos aços endurecidos por precipitação..................52

3.2.6. Sulfato como inibidor de corrosão por pite ...........................................54

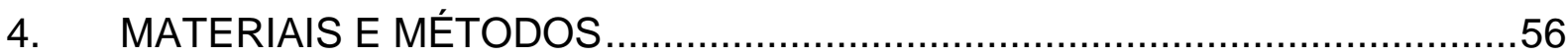

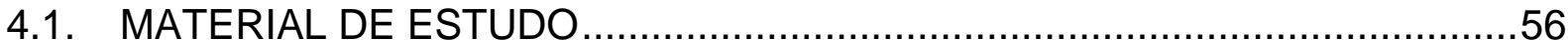

4.2. TRATAMENTO TÉRMICO E ENSAIOS MECÂNICOS ...............................56

4.3. POLARIZAÇÃO POTENCIODINÂMICA ................................................. 59

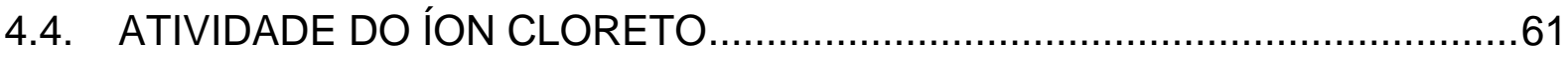

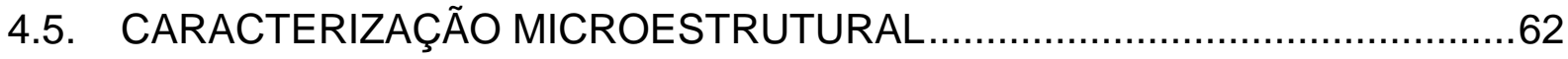

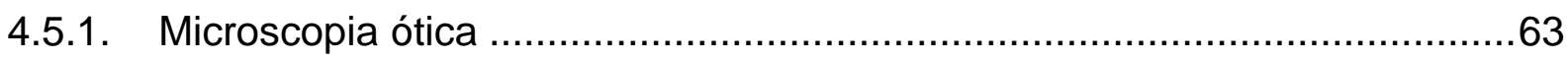

4.5.2. Microscopia eletrônica de varredura ...........................................63

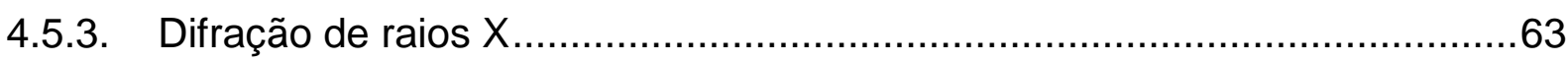




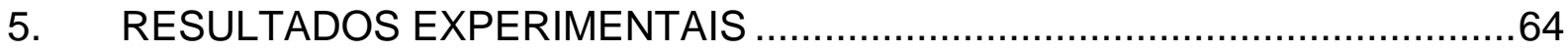

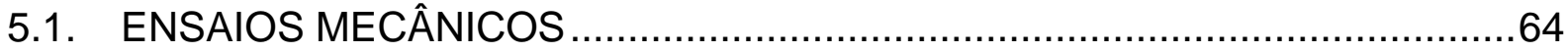

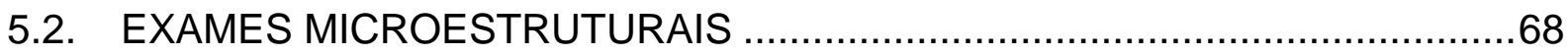

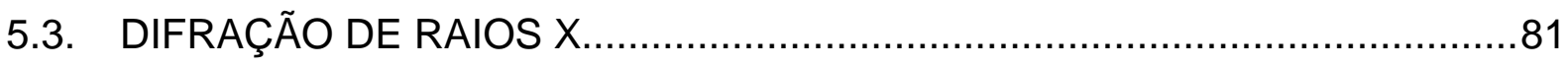

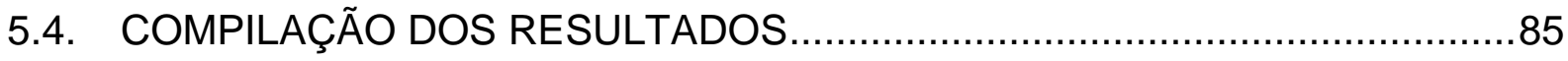

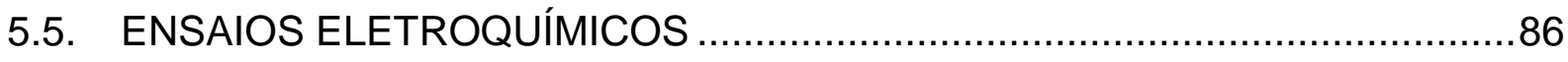

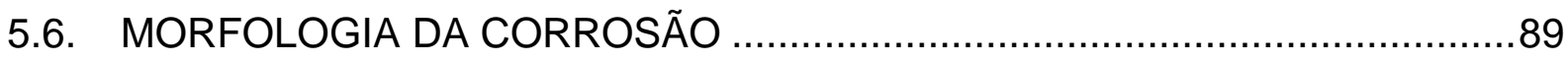

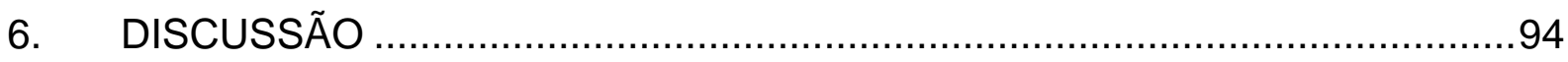

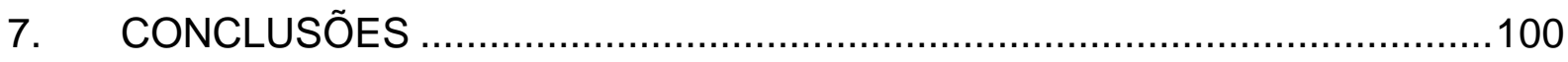

8. SUGESTÕES PARA TRABALHOS FUTUROS.........................................101

9. REFERÊNCIAS BIBLIOGRÁFICAS ….................................................102 


\section{INTRODUÇÃO E JUSTIFICATIVA}

Uma pesquisa realizada em 2006 mostrou que nos Estados Unidos os custos com a prevenção da corrosão estão na ordem de 20 bilhões de dólares por ano. (CRAIG; LANE; ROSE, 2006). No Brasil, segundo Nunes (2007), é comum adotar-se o índice de $3,5 \%$ do Produto Interno Bruto como o valor devido aos gastos diretos e indiretos gerados por problemas de corrosão, o que para o ano de 2012 corresponderia a cerca de 40 bilhões de reais. (NUNES, 2007; IBGE, 2013). O que se observa é que são frequentes os casos em que na fase de concepção do projeto, os sistemas e componentes são desenhados para atender requisitos funcionais, elétricos, peso, enquanto que atributos como a resistência à corrosão e meio ambiente recebem menor atenção. (CRAIG; LANE; ROSE, 2006)

No caso da fabricação de componentes que necessitam de alto desempenho estrutural, devido a fatores econômicos, em geral são empregados os aços carbono que oferecem alta resistência mecânica. No entanto, esses materiais que exibem limite de resistência na faixa de 1650 MPa a 2070 MPa, possuem baixa resistência à corrosão e em algumas faixas dessa resistência mecânica são susceptíveis à fragilização por hidrogênio.

Esses aços carbono de alta resistência mecânica e baixa quantidade de elementos de liga, como por exemplo, os aços UNS G43406 (4340) e UNS K44220 (300M), são largamente empregados na indústria aeronáutica, sendo aplicados em componentes estruturais, como o trem de pouso. O emprego desses materiais exige a aplicação de tratamentos superficiais, para melhorar a resistência à corrosão. O cádmio é o principal elemento utilizado para promover essa propriedade. (MARTIN; KOSA; DULMAINE, 1997)

No entanto, atualmente, além de atender as propriedades especificadas em projeto, os materiais são analisados com relação ao seu efeito sobre o meio ambiente. Por meio de conferências, leis e protocolos, como por exemplo o Protocolo de Kyoto, assinado pelo Brasil, os países estão buscando novas tecnologias que preservem o meio ambiente e a saúde humana.

A União Européia por meio da regulamentação denominada REACH (Regulation on Registration, Evaluation, Authorisation and Restriction of Chemicals), vem assegurar 
a proteção da saúde humana e do meio ambiente, dos riscos que são oferecidos por componentes químicos, ao mesmo tempo em que está promovendo o desenvolvimento de métodos alternativos, novos materiais, a competitividade e a inovação. (European Comission, 2012) No mundo globalizado, essas leis acabam se estendendo a todos os fabricantes que servem os clientes europeus, uma vez que estes não aceitarão produtos que infrinjam as leis do REACH. Dentro desse escopo, o cádmio e seus compostos foram catalogados e já possuem restrições quanto à sua utilização. No presente ano, ele entrou na lista de substâncias candidatas a serem banidas (SVHC - Substances of Very High Concern); ou seja, as indústrias dos setores aeronáutico, aeroespacial, mineração, offshore e setores nucleares que utilizarem o cádmio em seus produtos numa concentração superior a 0,1\% devem notificar o órgão químico responsável, ECHA (European Chemicals Agency). Este órgão irá fiscalizar e acompanhar o cumprimento das obrigações legais a que os fabricantes estão sujeitos. (ECHA, 2013)

Devido a esses fatores, novos materiais foram desenvolvidos combinando alta resistência mecânica, tenacidade à fratura e resistência à corrosão. Um desses materiais é o aço inoxidável martensítico endurecido por precipitação, UNS S46500, conhecido comercialmente como Custom 465®. Este aço, patenteado pela empresa americana Carpenter Technology Inc. (número da patente 5.681.528), atende à especificação AMS 5963, sendo de composição similar ao UNS S46500. O Custom $465 \AA$ além da aplicação aeronáutica vem sendo empregado na indústria marinha, óleo e gás, ferramentas, médica, entre outros. (DEPARTMENT OF DEFENSE, 2003; MARTIN; KOSA; DULMAINE, 1997)

Desse modo, as novas propostas trocam materiais que apresentam em serviço corrosão uniforme (generalizada), pois são aços carbono, por um material cuja principal forma de corrosão é a corrosão localizada (pite, fresta, corrosão sob tensão), pois trata-se de aço inoxidável, o qual deve trabalhar na condição passiva. Particularmente, na aplicação aeronáutica a principal preocupação é a falha por corrosão sob tensão, uma vez que os componentes trabalham sob solicitação de esforços mecânicos e os ambientes podem variar desde a atmosfera úmida, passando pela poluída industrialmente e pela salina (regiões marítimas). Deve-se lembrar de que um dos fatores que levam à falha por corrosão sob tensão é a 
concentração de tensão na base de pites, originados em ambientes que contém umidade e cloreto.

Portanto, neste estudo escolheu-se avaliar a resistência à corrosão por pite do aço inoxidável endurecido por precipitação (Custom 465®), que é uma das opções para substituição dos aços carbono tratados superficialmente contra à corrosão. A corrosão por pite é uma forma de corrosão localizada, onde pequenas cavidades se formam devido à quebra da película passiva quando em contato com um meio agressivo. Um dos agentes mais agressivos para a corrosão localizada é o cloreto. (SEDRIKS, 1996)

O presente trabalho estuda o efeito da temperatura de envelhecimento sobre a resistência à corrosão por pite do aço Custom $465 \AA$. Para tanto, foi utilizado o método da PP e eletrólitos contendo 0,6M NaCl, com adições de $\mathrm{Na}_{2} \mathrm{SO}_{4}$. Ressaltase que a adição de sulfato é necessária para a obtenção de um eletrólito que permita a determinação do potencial de pite, uma vez que o teor de $0,6 \mathrm{M} \mathrm{NaCl}$ é muito agressivo para aços que contém menos de $17 \% \mathrm{Cr}$, o que acaba por deformar as curvas PP, impedindo a leitura do potencial de pite (Ep).

Conforme mencionado, não basta apenas a resistência à corrosão. Para a aplicação do aço Custom $465 \AA$, é necessário um rígido controle das propriedades mecânicas. Estudos mostram (WRIGHT; JUNG, 2011), que o envelhecimento do aço Custom $465 \AA$ a $482^{\circ} \mathrm{C}\left(900^{\circ} \mathrm{F}\right)$, proporciona a obtenção da maior resistência mecânica, no entanto, o material torna-se susceptível a corrosão sob tensão, o que acaba limitando sua aplicação. Deste modo, existem limitações quanto ao envelhecimento empregado nos aços endurecidos por precipitação. No caso do Custom 465®, os tratamentos de envelhecimento indicados são os conhecidos como H950 e H1000 conforme AMS 5963. (AMS 5963, 2007) Ambos são realizados por 4 horas, variando somente a temperatura de envelhecimento, que no caso do $\mathrm{H} 950$ é de $510^{\circ} \mathrm{C}$ $\left(950^{\circ} \mathrm{F}\right)$ e do $\mathrm{H} 1000$ é de $538^{\circ} \mathrm{C}\left(1000^{\circ} \mathrm{F}\right)$.

Deste modo, justifica-se um estudo que contemple a caracterização microestrutural e sua relação com a resistência mecânica e resistência à corrosão por pite. 


\section{OBJETIVO}

O objetivo deste trabalho é caracterizar a microestrutura, as propriedades mecânicas (resistência à tração e dureza) e determinar a resistência à corrosão por pite do aço inoxidável martensítico endurecível por precipitação, UNS S46500, conhecido comercialmente como Custom $465 \AA$, em função dos tratamentos de envelhecimento H950 e H1000, constantes da norma AMS 5963 (2007). 


\section{REVISÃO BIBLIOGRÁFICA}

Os aços inoxidáveis endurecidos por precipitação, conhecidos desde 1930, são utilizados quando é necessário que se tenha resistência mecânica associada com resistência à corrosão elevada. Eles são geralmente fornecidos na condição martensítica, e a precipitação se dá por um tratamento complementar de envelhecimento.

\subsection{METALURGIA DO AÇO CUSTOM $465 \circledR$}

\subsubsection{Aços inoxidáveis endurecidos por precipitação}

A resistência à deformação plástica dos aços pode ser alterada dependendo da composição e do tipo de processamento realizado. Assim todos os metais, até as mais modernas ligas têm a sua resistência mecânica obtida por um dos métodos: trabalho a frio, refino de grão, endurecimento por solução sólida e precipitação de partículas de segunda fase.

O primeiro aço inoxidável endurecido por precipitação foi desenvolvido em 1940, mas somente foi comercializado em 1946. Este aço é o 635 (conhecido também como aço inoxidável "W"), que era composto de: 0,08\%C, $16-17 \% \mathrm{Cr}, 6-7 \% \mathrm{Ni}$, $1 \% \mathrm{Mn}, \quad 1 \% \mathrm{Si}, \quad 0,040 \% \mathrm{P}, \quad 0,030 \% \mathrm{~S}$ e $0,4 \% \mathrm{Al}+1,2 \% \mathrm{Ti}$. (DAVISON; DEBOLD; JOHNSON, 1987) A partir desta data, essas ligas vêm sendo desenvolvidas para atender requisitos estruturais da indústria aeronáutica, aeroespacial e defesa, em que a combinação entre resistência mecânica, tenacidade e corrosão é necessária. (KARAMINEZHAAD; SHARAFI; DALILI, 2006; NAKAGAWA; MIYAZAKI, 1999)

Os aços inoxidáveis são aços que contém no mínimo 10,5\% de cromo em solução sólida na sua composição. Outros elementos como níquel, vanádio, titânio, molibdênio também estão presentes nesses materiais para alterar/melhorar suas propriedades. Eles são classificados conforme sua estrutura cristalina. Cada família exibe suas características em termos de propriedades mecânicas, resistência à corrosão e consequentemente o seu custo associado. As famílias são: ferríticos, austeníticos, duplex, martensíticos e endurecidos por precipitação. (DAVISON; DEBOLD; JOHNSON, 1987; WERT, 2006)

A precipitação de finas partículas de segunda fase a partir de uma solução sólida supersaturada, no tratamento final de envelhecimento, introduz uma deformação na 
estrutura cristalina do material que é responsável pelo endurecimento da liga. Os aços martensíticos geralmente são fornecidos na condição martensítica e a precipitação se dá pelo tratamento de envelhecimento realizado em temperaturas entre $400^{\circ} \mathrm{C}$ e $600^{\circ} \mathrm{C}$. (WERT, 2006; BENSCOTER, 1985) Esses aços apresentam microestrutura tetragonal de corpo centrado (TCC) obtida pela composição de baixa quantidade de carbono, aproximadamente 8 a 15\% de cromo e 7 a 14\% de níquel e adição de outros elementos substitucionais, como molibdênio, cobalto, titânio, tungstênio, alumínio e cobre. (WRIGHT; JUNG, 2011) Na precipitação, finos intermetálicos formados dispersos uniformemente na matriz martensítica impedem o deslocamento das discordâncias, alguns exemplos são fases de Laves, $\mathrm{Ni}_{3} \mathrm{Ti}$, e carbonetos. O tipo de precipitado formado irá depender do tipo de elemento de liga adicionado. Prolongado tempo de envelhecimento ou a aplicação de alta temperatura causam o crescimento e coalescimento desses precipitados, resultando na diminuição da resistência mecânica. (SEDRIKS, 1966; WRIGHT; JUNG, 2011).

A Figura 1 apresenta a relação entre microestrutura, processamento e propriedades que possibilita a obtenção de um material ideal em termos de resistência mecânica e resistência à corrosão. (WRIGHT; JUNG, 2011)

Exemplos de aços inoxidáveis martensíticos endurecidos por precipitação são 174PH, 15-5PH, PH13-8Mo, Custom 450® e Custom 465®. A composição química desses materiais está apresentada na Tabela 1.

Os aços inoxidáveis endurecidos por precipitação se assemelham aos aços maragings, com relação à microestrutura, onde o endurecimento se dá pela precipitação de finos intermetálicos. No entanto, os aços maragings são aços de alta resistência mecânica e baixo carbono, onde o principal elemento adicionado é o níquel, não apresentando o cromo, o que fornece a característica principal dos aços inoxidáveis. Exemplos de aços maragings são 18Ni(200), 18 Ni (350). (ROHRBACH; SCHMIDT, 1993) 


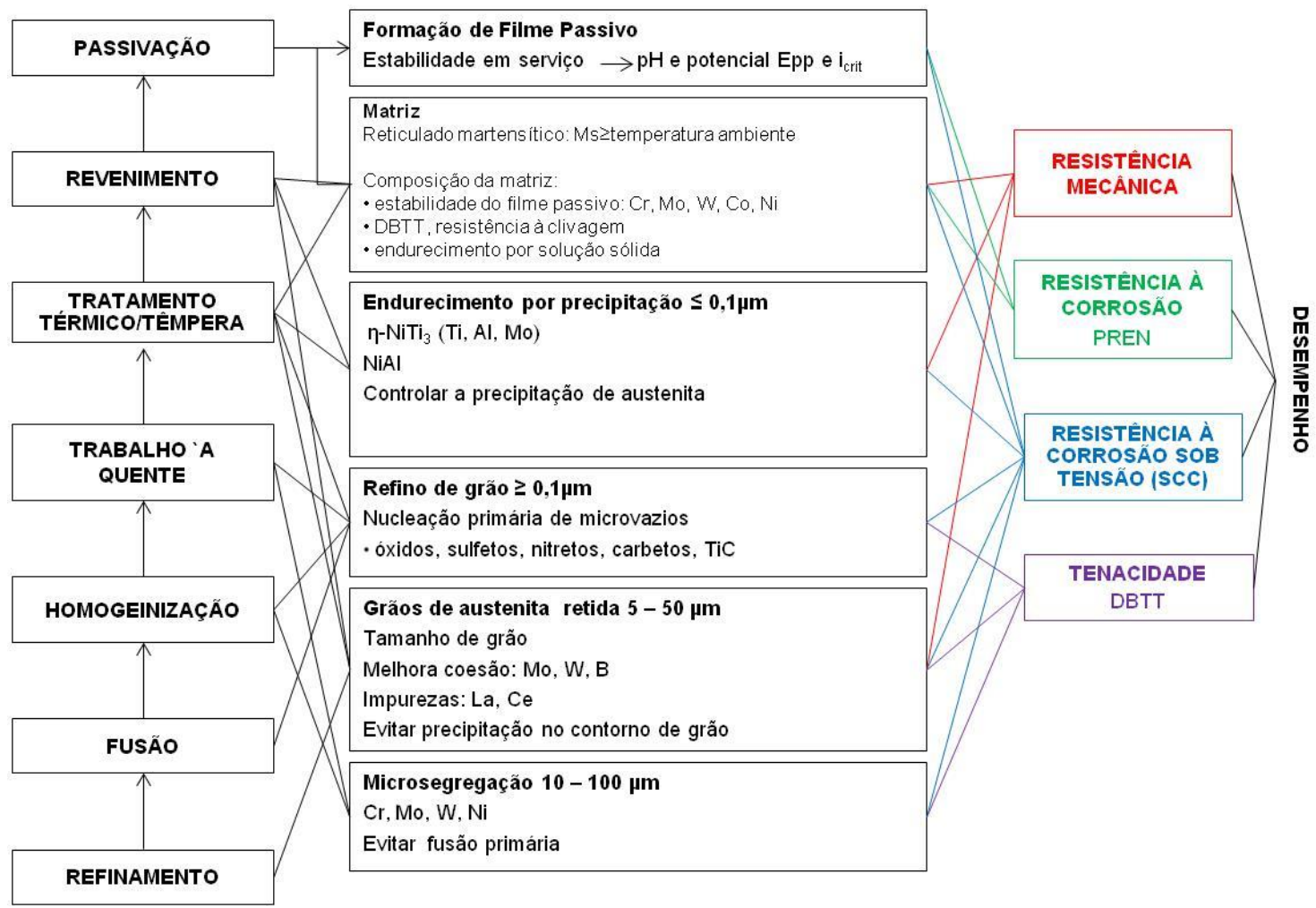

Figura 1: Diagrama mostrando a relação entre processamento - microestrutura - propriedades. (Modificado. WRIGHT; JUNG, 2011)

Ep: potencial de pite; i crit: densidade de corrente crítica para passivação

Tabela 1: Composição química de aços inoxidáveis martensíticos endurecidos por precipitação. (AMS 5963, 2007; WASKO; AGGEN, 1993)

\begin{tabular}{|c|c|c|c|c|c|c|c|c|c|}
\hline \multirow{2}{*}{ Nome } & \multirow{2}{*}{ UNS } & \multicolumn{8}{|c|}{ Composição (\% peso) } \\
\hline & & C & Mn & Si & $\mathrm{Cr}$ & $\mathrm{Ni}$ & $\mathbf{P}$ & $\mathbf{s}$ & Outros \\
\hline PH13-8Mo & $S 13800$ & 0,05 & 0,20 & 0,10 & $12,25-13,25$ & $7,50-8,50$ & 0,01 & 0,01 & $\begin{array}{c}2,00-2,50 \mathrm{Mo} \\
0,90-1,35 \mathrm{Al} \\
0,01 \mathrm{~N}\end{array}$ \\
\hline $15-5 \mathrm{PH}$ & S15500 & 0,07 & 1,00 & 1,00 & $14,00-15,50$ & $3,50-5,50$ & 0,04 & 0,03 & $\begin{array}{c}2,50-4,50 \mathrm{Cu} ; \\
0,15-0,45 \mathrm{Nb}\end{array}$ \\
\hline $17-4 \mathrm{PH}$ & $S 17400$ & 0,07 & 1,00 & 1,00 & $15,50-17,50$ & $3,00-5,00$ & 0,04 & 0,03 & $\begin{array}{c}3,00-5,00 \mathrm{Cu} ; \\
0,15-0,45 \mathrm{Nb}\end{array}$ \\
\hline 17-7PH & S17700 & 0,09 & 1,00 & 1,00 & $16,00-18,00$ & $6,50-7,75$ & 0,04 & 0,04 & $0,75-1,50 \mathrm{Al}$ \\
\hline $\begin{array}{l}\text { Custom450® } \\
\text { (XM-25) }\end{array}$ & S45000 & 0,05 & 1,00 & 1,00 & $14,00-16,00$ & $5,00-7,00$ & 0,03 & 0,03 & $\begin{array}{r}1,25-1,75 \mathrm{Cu} ; \\
0,50-1,00 \mathrm{Mo} ; \\
8 \times \% \mathrm{C} \text { min Nb}\end{array}$ \\
\hline Custom $465 \AA$ & S46500 & 0,02 & 0,35 & 0,25 & $11,00-12,50$ & $10,75-11,25$ & 0,02 & 0,01 & $\begin{array}{c}0,75-1,25 \mathrm{Mo} ; \\
1,50-1,80 \mathrm{Ti}\end{array}$ \\
\hline
\end{tabular}




\subsubsection{Diagrama de fases}

A definição dos parâmetros de tratamento térmico para se obterem as propriedades desejadas dos aços inoxidáveis endurecidos por precipitação envolvem o estudo dos diagramas de fases considerando os principais elementos de liga que compõem o material. Deste modo, é importante analisar a relação entre Fe-Cr-Ni e no caso do aço estudado devido a presença dos elementos Mo e Ti, tem-se também a avaliação dos diagramas Fe-Cr-Ti e Fe-Cr-Ni-Mo.

Analisando as isotermas do diagrama Fe-Cr-Ni, a $1300^{\circ} \mathrm{C}, 1200^{\circ} \mathrm{C}, 1100^{\circ} \mathrm{C}$ e $1000^{\circ} \mathrm{C}$ (Figura 2) observa-se que o campo de mistura das fases a (alfa) e y (gama) aumenta com a diminuição da temperatura. Continuando o resfriamento, isotermas a $900^{\circ} \mathrm{C}, 800^{\circ} \mathrm{C}$ e $650^{\circ} \mathrm{C}$, observa-se a formação da fase $\sigma$ (sigma) e o campo de equilíbrio de três fases, $\sigma+\alpha+\gamma$ (Figura 3). (RAYNOR; RIVLIN, 1988) (A título de exemplificação, a composição química do aço Custom $465 \AA$ está indicada nestes diagramas ternários e nos seguintes. No entanto, ressalta-se que isto é apenas um exercício, pois o aço Custom $465 \AA$ é um sistema multicomponente e deve ser analisado termodinamicamente como tal. No item Resultados, do presente trabalho, é feita esta análise através do programa Thermo-Calc.)

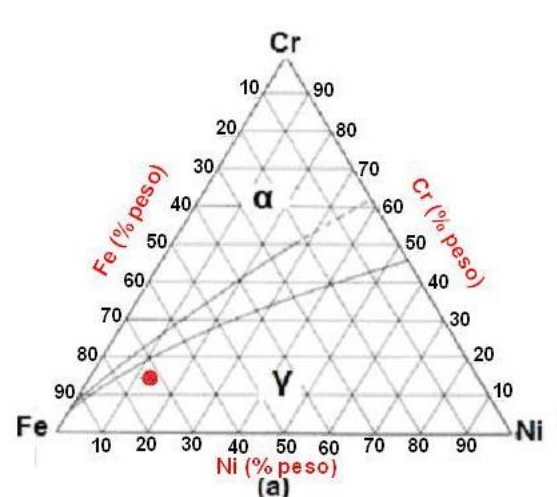

(a)

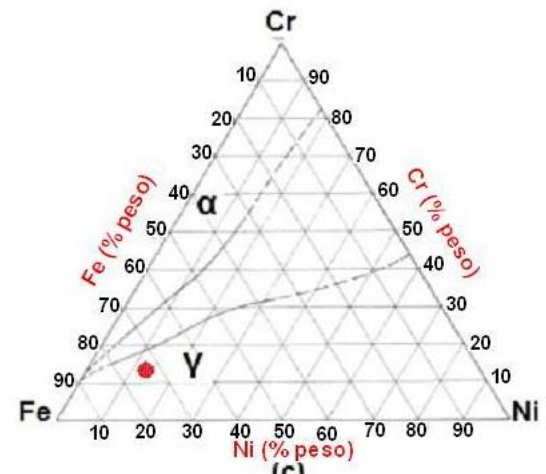

(c)

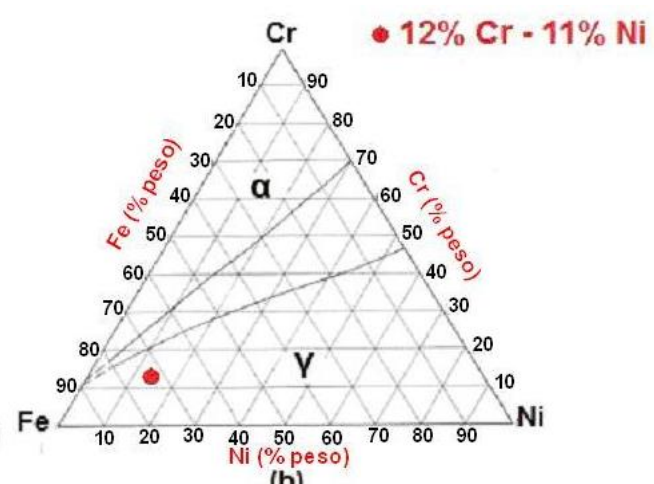

(b)

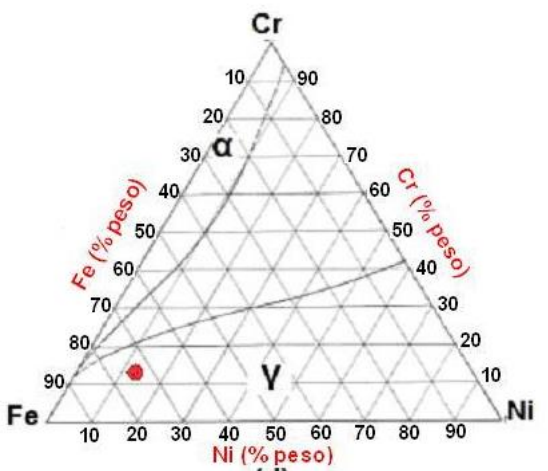

(d)

Figura 2: Isotermas do diagrama Fe-Cr-Ni a (a) $1300^{\circ} \mathrm{C}$, (b) $1200^{\circ} \mathrm{C}$, (c) $1100^{\circ} \mathrm{C} \mathrm{e}$ (d) $1000^{\circ} \mathrm{C}$. (Modificado. RAYNOR; RIVLIN, 1988) 

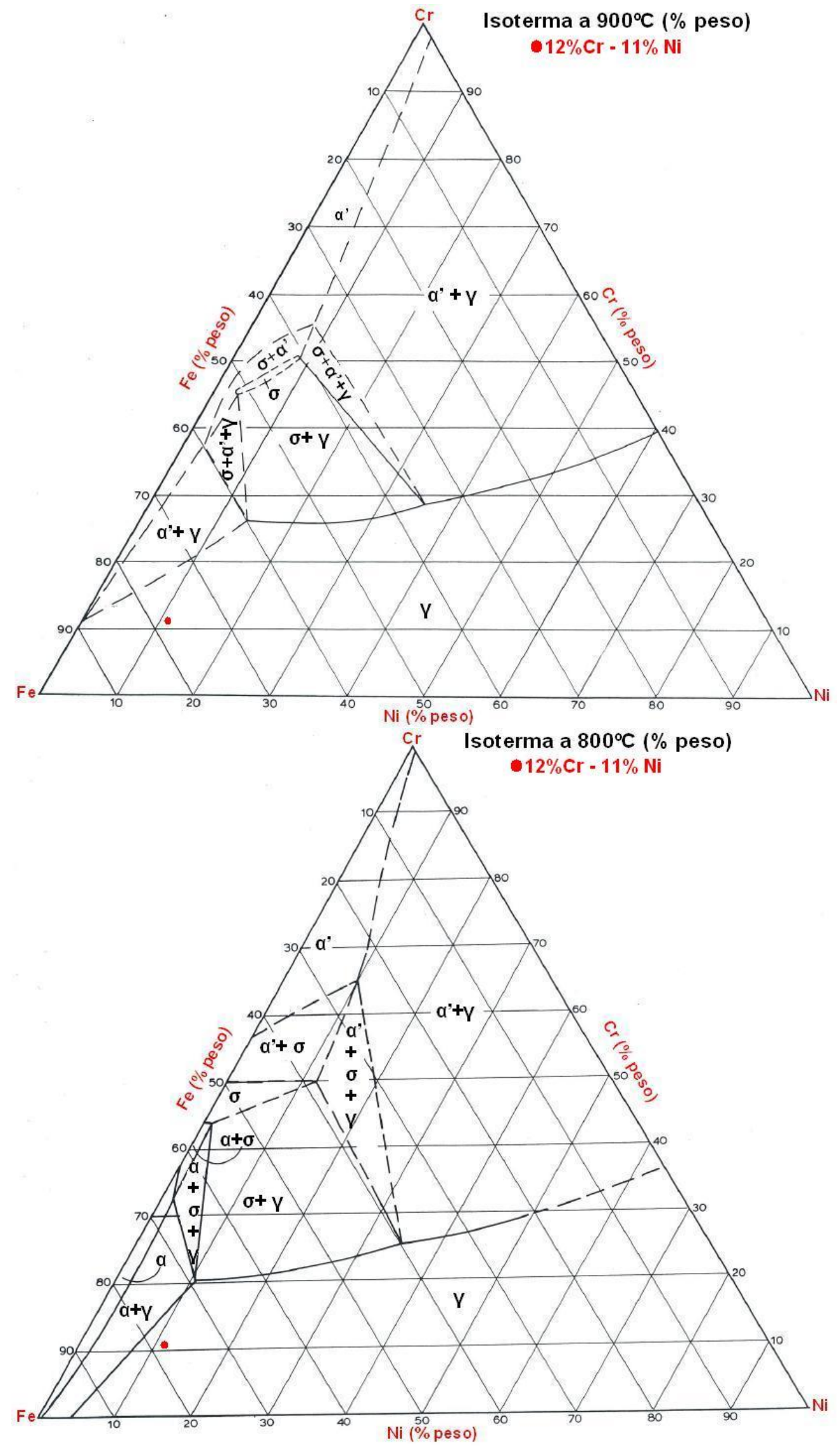


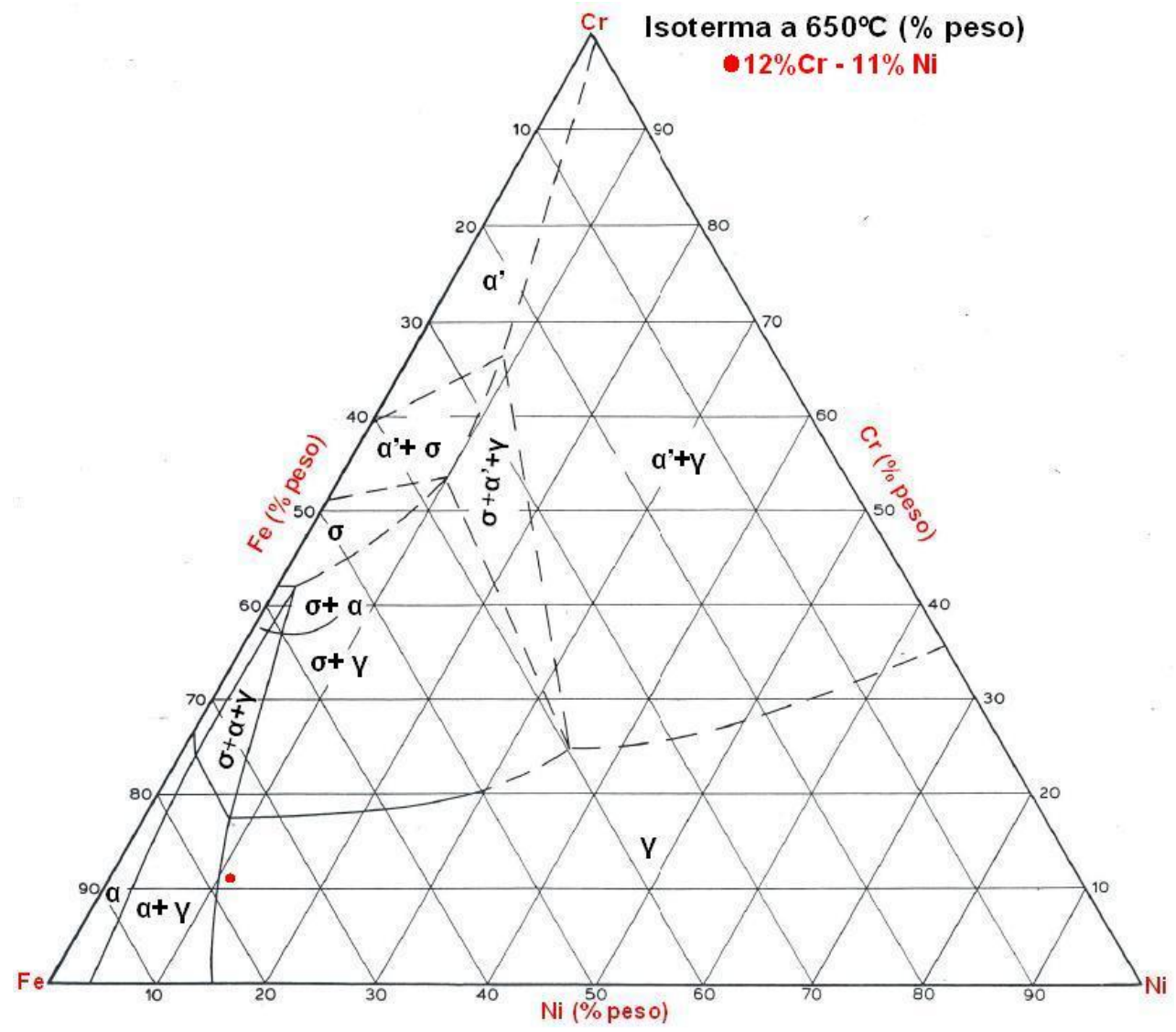

Figura 3: Isotermas do diagrama Fe-Cr-Ni a $900^{\circ} \mathrm{C}, 800^{\circ} \mathrm{C}$ e $650^{\circ} \mathrm{C}$. (Modificado. RAYNOR; RIVLIN, 1988)

A Figura 4 apresenta cortes isotérmicos do diagrama $\mathrm{Fe}-\mathrm{Cr}-\mathrm{Ti}$ a $1000^{\circ} \mathrm{C}, 800^{\circ} \mathrm{C}$ e $550^{\circ} \mathrm{C}$. Pela análise da isoterma, são identificadas 4 fases na cristalização primária: $\mathrm{FeTi}, \lambda, \mathrm{X}$ (chi), e as fases cúbicas de corpo centrado ( $\beta \mathrm{Ti} ; \alpha \mathrm{Cr}$; $\alpha \mathrm{Fe}$ ). A única fase ternária observada é $X$, possivelmente representada por $\mathrm{Ti}_{5} \mathrm{Cr}_{7} \mathrm{Fe}_{17}$. Cortes isotérmicos em temperaturas de tratamento térmico mais baixas $\left(800^{\circ} \mathrm{C}\right.$ e $\left.550^{\circ} \mathrm{C}\right)$ apresentam a formação de aTi ao longo dos campos Ti-Fe ( $\alpha \mathrm{Ti}+\mathrm{FeTi}$ ) e $\mathrm{Ti}-\mathrm{Cr}$ (aTi+Cr2 $\mathrm{Cr}_{2}$ ) devido ao fato do $\mathrm{Fe}$ e $\mathrm{Cr}$ serem estabilizadores da fase $\alpha \mathrm{Ti}$. (RAGHAVAN, 1987) (Analogamente ao mesmo exercício realizado anteriormente, isto é, considerando-se a composição química do aço Custom $465 \AA$ para estes elementos - $12 \% \mathrm{Cr}$ e $2 \% \mathrm{Ti}$ - pode-se concluir que tratamentos térmicos nas temperaturas de $1000^{\circ} \mathrm{C}, 800^{\circ} \mathrm{C}$ e $550^{\circ} \mathrm{C}$ dão origem a uma liga monofásica constituída de ferrita $(\alpha \mathrm{Fe})$.) 

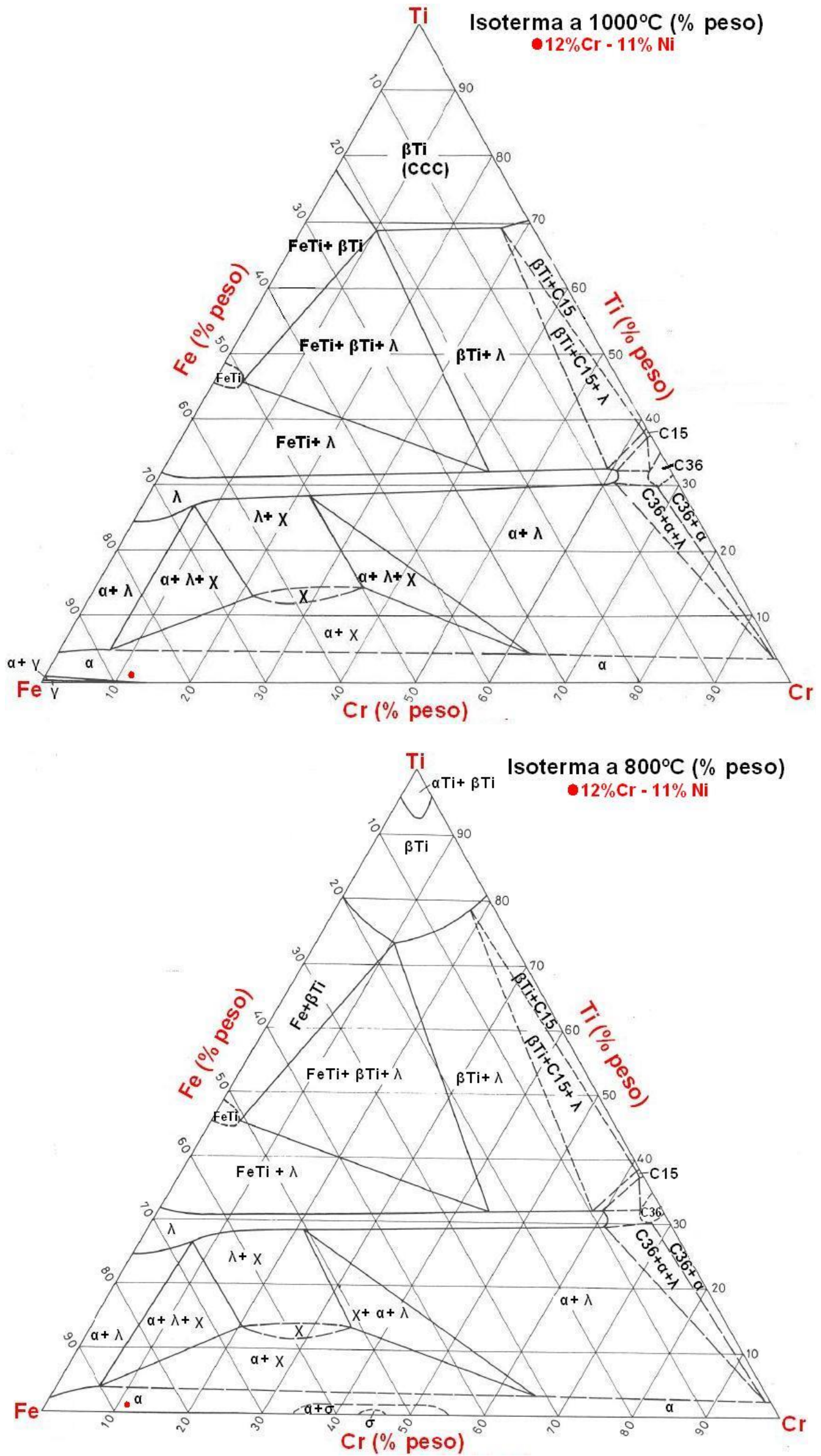


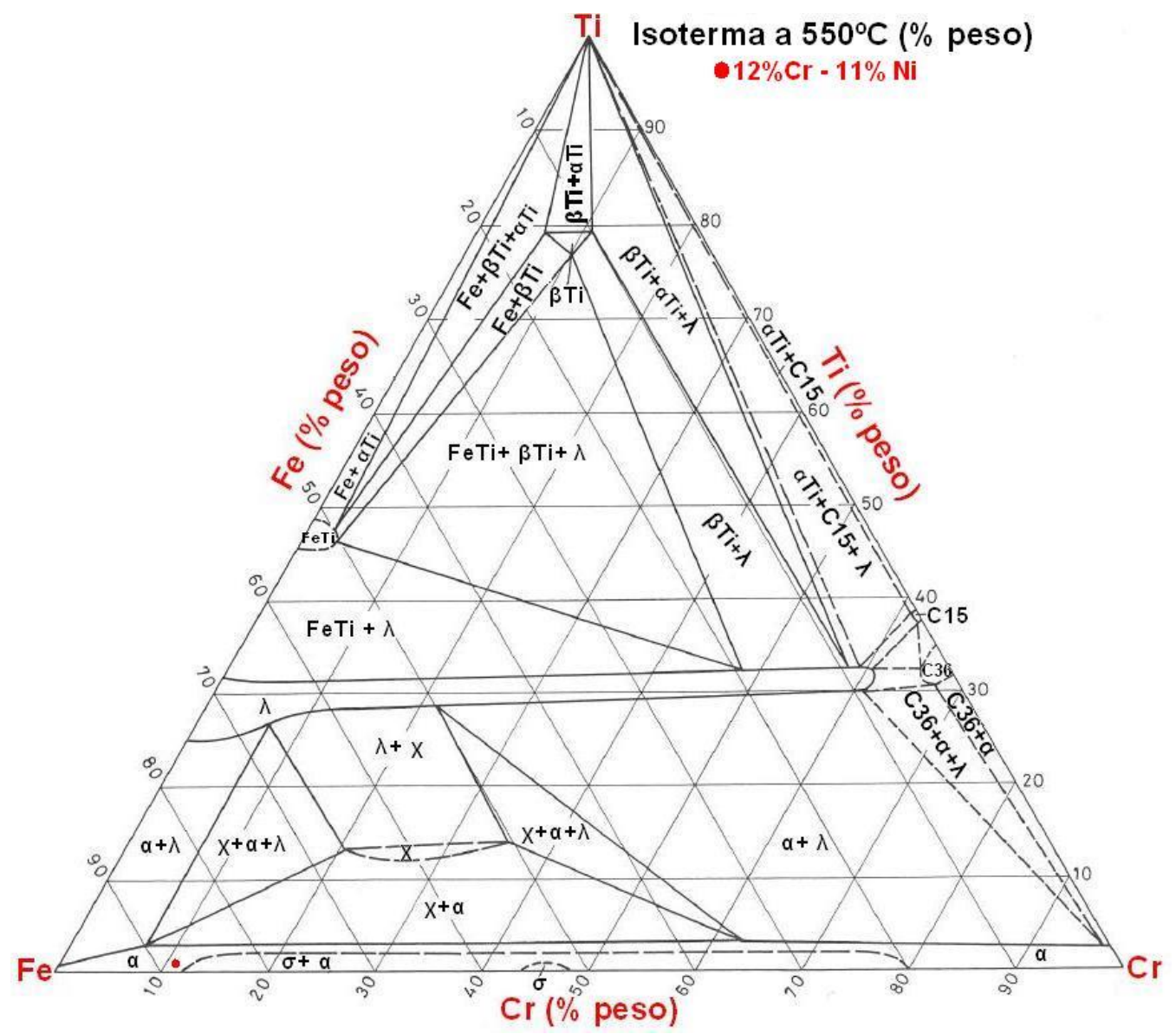

Figura 4: Isotermas do diagrama Fe-Ti-Cr. (Modificado. RAGHAVAN, 1987).

Um estudo realizado por Bechtoldt (1957) para o diagrama Fe-Cr-Ni-Mo indicou a existência de 7 fases coexistindo neste diagrama: $\alpha$-Fe (ferrita), $\gamma$-Fe (austenita), $\sigma$ (sigma), $x$ (chi), $\varepsilon$ (épsilon), $\eta$ (eta) e $\rho$ (rho). As fases $\alpha-F e, \gamma-F e$, conhecidas como fases terminais, são mais dúteis quando comparadas com as fases intermediárias $\sigma$, $X, \varepsilon, \eta$ e $\rho$, que são duras e frágeis. A Figura 5 mostra um esquema da distribuição das fases intermediárias no sistema Fe-Cr-Mo e a Tabela 2 apresenta as características dessas fases. (BECHTOLD; VACHER, 1957) 


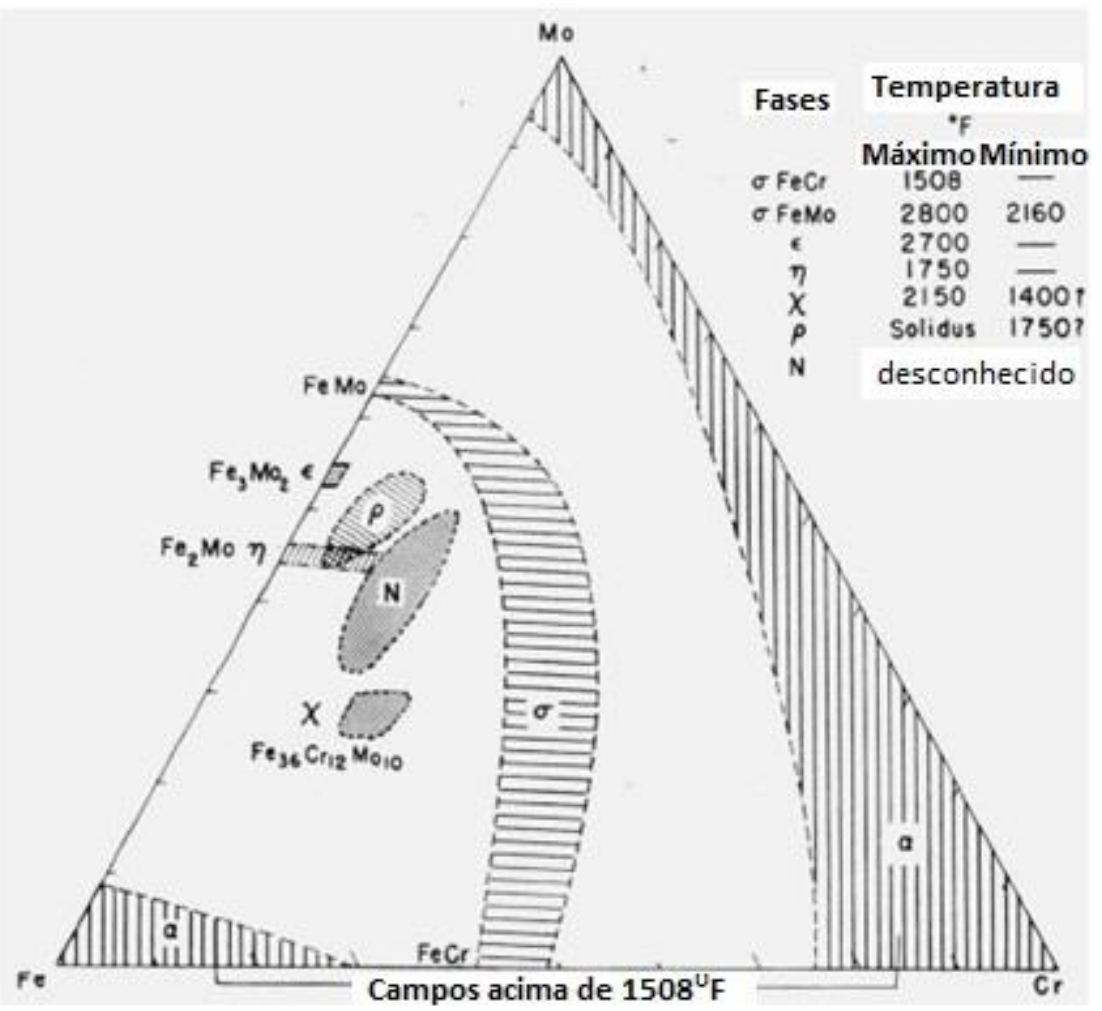

Figura 5: Representação esquemática da composição das fases intermediárias no sistema ferro-cromo-molibdênio. (Modificado. BECHTOLD; VACHER, 1957)

Tabela 2: Características das fases intermediárias no diagrama Fe-Cr-Mo-Ni. (BECHTOLD; VACHER, 1957)

\begin{tabular}{|c|c|c|c|}
\hline FASE & COMPOSIÇÃO & $\begin{array}{l}\text { ESTRUTURA } \\
\text { CRISTALINA }\end{array}$ & Observação \\
\hline$\sigma$ & $\mathrm{FeCr}$ & $\begin{array}{l}\text { tetragonal de corpo } \\
\text { centrado (TCC) }\end{array}$ & $\begin{array}{l}\text { Estabilidade abaixo } \\
\text { de } 820^{\circ} \mathrm{C}\end{array}$ \\
\hline$x$ & $\mathrm{Fe}_{36} \mathrm{Cr}_{12} \mathrm{Mo}_{10}$ & Cúbica & $\begin{array}{c}\text { Estabilidade abaixo } \\
\text { de } 1177^{\circ} \mathrm{C} \\
\text { Identificada no } \\
\text { sistema Fe-Cr-Mo }\end{array}$ \\
\hline$\varepsilon$ & $\mathrm{Fe}_{3} \mathrm{Mo}_{2}$ & romboédrica & $\begin{array}{c}\text { Dissolve } \\
\text { considerável } \\
\text { quantidade de } \mathrm{Ni} \mathrm{e} \\
\text { pouco } \mathrm{Cr}\end{array}$ \\
\hline$\eta$ & $\mathrm{Fe}_{2} \mathrm{Mo}$ & hexagonal & $\begin{array}{c}\text { Estrutura } \\
\text { semelhante à da } \\
\text { fase de Laves } \\
\mathrm{MgZn_{2 }}\end{array}$ \\
\hline$\rho$ & $\begin{array}{l}\text { Provavelmente metaestável } \\
\text { que precipita formando } \\
\text { estrutura de Widmanstatten } \\
\text { ( }(\alpha-F e \text { e } \rho) \text {. }\end{array}$ & - & $\begin{array}{l}\text { Identificada no } \\
\text { sistema Fe-Cr-Mo }\end{array}$ \\
\hline
\end{tabular}


A Figura 6 apresenta as isotermas a: $1204^{\circ} \mathrm{C}, 1093^{\circ} \mathrm{C}, 982^{\circ} \mathrm{C}, 899^{\circ} \mathrm{C}$ e $816^{\circ} \mathrm{C}$, do diagrama Cr-Ni-Mo para uma liga com $70 \%$ de ferro. Considerando uma liga com aproximadamente $11 \% \mathrm{Ni}$ e $1 \% \mathrm{Mo}$ (que são os teores do aço Custom $465 \AA$, sendo que o teor de cromo fica mais elevado: $28 \% \mathrm{Cr}$ ao invés de $12 \% \mathrm{Cr}$ ), na temperatura de solubilização de $1204^{\circ} \mathrm{C}$ tem-se somente austenita e à medida que esta temperatura diminui, há a formação de ferrita, e a $816^{\circ} \mathrm{C}$ tem-se formação de austenita e fase $\sigma$. Por outro lado, mantendo-se o valor de molibdênio em $1 \% \mathrm{Mo} e$ $12 \% \mathrm{Cr}$ (ficando o níquel em $27 \% \mathrm{Ni}$ ao invés de $11 \% \mathrm{Ni}$ ), pode-se concluir que após tratamento térmico de solubilização a $816^{\circ} \mathrm{C}$, esta liga é totalmente constituída de austenita $(\mathrm{\gamma}-\mathrm{Fe})$. Assim, após a solubilização a $816^{\circ} \mathrm{C}$, podem-se ter as fases austenita e $\sigma$ como microconstituintes do aço Custom $465 \circledast$, dependendo dos teores de $\mathrm{Cr}$ e Ni. Por outro lado, repetindo-se o raciocínio para a temperatura de $982^{\circ} \mathrm{C}$, nota-se que o microconstituinte destas composições, que contemplam a composição química do aço Custom $465 \AA$, dão origem a apenas austenita; de fato, esta é a temperatura de solubilização recomendada para este aço. (AMS 5963, 2007) 

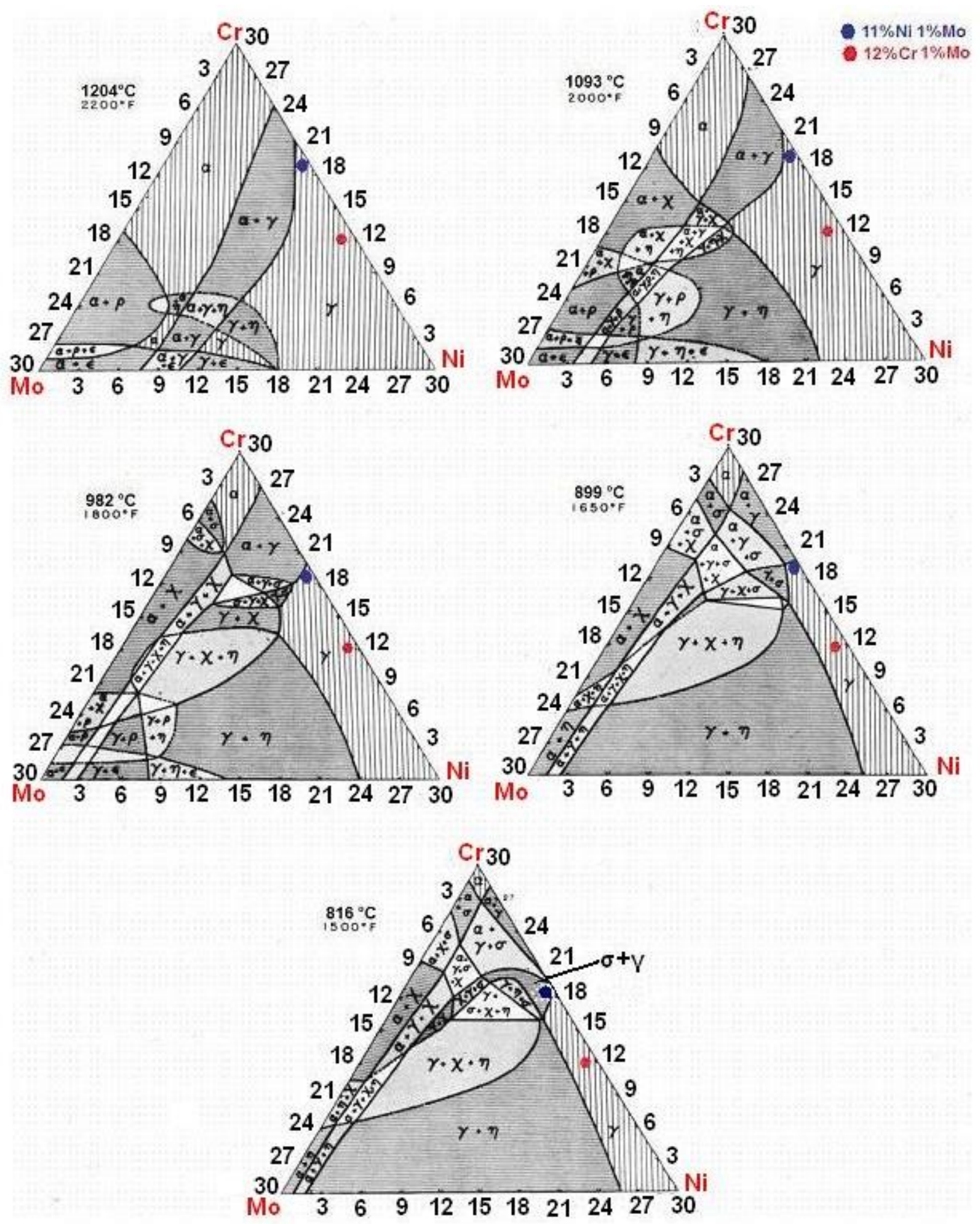

Figura 6: Isotermas do diagrama de fases Fe-Cr-Mo-Ni da liga contendo $70 \% \mathrm{Fe}$. (BECHTOLD; VACHER, 1957) 


\subsubsection{Tratamento térmico dos aços martensíticos endurecidos por precipitação}

Os aços inoxidáveis martensíticos endurecidos por precipitação são geralmente fornecidos na condição solubilizada. Eles possuem estrutura austenítica a temperaturas elevadas que se transformam em martensíticos pelo resfriamento rápido a temperatura ambiente.

O tratamento térmico dos aços martensíticos endurecidos por precipitação é realizado conforme indicado na Figura 7; ou seja, o material passa pelas seguintes etapas: homogeneização, austenitização, tratamento criogênico e precipitação. $\mathrm{Na}$ homogeneização o material é aquecido a elevadas temperaturas entre $1220^{\circ} \mathrm{C}$ a $1250^{\circ} \mathrm{C}$. Na austenitização o material é mantido em tempo suficiente para que haja a dissolução dos elementos de liga. Há então o resfriamento rápido da liga, geralmente realizado em água ou em óleo, e assim tem-se a transformação da austenita em martensita. A AMS 5963 recomenda que após a austenitização o material deve ser resfriado em temperatura ambiente (aproximadamente $25^{\circ} \mathrm{C}$ ). (AMS 5963, 2007) Alguns materiais necessitam de um tratamento criogênico adicional, que permite que toda a austenita se transforme em martensita, não havendo a presença de austenita retida na temperatura ambiente. Após a têmpera, o material é submetido ao tratamento de envelhecimento em temperaturas entre $450 \mathrm{e}$ $550^{\circ} \mathrm{C}$, onde há a formação dos precipitados. Deste modo, os precipitados são os principais responsáveis pelo endurecimento dos aços endurecíveis por precipitação. A precipitação pode ser realizada na peça fabricada ou em barras, placas ou forjados. Nesses materiais as quantidades de carbono e nitrogênio são baixas e devem ser controladas para evitar a formação de compostos indesejados, como carboneto de titânio e carboneto de cromo (WASHKO; AGGEN, 1993).

Portanto, a adição dos elementos de liga é necessária para a obtenção de propriedades como tenacidade, resistência à corrosão e resistência mecânica, ao mesmo tempo que sua quantidade deve ser balanceada de modo que as temperaturas de início e final da transformação martensítica sejam possíveis de serem obtidas. Algumas equações são utilizadas na tentativa de se calcular a temperatura de início de formação da martensita (Ms). Uma delas, representada por Monkman; Cuff e Grant (1957) em seu trabalho assume que existe uma relação 
linear entre a composição e a temperatura Ms. Apesar de o autor considerar a fórmula imprecisa, devido à complexa influência do carbono e do nitrogênio, a equação pode ser aplicada para alguns materiais. (MONKMAN; CUFF; GRANT, 1957)

Equação para cálculo da Ms (MONKMAN; CUFF; GRANT, 1957):

Ms $\left({ }^{\circ} \mathrm{F}\right)=2160-66^{*}(\% \mathrm{Cr})-102^{*}(\% \mathrm{Ni})-2620^{*}(\% \mathrm{C}+\% \mathrm{~N})$

onde: ${ }^{\circ} \mathrm{C}=\left({ }^{\circ} \mathrm{F}-32\right) / 1,8$

Outra expressão para cálculo da Ms está apresentada no AMS Handbook de tratamento térmico (ERICSSON, 1991):

$\operatorname{Ms}\left({ }^{\circ} \mathrm{C}\right)=512-453^{*} \mathrm{C}-16,9^{*} \mathrm{Ni}+15^{*} \mathrm{Cr}-9,5^{*} \mathrm{Mo}+217^{*}(\mathrm{C})^{2}-71,5^{*}(\mathrm{C})^{*}(\mathrm{Mn})-67,6^{*}(\mathrm{C})^{*}(\mathrm{Cr})$

Estas equações foram aplicadas para o aço Custom $465 \AA$ e os valores encontrados para Ms foram $121^{\circ} \mathrm{C}$ e $485^{\circ} \mathrm{C}$, respectivamente. Conforme observação encontrada no próprio trabalho de Monkman; Cuff; Grant (1957) a aplicação dessa equação para aços com baixos teores de carbono e nitrogênio, que é o caso do aço Custom $465 \AA$, pode levar a erro. De qualquer forma, apesar das imprecisões esperadas, percebese que já na temperatura ambiente o material tem estrutura martensítica. Não foram encontrados na literatura equações para a temperatura de fim de transformação martensítica (Mf). No entanto, a prática industrial indica que o tratamento criogênico é suficiente para garantir as propriedades mínimas especificadas.

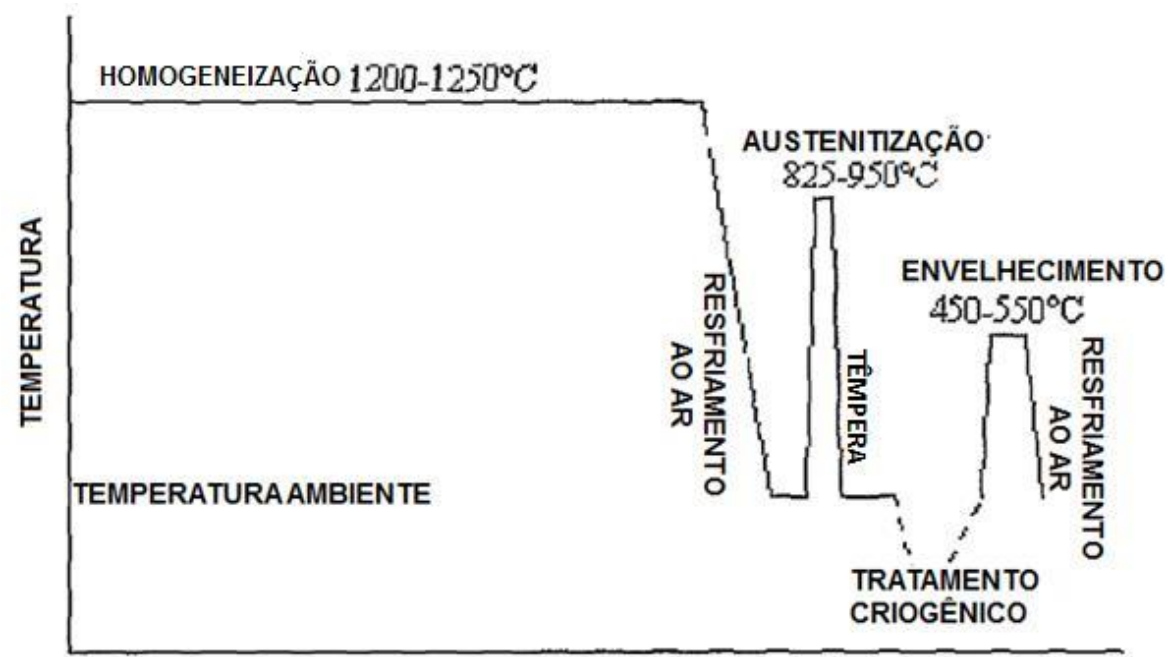

TEMPO

Figura 7: Diagrama ilustrando o tratamento térmico dos aços endurecidos por precipitação. (Modificado. WRIGHT; JUNG, 2011). 
As propriedades mecânicas típicas de alguns dos aços martensíticos endurecidos por precipitação estão apresentadas na Tabela 3. Como é possível observar, o aço Custom $465 \AA$, endurecido por precipitados intermetálicos de $\mathrm{Ni}_{3} \mathrm{Ti}$, possui valores de resistência mecânica acima dos valores encontrados para outros aços inoxidáveis endurecidos por precipitação. (GARRISON, 2008)

Tabela 3: Propriedades mecânicas típicas de aços inoxidáveis martensíticos endurecidos por precipitação. (AMS 5963, 2007; SEDRIKS, 1996)

\begin{tabular}{cccccc}
\hline Nome & UNS & $\begin{array}{c}\text { Limite de } \\
\text { resistência } \\
(\mathbf{M P a})\end{array}$ & $\begin{array}{c}\text { Limite de } \\
\text { escoamento } \\
(\mathbf{M P a})\end{array}$ & $\begin{array}{c}\text { Alongamento } \\
(\%)\end{array}$ & $\begin{array}{c}\text { Dureza } \\
\text { (HRc) }\end{array}$ \\
\hline 17-4PH & $\mathbf{S 1 7 4 0 0}$ & 1379 & 1227 & 12 & 44 \\
15-5PH & $\mathbf{S 1 5 5 0 0}$ & 1379 & 1275 & 14 & 44 \\
PH13-8Mo & $\mathbf{S 1 3 8 0 0}$ & 1551 & 1379 & 13 & 48 \\
Custom 450® & $\mathbf{S 4 5 0 0 0}$ & 1344 & 1282 & 14 & 43 \\
Custom 465® & $\mathbf{S 4 6 5 0 0}$ & 1655 & 1515 & 10 & 47 \\
\hline
\end{tabular}

\subsubsection{Austenita retida/revertida}

A austenita retida/revertida tem efeito importante sobre as propriedades mecânicas dos aços endurecidos por precipitação. Ela atua principalmente na tenacidade à fratura do material, propriedade que é muitas vezes comprometida em materiais que apresentam alta resistência mecânica (limite de escoamento e de resistência).

A austenita retida é aquela que ocorre devido a não transformação da austenita na etapa da têmpera; e a austenita revertida é aquela que ocorre durante as transformações de fase no envelhecimento do material, esta última depende do tempo e da temperatura empregados no tratamento térmico.

Schnitzer et at., 2010 estudaram a formação da austenita retida no aço 13Cr-8Ni-Mo e não encontraram sinais de austenita retida quando o material se encontrava na condição solubilizada e temperada. Por sua vez, as mesmas amostras apresentaram austenita revertida após tratamento de envelhecimento realizado na temperatura de $575^{\circ} \mathrm{C}$ por 3 horas. Resultado semelhante foi obtido por Li e Yin (1995), onde a austenita somente foi observada após envelhecimento realizado a $500^{\circ} \mathrm{C}$ por 8 horas. Esses estudos mostram que a austenita revertida é formada durante o tratamento de envelhecimento. (SCHNITZER et al., 2010; LI; YIN, 1995). 
As principais propostas de mecanismos para a formação de austenita revertida envolvem a dissolução de precipitados ricos em $\mathrm{Ni}$ (Ni-Ti; Ni-Al) ou a difusão de $\mathrm{Ni}$ até sítios já enriquecidos em elementos austenitizantes. Schnitzer et al. (2010) na introdução de seu trabalho, cita os trabalhos de Li e Yin (1995), Viswanathan; Banerjee e Krishnan (1988) e Farooque et al. (1998), os quais defendem o mecanismo da dissolução dos precipitados ricos em $\mathrm{Ni}$, dando origem à austenita revertida e, também cita os trabalhos de Sinha et al (1995) e Kim e Wayman (1990), os quais defendem o mecanismo de nucleação de austenita revertida por processo controlado por difusão (diffusion-controlled process).

Schnitzer et al. (2010), mostraram que austenita revertida se forma simultaneamente à formação dos precipitados ricos em $\mathrm{Ni}$, isto é, não é necessário que ocorra a precipitação de $\mathrm{Ni}-\mathrm{X}$, e depois a sua dissolução, para que seja formada a austenita; isso reforça a rejeição ao mecanismo de dissolução dos precipitados $\mathrm{Ni} X \mathrm{X}$ para a nucleação da austenita revertida. Já para o seu crescimento, será necessária a difusão de $\mathrm{Ni}$ a partir dos precipitados ricos em Ni inicialmente formados, conforme está descrito a seguir.

De forma resumida, a proposta de Schnitzer et al., 2010 é composta das seguintes etapas (Figura 8):

I. Martensita é formada após a têmpera com alta densidade de discordâncias.

II. No envelhecimento há a nucleação dos precipitados $\mathrm{Ni}-\mathrm{X}$ (onde $\mathrm{X}$ é $\mathrm{Al}$ ou Ti) homogeneamente dispersos pela matriz. Simultaneamente, ocorre a difusão de $\mathrm{Ni}$, preferencialmente nos contornos de grão da antiga austenita e nos contornos das ripas de martensita, onde micro-segregação de elementos austenitizantes levam à nucleação de austenita.

III. Neste estágio, ao longo do tempo de envelhecimento, há a transferência de Ni dos precipitados ricos nesse elemento, até as regiões de austenita revertida, promovendo seu crescimento. O autor (SCHNITZER et al., 2010) não menciona a razão da transferência de $\mathrm{Ni}$ do precipitado para a austenita; acredita-se que isso se deve à precipitação inicial de fases ricas em $\mathrm{Ni}$, as quais não correspondem à fase de equilíbrio NiAl do trabalho de Schnitzer et al. (2010). Sendo tais precipitados inicialmente formados enriquecidos em Ni, 
a transferência desse elemento para a austenita revertida torna-se um processo termodinamicamente viável.

IV. A microestrutura final consiste na matriz martensítica, com os precipitados homogeneamente dispersos e uma quantidade significativa de austenita revertida.

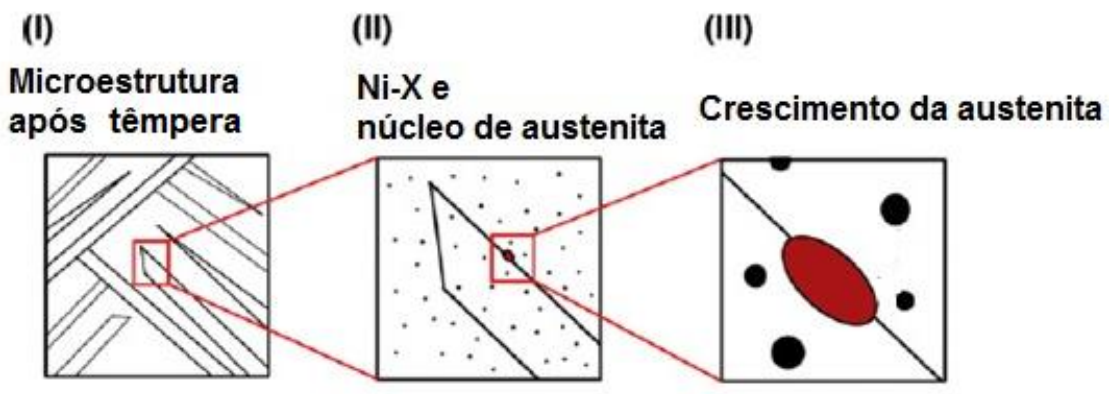

(IV) Microestrutura Final

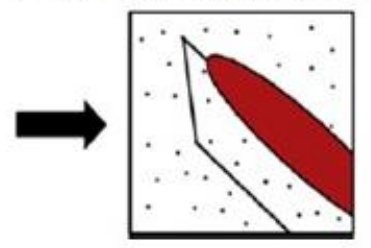

Figura 8: Modelo proposto por SCHNITZER et al. (2010) para explicar a formação da austenita revertida. (Modificado. SCHNITZER et al., 2010)

Para aços 13Cr-8Ni-Mo (SCHNITZER, et al., 2010) que contém $\mathrm{Ni}$ e Al, aços $18 \mathrm{Ni}(350)$ (LI; YIN, 1995) que contém Ni e Ti, e o aço de composição 0,008\%C $1,78 \% \mathrm{Cu}-7,29 \% \mathrm{Ni}-15,91 \% \mathrm{Cr}-1,16 \% \mathrm{Mo}-0,08 \% \mathrm{Nb}-0,017 \% \mathrm{~N}$ (NAKAGAWA; MIYAZAKI, 1999), a austenita revertida se apresenta na forma de ripas ou placas, dentro das ripas de martensita, ao longo dos contornos de grão da antiga austenita ou nos contornos das ripas de martensita. A Figura 9 apresenta um exemplo de austenita revertida para o aço $13 \mathrm{Cr}-8 \mathrm{Ni}-\mathrm{Mo}$, obtida após envelhecimento a $575^{\circ} \mathrm{C}$ por 3h, encontrada por Schnitzer et al. (2010), após exame em microscopia eletrônica de transmissão (MET). 


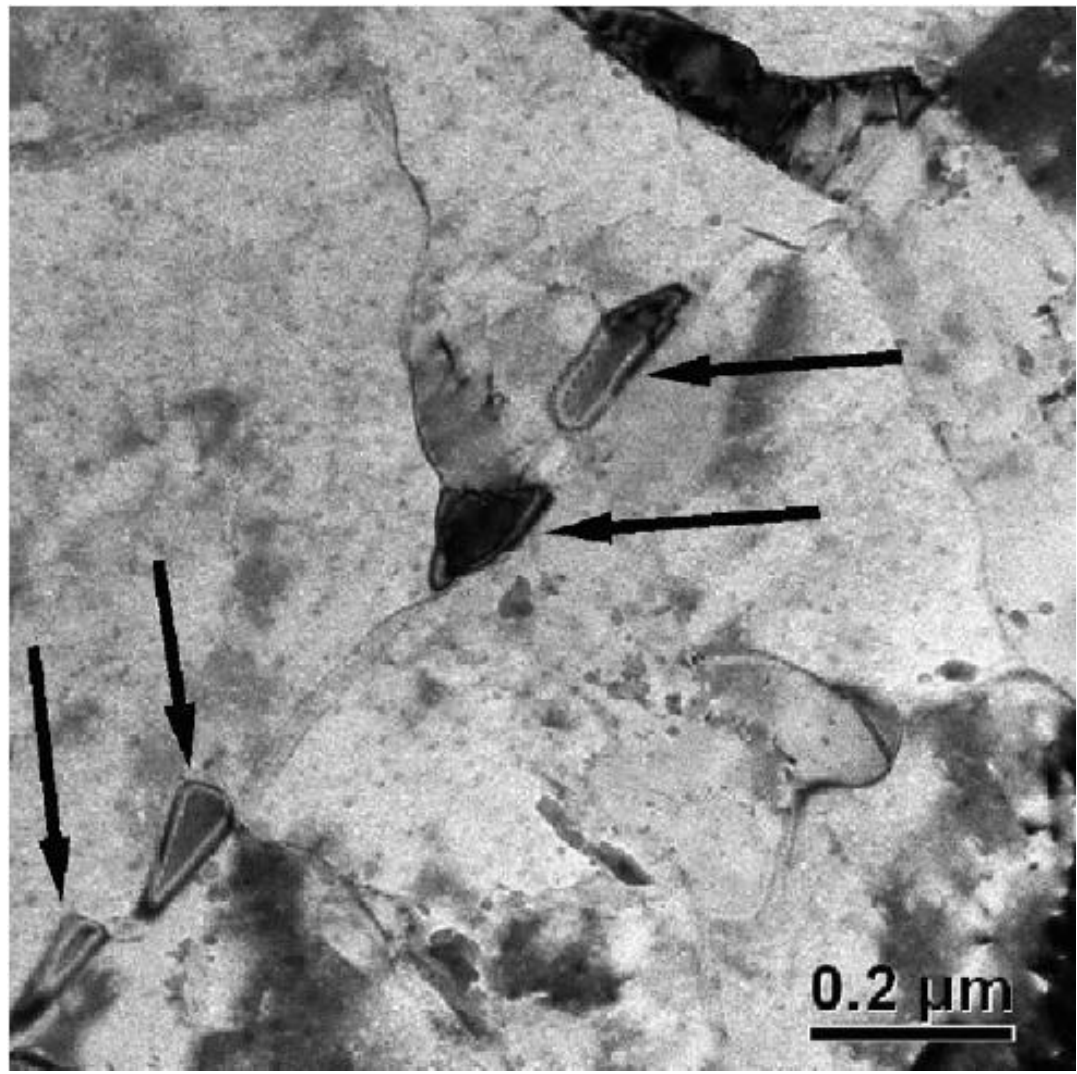

Figura 9: Imagem de MET da amostra envelhecida a $575^{\circ} \mathrm{C}$ por $3 \mathrm{~h}$. Austenita revertida (marcada pelas setas) nos grãos da antiga austenita. Aço $13 \mathrm{Cr}-8 \mathrm{Ni}-$ Mo, contento Ni e Al. (SCHNITZER et al., 2010)

No presente trabalho, estuda-se o aço Custom 465®, para o qual, não são encontrados na literatura especializada (Web of Knowledge (1945 até agora) e Compendex Engineering Index (1969 até agora), Metadex - Materials Research Database (1965 até agora) e CSA - Cambridge Scientific Abstracts (1962 até hoje)) trabalhos de transformação de fase, semelhantes aos aqui apresentados (SCHNITZER et al., 2010; NAKAGAWA; MIYAZAKI, 1999 e LI; YIN, 1995). No entanto, dada a semelhança entre estes aços e o Custom 465®, espera-se comportamento semelhante, isto é, como esse material contém $\mathrm{Ni}$ e Ti, o tratamento de envelhecimento dá origem a precipitados de $\mathrm{Ni}$-Ti e austenita revertida durante o tratamento de envelhecimento.

A influência da austenita nas propriedades mecânicas do material pode ser observada pela Figura 10. É possível observar que a presença da austenita reduz a resistência mecânica do material. 


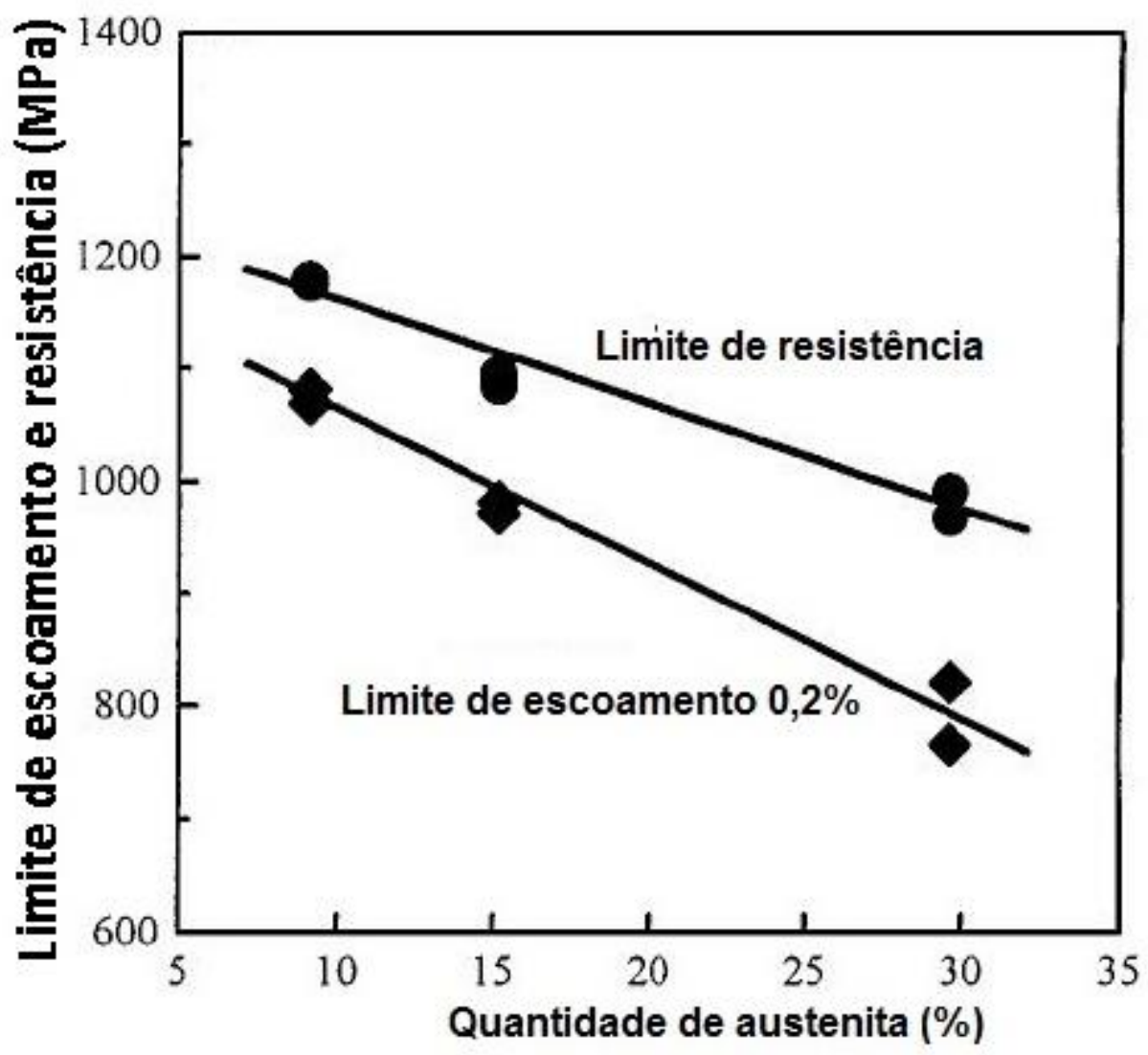

Figura 10: Efeito da quantidade de austenita sobre o limite de escoamento (LE) e limite de resistência (LR) do aço PH 17-4 (contém Ni e Cu). (Modificado. NAKAGAWA; MIYAZAKI, 1999)

\subsubsection{Influência dos elementos de liga}

Alguns elementos de liga são adicionados para se obter as propriedades mecânicas e resistência à corrosão desejados. Para o aço em estudo, Custom $465 \AA$, os principais elementos adicionados são o cromo, níquel, titânio e molibdênio.

O Cr é o principal responsável por fornecer a resistência à corrosão ao material. $\mathrm{Na}$ sua presença é formado um filme fino de óxido, $(\mathrm{Fe}, \mathrm{Cr})_{2} \mathrm{O}_{3}$, aderente e uniforme na superfície do metal, que o protege contra ataque uniforme ou localizado. (MARCUS; OUDAR, 1995) Este elemento forma e estabiliza a ferrita e também contribui para redução da temperatura Ms. Deste modo, para aços estruturais que necessitam de alto limite de escoamento, a quantidade de cromo adicionada deve ser balanceada para permitir a fabricação do material. Elevados níveis de cromo promovem também a microsegregação, que é de difícil eliminação em tratamentos de homogeneização. (KUEHMANN; OLSON; JOU, 2010; WRIGHT; JUNG, 2011) 
Outro elemento presente nos aços inoxidáveis é o Ni. Este elemento é responsável por estabilizar austenita, o que resulta em um aumento no limite de escoamento do material. Além disso, a presença deste elemento em aços inoxidáveis endurecidos por precipitação aumenta o potencial termodinâmico para nucleação das fases $\mathrm{Ni}-\mathrm{X}$ $(\mathrm{X}=\mathrm{Ti}, \mathrm{Al})$, as quais também contribuem para formação da austenita revertida e, portanto diminuição da temperatura de transição dúctil-frágil. (WRIGHT; JUNG, 2011) Com relação à resistência à corrosão, o Ni não exerce influência direta no filme passivo, no entanto, este elemento promove um efeito benéfico na resistência à corrosão do material em meios oxidantes. (Euro Inox, 2013)

A adição de Ti está diretamente relacionada com o aumento da resistência à corrosão intergranular, a qual envolve a precipitação de carbonetos de cromo, principalmente nos contornos de grão, durante tratamento térmico e/ou soldagem. Conforme trabalho de Gates e Jago (1987), adições de 0,17 a 0,29\% de Ti em aços ferríticos 444 (18\%Cr-2\%Mo), promovem a estabilização do material contra a corrosão intergranular devido à formação de estáveis nitretos/carbonetos de titânio $(\mathrm{Ti}(\mathrm{C}, \mathrm{N}))$. Em seu trabalho foi calculada a temperatura solvus de vários compostos estabilizadores, inclusive os compostos de Ti (Figura 11). Observa-se na Figura 11 que os TiN tem uma ampla faixa de temperatura de precipitação, formando-se quando o metal está líquido. Além de melhorar a resistência à corrosão intergranular, a formação do TiN quando o metal ainda está líquido também atua como sítios para nucleação levando ao refino da microestrutura pela formação de uma fina estrutura de grão equiaxiais. Como os precipitados de TiN se formam em temperaturas mais elevadas, são mais estáveis que os TiC e são em geral mais grosseiros que os carbonetos de cromo. (GORDON; BENNEKOM, 1996). 


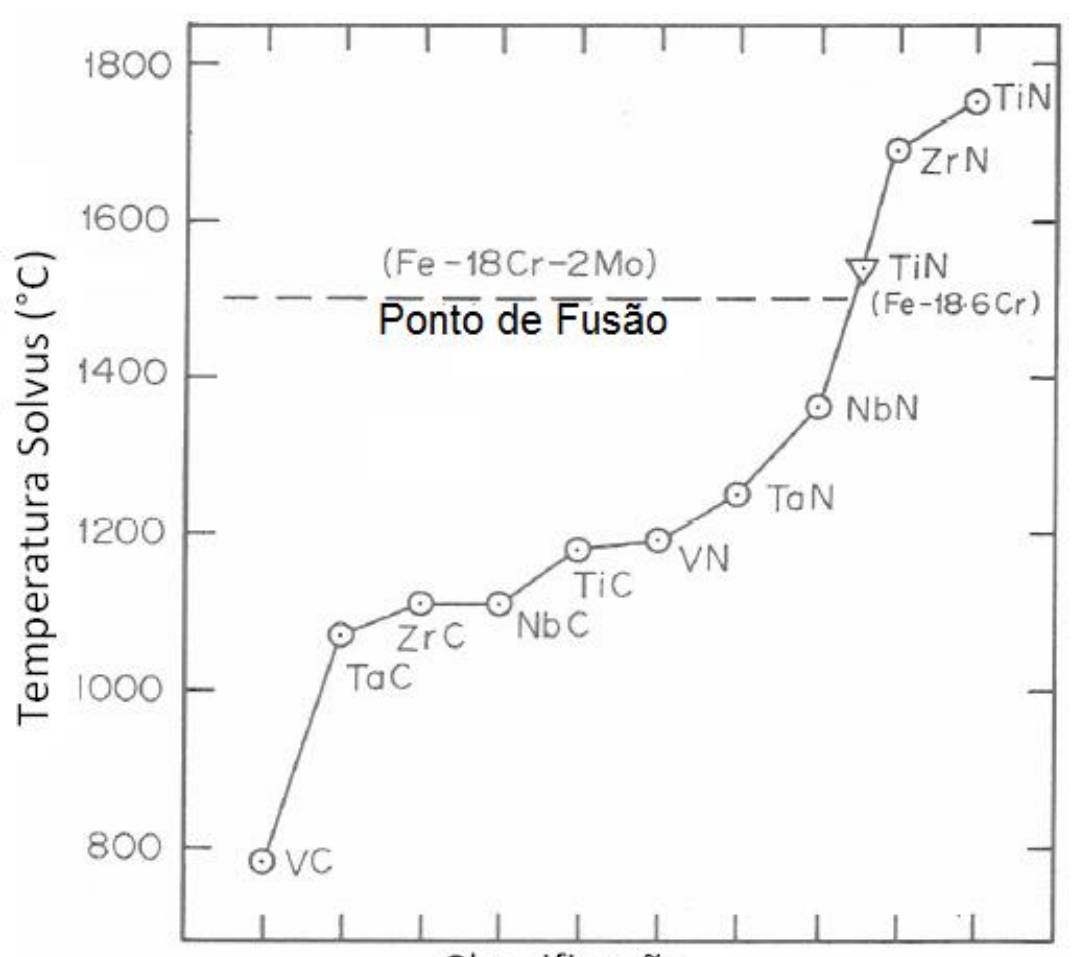

Classificação

Figura 11: Temperatura solvus para compostos estabilizadores do tipo MX (onde M é o metal e X é o C ou N). (Modificado. GATES; JAGO, 1987) Os valores indicados por círculos correspondem a nitreto e carboneto formados em Fe não-ligado. $O$ ponto indicado por triângulo corresponde a nitreto de titânio formado na liga $\mathrm{Fe}-18 \% \mathrm{Cr}-2 \% \mathrm{Mo}$. Na presença de $\mathrm{Cr}$, o TiN forma-se em temperatura mais baixa porque o $\mathrm{Cr}$ aumenta a solubilidade do Ti no Fe.

Ao contrário do observado nos aços ferríticos, a formação dos compostos Ti $(C, N)$ no aço em estudo, Custom $465 \AA$, tem efeito deletério sobre as propriedades mecânicas do material. Estes compostos diminuem a tenacidade à fratura, pois agem como nucleadores de trinca. Nesta liga, a adição de Ti tem como principal função fornecer a resistência mecânica desejada pela precipitação de finos intermetálicos $\mathrm{Ni}_{3} \mathrm{Ti}$. (WRIGHT; JUNG, 2011).

Juntamente com o $\mathrm{Cr}$, o Mo também forma e estabiliza a ferrita. O Mo tem importante influência na resistência à corrosão por pite dos aços inoxidáveis.

Mischler et al. (1991) estudaram a composição química do filme passivo dos aços inoxidáveis ferríticos Fe-24Cr e Fe-24Cr-11Mo por meio das técnicas AES, XPS e SIMS (análise de AES e XPS realizada em PHI 50/590A, utilizando o aparelho CMA com bombeamento diferencial de íons; análise de SIMS realizada em PHI545/Atomico Adida 3000-30, sendo AES/SIMS aparelho com um analisador de 
massa de quadruplo). Por meio da comparação desses aços e ensaios de polarização realizados em meio $0,1 \mathrm{M} \mathrm{H}_{2} \mathrm{SO}_{4}+0,4 \mathrm{M} \mathrm{Na} 2 \mathrm{SO}_{4}$ e $0,1 \mathrm{M} \mathrm{H}_{2} \mathrm{SO}_{4}+0,4 \mathrm{M}$

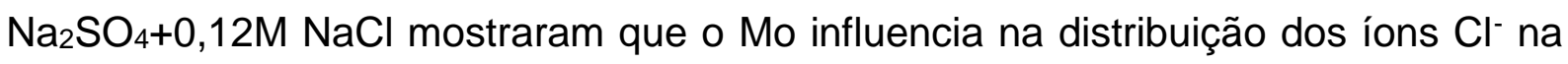
superfície do filme passivo; ou seja, a liga com Mo apresentou menor concentração de $\mathrm{Cl}^{-}$do que a liga sem Mo. A análise mostrou também que o Mo não tem influencia sobre a espessura do filme passivo. Esses resultados foram confirmados no estudo dos aços austeníticos, Fe20Cr20Ni e Fe20Cr20Ni6Mo, realizado por Wegrelius e Olefjord (1995). Em seu trabalho, Wegrelius e Olefjord propõem que o íon $\mathrm{Cl}^{-}$, presente no filme passivo substituí os íons $\mathrm{O}^{2-} \mathrm{e} \mathrm{OH}^{-}$enfraquecendo a ligação entre os cátions e o oxigênio e deste modo facilitam o ataque localizado. O Mo atua formando uma série de oxicloretos complexos; sendo alguns deles solúveis em ácido enquanto outros são estáveis. Deste modo, a diminuição da quantidade de $\mathrm{Cl}^{-}$ presente no filme passivo se deve a formação de oxicloretos solúveis em água e o restante do $\mathrm{Cl}^{-}$presente se liga com o Mo formando compostos insolúveis Mooxicloretos. Portanto, o filme passivo das ligas que contém Mo apresenta menor quantidade de $\mathrm{Cl}^{-}$, melhor resistência à corrosão por pite. Na Figura 12 é possível observar que a liga com Mo e Mo-N não apresenta formação de pite, há somente passivação e transpassivação.

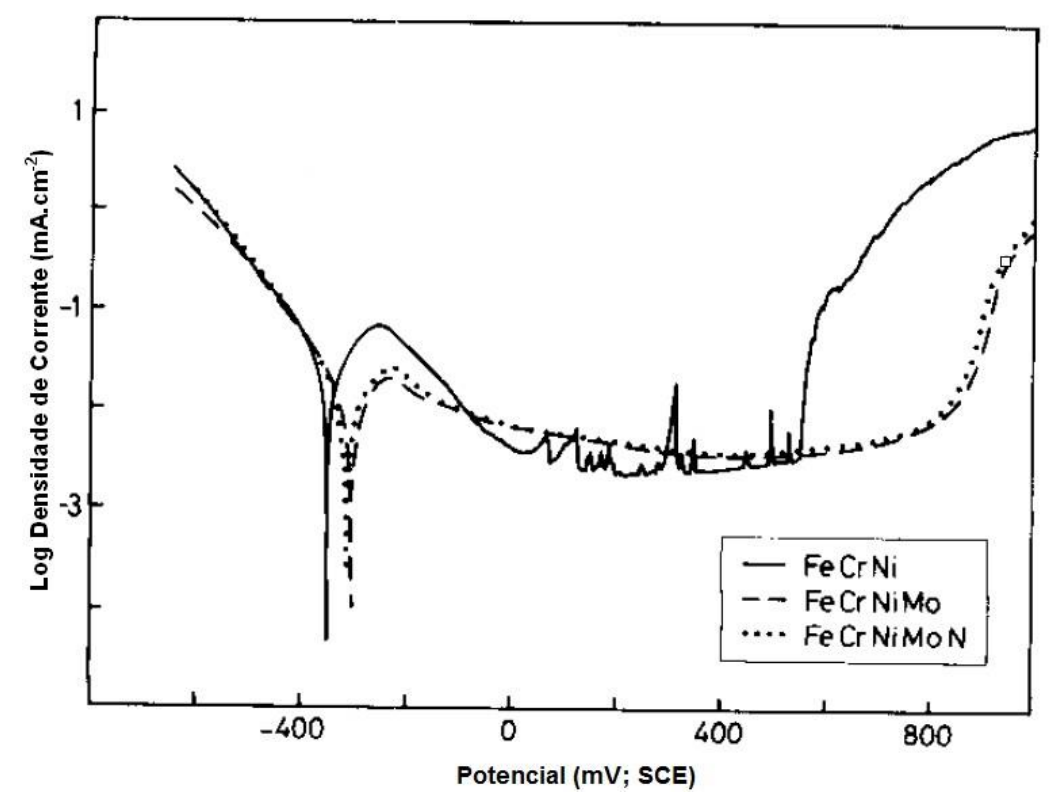

Figura 12: Curva de polarização em meio $0,1 \mathrm{M} \mathrm{HCl}+0,4 \mathrm{M} \mathrm{NaCl}$ a temperatura ambiente. Velocidade de varredura $0,1 \mathrm{mV}^{-\mathrm{s}^{-1}}$. (Modificado. WEGRELIUS; OLEFJORD, 1995) 
Além do aumento da resistência à corrosão por pite, o Mo melhora a resistência mecânica e a dureza dos aços inoxidáveis, por meio da formação de finos intermetálicos, como o $\mathrm{Fe}_{2} \mathrm{Mo}$, que tem estrutura semelhante à das fases de Laves, a fase chi, $\mathrm{Fe}_{36} \mathrm{Cr}_{12} \mathrm{Mo}_{10}$, conforme descrito no item Diagrama de Fases. A formação desses compostos deve ser controlada, pois sua presença em excesso pode levar a fragilização e à redução da resistência à corrosão do material.

\subsection{CORROSÃO POR PITE EM AÇOS INOXIDÁVEIS}

\subsubsection{Introdução}

Dentre as formas de corrosão localizada, a corrosão por pite é a principal forma de ataque nos aços inoxidáveis. Esse tipo de corrosão associado com a quebra da película passiva quando em contato com meio agressivo, forma pequenas e profundas cavidades na superfície do metal. Normalmente os pites são mais profundos do que largos, sendo que esta relação pode variar dependendo de vários fatores, como composição química do material, microestrutura, composição do eletrólito, entre outras. Esse tipo de ataque pode ser detectado a olho nu, mas frequentemente não são observados devido aos pites estarem cobertos com os produtos da corrosão.

A corrosão por pite é uma forma de defeito difícil de lidar, podendo acarretar uma falha estrutural do material, interferindo na falha por fadiga, na fratura frágil e ocasionando falha por corrosão sob tensão (CST). (SCHWEITZER et al., 2010; SEDRIKS, 1966)

Antes de apresentar as teorias para formação dos pites é importante explicar a formação e a característica do filme passivo observado para alguns materiais.

\subsubsection{Passivação}

O filme passivo se forma em vários metais reativos. Por exemplo, $\mathrm{Cr}, \mathrm{Ni}, \mathrm{Al}, \mathrm{Si}, \mathrm{Ta}$, $\mathrm{Ti}$ e $\mathrm{Nb}$. O campo elétrico dentro do filme passivo é da ordem de $10^{6} \mathrm{~V} \cdot \mathrm{cm}^{-1}$, o que permite a migração de íons através do filme, em temperatura de $25^{\circ} \mathrm{C}$, com densidades de corrente da ordem de $\mu \mathrm{A} \cdot \mathrm{cm}^{-2}$. A composição e estrutura do filme 
passivo não são bem definidas. Utilizando água tritiada e técnicas que permitem detectar variações em filmes finos, Okamoto (1973) em seu trabalho, mediu a quantidade de água no filme passivo formado em aços inoxidáveis $18 \mathrm{Cr}-8 \mathrm{Ni}$ em meio $0,5 \mathrm{M} \mathrm{H}_{2} \mathrm{SO}_{4}$. Neste estudo foi observado que o filme é formado por uma estrutura amorfa de óxidos hidratados e alguns metais especiais. A Figura 13 apresenta o modelo proposto. Sua composição depende do potencial aplicado e do tempo. Assim sua espessura aumenta com o aumento do potencial aplicado até que seja atingida sua estabilidade. Acima de um valor de potencial crítico esse filme perde sua propriedade passiva, o filme é dissolvido e é observada corrosão generalizada no metal. (SATO; KUDO; NODA, 1971)

Percebe-se do exposto que diferentes arranjos iônicos podem estar presentes no filme passivo. Dessa forma, a resistência à corrosão dos metais e ligas que se passivam apresenta diferenças em função das condições de formação e constituição do filme passivo.
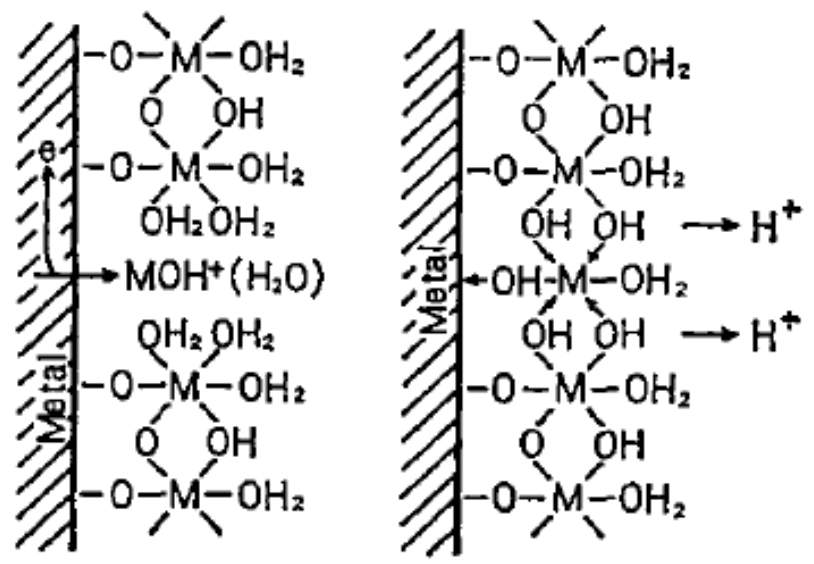

Figura 13: Modelo da estrutura do filme passivo proposto por Okamoto (1973).

\subsubsection{Nucleação de Pite}

A corrosão por pite pode ser estudada em 3 estágios principais, onde cada um deles ajuda a entender o processo de corrosão observado na superfície de metais passivados. Os estágios são:

1. Nucleação do pite

2. Crescimento do pite

3. Fenômeno da repassivação do pite 
O comportamento de cada estágio da corrosão por pite depende da composição química do metal, do eletrólito e das condições ambientais.

Para o primeiro estágio, 3 mecanismos são propostos na tentativa de explicar a ocorrência da quebra do filme passivo:

Mecanismo da penetração

Mecanismo da quebra mecânica do filme passivo

Mecanismo da adsorção competitiva

Após a nucleação do pite, o processo de corrosão dentro do pite produz condições que estimulam o seu crescimento e atividade dentro do pite. Neste trabalho será dada maior atenção ao estágio 1 e 2, que será apresentado nos itens posteriores, onde estão apresentadas as características que envolvem cada um dos mecanismos e como se dá o crescimento do pite. O fenômeno da repassivação não será apresentado neste trabalho por não ser o foco principal deste estudo.

\section{Mecanismo da penetração}

O mecanismo da penetração é caracterizado pelo movimento dos cátions do metal para o eletrólito e a migração de ânions da solução e ânions agressivos através do filme passivo para a interface óxido/metal através de defeitos localizados na camada de óxido. (MARCUS; OUDAR, 1995)

Hoar; Mears e Rothwell (1965) em seu trabalho propõem que a penetração dos íons agressivos ocorre quando o potencial no filme passivo corresponde ao potencial de quebra do filme. Os ânions agressivos penetram na camada passiva pelas regiões menos ordenadas (rupturas devido ao potencial alcançado) e, também, em regiões como contornos de grão e de impurezas, sem que haja troca de carga elétrica. $O$ filme de óxido contaminado tem maior condutividade que o original, o que possibilita a produção de maior quantidade de ânions $/ \mathrm{O}^{2-}$, deste modo há a formação de vazio na interface metal/filme e a saída de cátions do metal, e consequentemente a formação do pite.

Para Marcus e Oudar (1995) o transporte das diferentes espécies (ânions, cátions e íons agressivos) dentro do filme passivo depende de vários fatores, entre eles o 
tamanho dos ânions e cátions. A Figura 14 (MARCUS; OUDAR, 1995) esquematiza o mecanismo proposto por Hoar; Mears e Rothwell (1965).
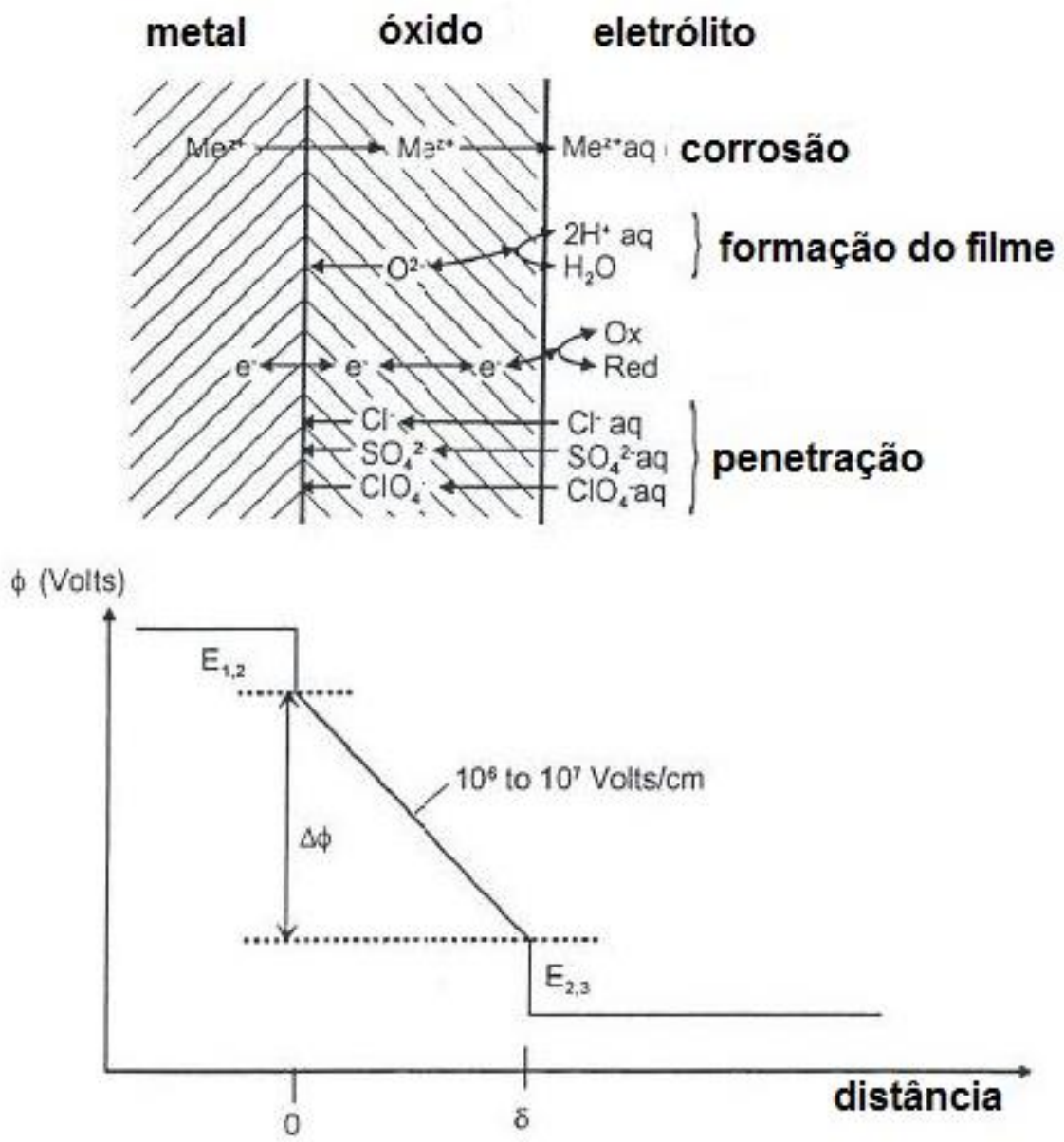

Figura 14: Modelo do mecanismo de penetração. (Modificado. MARCUS; OUDAR, 1995)

\section{Mecanismo da quebra mecânica do filme passivo}

Outra tentativa de explicar como o pite é formado foi proposta por Sato (1971). O autor estudou a influência da tensão interfacial e pressão de eletroestricção na quebra mecânica do filme passivo (Nota: Eletroestricção é a mudança de dimensão ou deformação mecânica do material devido à aplicação de um campo elétrico. $O$ campo elétrico interage com as moléculas ou íons de modo que cria um dipolo elétrico.). Conforme indicado em seu trabalho, o campo elétrico nos filmes anódicos é da ordem de $10^{6}$ a $10^{7} \mathrm{~V} . \mathrm{cm}^{-1}$, o qual é grande o suficiente para produzir uma pressão de eletroestricção considerável. Por outro lado, a espessura da camada do filme passivo é extremamente pequena, 100 a $1000 \AA$, o que indica que há tensão 
interfacial agindo sobre o filme passivo. Deste modo, essas duas propriedades não podem ser desconsideradas no estudo da formação do pite.

Os estudos termodinâmicos revelam que com o aumento da espessura do filme de óxido a pressão do filme aumenta atingindo o limite da pressão de eletroestricção (Figura 15). Caso a pressão de eletroestricção exceda a tensão de quebra do filme, haverá sua quebra mecânica.

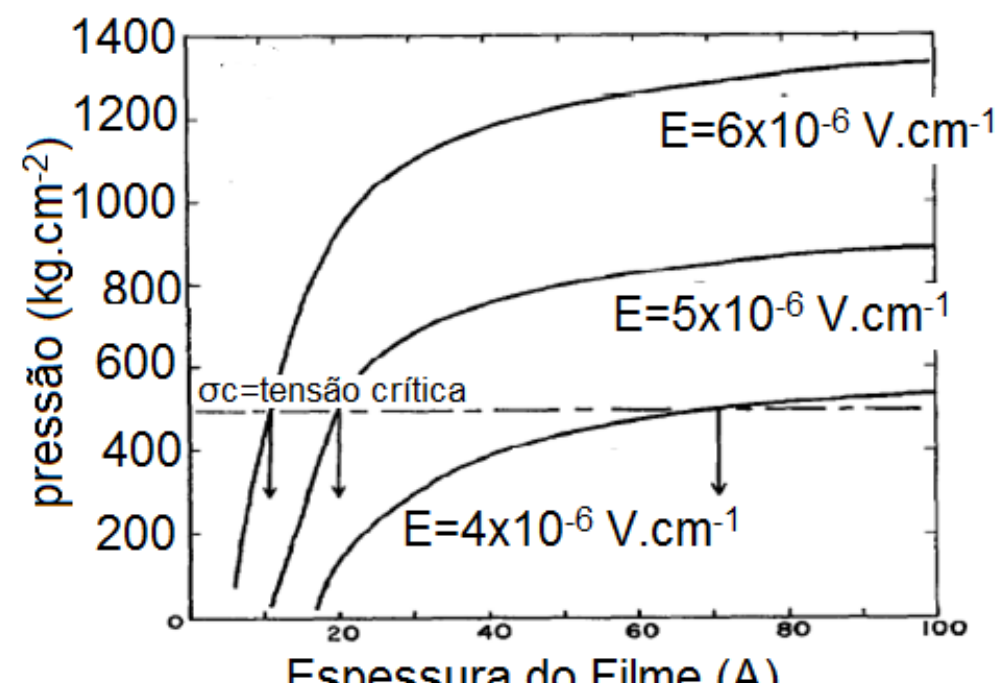

Espessura do Filme (A)

Figura 15: Pressão do filme passivo calculada como função da espessura do filme, considerando a superfície do filme com constante dielétrica $\varepsilon=10$, tensão superficial $y=100$ dina.cm ${ }^{-1}$ e campo elétrico $E=4 \times 10^{6}, 5 \times 10^{6}$ e $6 \times 10^{6} \mathrm{~V}^{-\mathrm{cm}^{-1}}$. (Modificado. SATO, 1971)

A Figura 16 apresenta o efeito da tensão superficial sobre a espessura do filme. É possível observar que quanto maior é a tensão superficial, maior é a espessura crítica para quebra do filme passivo.

Assim, as alterações de potencial resultam em fissuras no filme passivo, deixando uma quantidade suficiente da superfície do metal sem proteção, que quando em contato com o eletrólito levará à dissolução do metal (Figura 17). (MARCUS; OUDAR, 1995)

Este mecanismo assume que o potencial de quebra do filme passivo é crítico quando a pressão do filme excede a tensão crítica compressiva; e que a estabilidade do filme não é controlada somente pela reatividade eletroquímica do ânion agressivo, mas também pela propriedade mecânica e dielétrica do filme em si. 


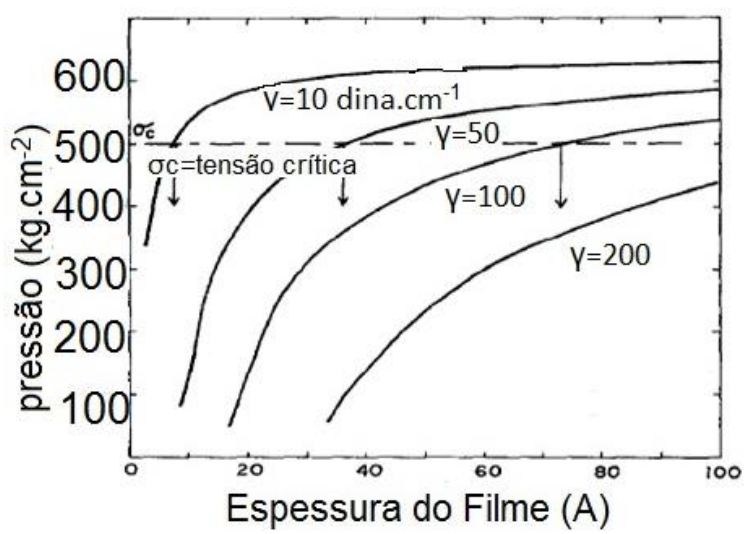

Figura 16: Pressão do filme passivo calculada como função da espessura do filme, considerando a superfície do filme com constante dielétrica $\varepsilon=10$, tensão superficial $y=100$ dina.cm ${ }^{-1}$ e campo elétrico $E=4 \times 10^{6} \mathrm{~V} . \mathrm{cm}^{-1}$, e tensão superficial $y=10,50,100$ e 200 dina.cm $^{-1}$. (Modificado. SATO, 1971)

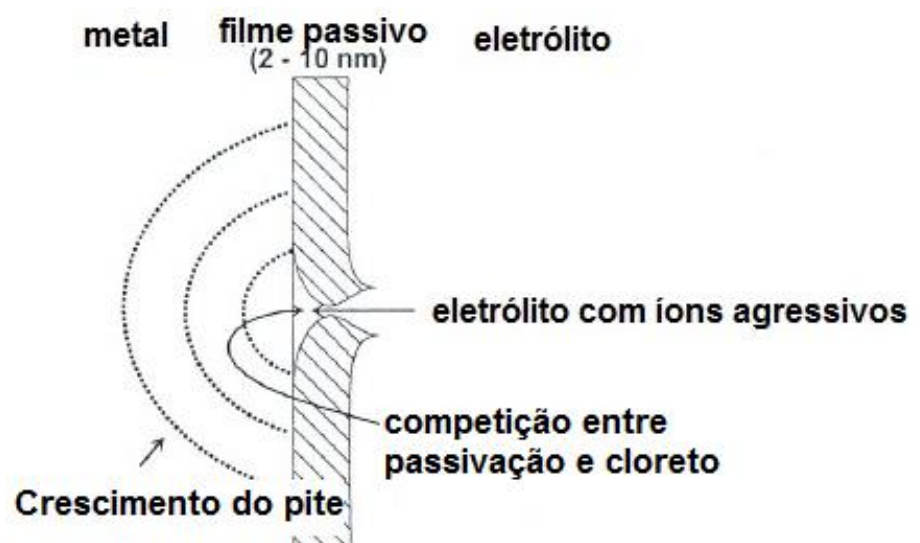

Figura 17: Modelo do mecanismo da quebra mecânica do filme passivo. (Modificado. MARCUS; OUDAR, 1995)

\section{Mecanismo da adsorção competitiva}

Outro mecanismo para tentar explicar como se dá ação de cloreto sobre a quebra do filme foi estudado por Hoar e Jacob (1967). Nos seus experimentos foi avaliada a cinética da quebra do filme passivo do aço $18 \mathrm{Cr}-8 \mathrm{Ni}$ pela ação de cloreto e brometo. Um dos resultados encontrados está apresentado na Figura 18. Este resultado sugere que existe um tempo de indução onde há a adsorção de haleto no filme de óxido. Há então, a formação de superfícies complexas que podem se separar do óxido e se dissolver na solução mais rapidamente do que um cátion não complexo presente na superfície do filme na ausência de um íon de halogênio. (HOART; JACOB, 1967) 


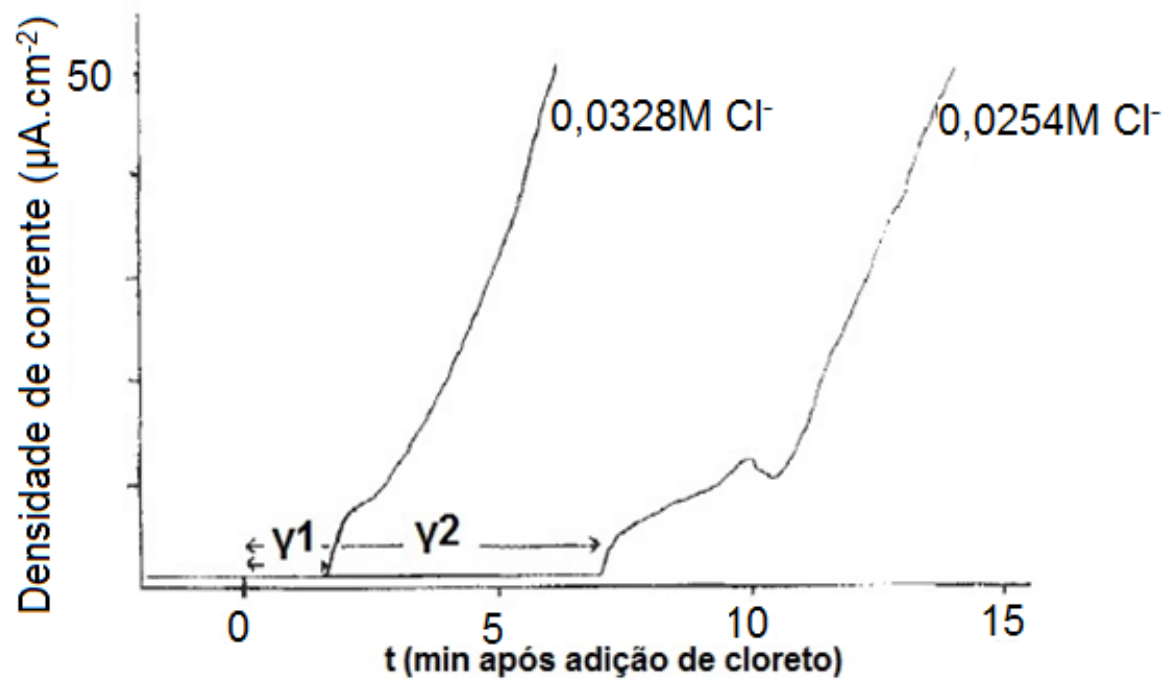

Figura 18: Curva para aço inoxidável 18-8 em solução $\mathrm{H}_{2} \mathrm{SO}_{4}$, mostrando o efeito da adição de $\mathrm{Cl}^{-} \cdot 25^{\circ} \mathrm{C}, \mathrm{pH}=2,05$ e $\mathrm{EH}=+800 \mathrm{mV}$, $\mathrm{y}=$ tempo de indução (Modificado. HOAR; JACOB, 1967)

Com a adsorção dos íons agressivos há a diminuição local do filme passivo e com a ação do potencial anódico constante, ocorre sua quebra e a formação do pite. Uma vez formado, o pite cresce pelo processo autocatalítico.

O mecanismo de adsorção mostra a influência da cinética sobre a taxa de quebra do filme passivo e os fatores que influenciam, apresentando deste modo uma completa explicação com relação à nucleação do pite.

Considerando a estrutura do filme passivo apresentado anteriormente, é possível concluir que os mecanismos propostos para explicar a nucleação do pite ocorrem simultaneamente; ou seja, os íons cloreto presentes adsorvem na superfície do filme e substituem as moléculas de água formando um complexo metal-cloreto solúvel, os quais removem os íons de metal do filme óxido, ocorrendo a quebra do filme. $O$ vazio criado pela saída do metal pode ser preenchido pela formação de novo filme passivo. Deste modo, o processo de indução de formação do pite é considerado um processo dinâmico, há a quebra do filme e ao mesmo tempo a formação de novo filme passivo de modo a manter o estado estacionário. No entanto, com o auxílio do campo elétrico, os íons cloreto migram para o filme, sendo adsorvidos. Neste caso, não há reparo das moléculas de água, e assim, há a penetração dos íons cloreto, formação dos íons solvatados do filme de sal e sua dissolução anódica, como mostrado na Figura 19. Deste modo, a resistência à corrosão dos aços inoxidáveis é 
controlada pela natureza dos filmes passivos. A ligação com a água pode reagir para fornecer várias espécies ou ser substituída por outros íons, como o cloreto, resultando em degradação do filme. (OKAMOTO, 1973)

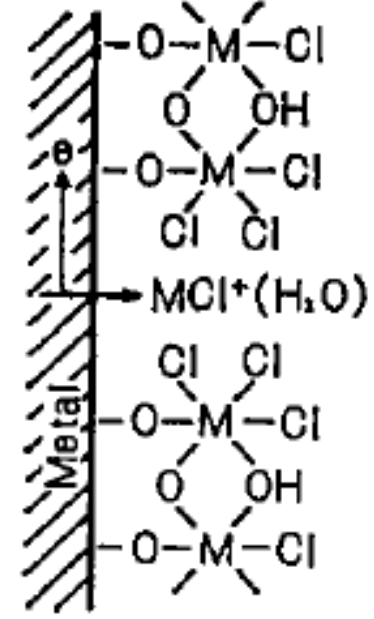

(a)

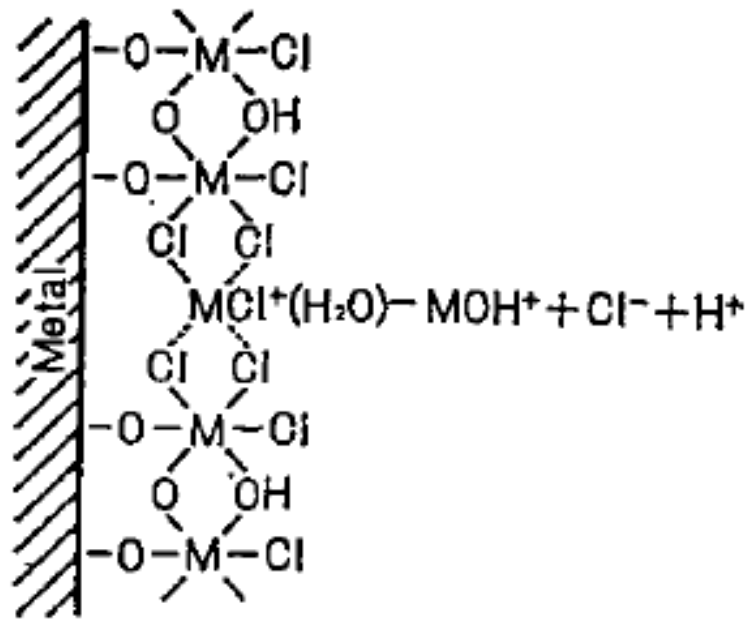

(a')

Figura 19: Íons cloreto substituindo as moléculas de água: (b) inibição da formação da ponte de hidrogênio; (a') resultando na quebra do filme passivo.

\subsubsection{Crescimento do pite}

Após a quebra da película passiva e nucleação do pite, este cresce por mecanismo autocatalítico (Figura 20). No interior do pite, a dissolução de íons de metal atrai o íon cloreto, na tentativa de reestabelecer o equilíbrio de cargas elétricas, e ocorrem ligações de sal $\mathrm{M}_{\mathrm{x}} \mathrm{Cly}$. Como resultado tem-se a hidrólise da água e assim, há a acidificação do eletrólito no interior do pite, o que leva ao processo autocatalítico de crescimento do pite. Ao mesmo tempo, nas regiões catódicas adjacentes (fora do pite) há a redução do oxigênio. As etapas do mecanismo de crescimento de pite estão resumidas a seguir.

- Dissolução dos metais: $\mathrm{Me} \rightarrow \mathrm{Me}^{+2}+\mathrm{ze}^{-}$

- Reação catódica: $\mathrm{O}_{2}+2 \mathrm{H}_{2} \mathrm{O}+4 \mathrm{e}^{-}=4 \mathrm{OH}^{-}$

- Migração de íons $\mathrm{Cl}^{-}$a fim de neutralizar as cargas positivas dos cátions

- Acidificação (hidrólise): $\mathrm{Me}^{+} \mathrm{Cl}^{-}+\mathrm{H}_{2} \mathrm{O}=\mathrm{MeOH}+\mathrm{H}^{+} \mathrm{Cl}$

- Mais dissolução - nova migração de $\mathrm{Cl}^{-}$- mais acidificação

Normalmente os pites são mais profundos do que largos, sendo que esta relação pode variar dependendo de vários fatores, como composição química do material, 
microestrutura, composição do eletrólito, entre outras. No entanto, deve-se ressaltar que o caráter localizado da corrosão por pite também se deve à formação de $\mathrm{OH}^{-}$ nas regiões adjacentes ao pite (Figura 20), onde ocorre a reação catódica de oxigênio. A produção de $\mathrm{OH}^{-}$nessas regiões melhora a passivação, de modo que estas ficam resistentes à nucleação de pite e ainda contribuem com um fator galvânico, uma vez que se tem uma grande área de superfície nobre ligada a uma pequena área de superfície não-nobre que é o pite. Esses fatores colaboram para a forma localizada do pite e também para a sua rápida cinética de corrosão.

(c)

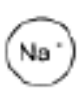

$\mathrm{O}_{2}$

(c)

Na.

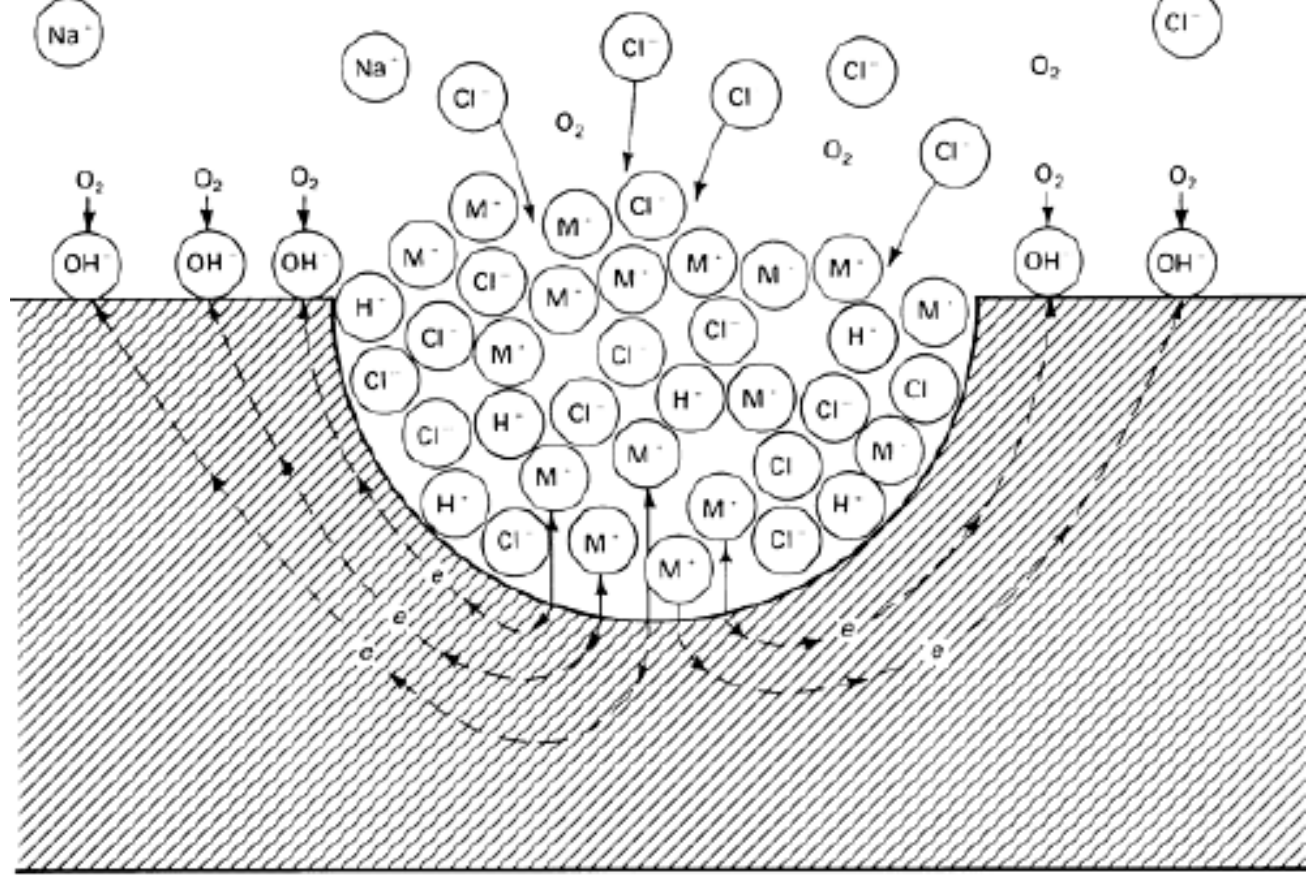

Figura 20: Crescimento autocatalítico do pite na presença de cloreto. As setas tracejadas indicam o movimento dos elétrons. (EVANS, U. R. apud DAVISON; DEBOLD; JOHNSON, 1987) 


\subsubsection{Resistência à corrosão dos aços endurecidos por precipitação}

A resistência à corrosão por pite pode ser estimada pelo parâmetro PRE (Pitting Resistance Equivalence). Embora o PRE não leve em consideração efeitos microestruturais e alguns elementos importantes presentes nos aços inoxidáveis como o $\mathrm{Ni}$ e o $\mathrm{Mn}$, ele é efetivo quando se comparam microestruturas semelhantes. Algumas equações foram propostas para se calcular o PRE, dentre elas, tem-se: (KITADA et al., 1987 apud ALFONSSON, QVAFORT, 1-1992)
(1) $\mathrm{PRE}=\mathrm{Cr}+3,0^{*} \mathrm{Mo}+12,8^{*} \mathrm{~N}$
Renner, et al (1986)
(2) $\mathrm{PRE}=\mathrm{Cr}+3.3^{\star} \mathrm{Mo}+16^{*} \mathrm{~N}$
Truman, (1987)
(3) $\mathrm{PRE}=\mathrm{Cr}+3,0^{*} \mathrm{Mo}+27^{*} \mathrm{~N}$
Kitada, et al (1987)
(4) $\mathrm{PRE}=\mathrm{Cr}+3,3^{*} \mathrm{Mo}+30^{*} \mathrm{~N}$
Herbsleb, (1982)

As equações acima foram aplicadas para o aço em estudo, Custom $465{ }^{\circledR}$, e o valor PRE encontrado foi de 15. O qual condiz com o valor encontrado por Wright e Jung (2011), onde foi aplicada a equação $\mathrm{Cr}+3,3^{*}\left(\mathrm{Mo}+1 / 2^{*} \mathrm{~W}\right)$.

No trabalho de Calderón-Hernandez (2012), ao invés do parâmetro PRE foi aplicada a equação MARC (Measure of Alloying for Resistance to Corrosion, $\mathrm{MARC}=\% \mathrm{Cr}+$ $3,3(\% \mathrm{Mo})+20(\% \mathrm{~N})+20(\% \mathrm{C})-0,5(\% \mathrm{Mn})-0,25(\% \mathrm{Ni}))$ a qual leva em conta o teor de $\mathrm{Mn}$, para estimar a resistência à corrosão do aço 298 (inoxidável contendo Cr-Ni$\mathrm{Mn}$ ) (Speidel, 2006). Aplicando-se esta mesma equação para os aços Custom $465 \AA$ e 304L obtém-se o valor de 12 e 17, respectivamente, mostrando que o aço em estudo, Custom $465 \AA$, apresenta resistência à corrosão inferior à do aço 304L.

Os trabalhos encontrados na literatura especializada para os aços endurecidos por precipitação (Web of Knowledge (1945 até agora) e Compendex Engineering Index (1969 até agora), Metadex - Materials Research Database (1965 até agora) e CSA Cambridge Scientific Abstracts (1962 até hoje)) estudam o efeito combinado entre a resistência à corrosão e as propriedades mecânicas do material, como por exemplo, o estudo da resistência à corrosão com aplicação de cargas cíclicas (corrosão em fadiga), CST e com relação ao tempo/temperatura de envelhecimento.

Lin e Tsai (2000) em seu trabalho estudaram a resistência à corrosão em fadiga do aço $15 \mathrm{Cr}-6 \mathrm{Ni}$ (Custom $450 \circledast$ ) em meio $0,6 \mathrm{M} \mathrm{NaCl}$ considerando três condições de tratamento térmico: solubilizado, envelhecido na condição H900 (solubilização 
seguido de envelhecimento a $482^{\circ} \mathrm{C}$ por 4 horas) e $\mathrm{H} 1150$ (solubilizado seguido de envelhecimento a $621^{\circ} \mathrm{C}$ por 4 horas). Eles verificaram que em todas as condições de tratamento térmico a resistência à fadiga foi reduzida pela presença de cloreto. Os processos predominantes para determinar a corrosão em fadiga são fortemente dependentes da ação combinada entre a tensão cíclica aplicada e o meio agressivo, os quais juntos levam a deformação localizada e intensificam o crescimento dos defeitos e de pequenas trincas. Deste modo, o pite atua no primeiro estágio da fadiga (estágio I), na nucleação da trinca. Isso foi comprovado para as amostras solubilizadas e envelhecidas na condição $\mathrm{H} 1150$, onde foi observado que a trinca originou-se devido à corrosão por pite na superfície do material. Foi observado também que a resistência à corrosão em fadiga para a condição H900 > solubilizada $>$ H1150, a qual pode ser atribuída à distribuição dos precipitados no material, onde para a condição H900 os precipitados se apresentam coerentes e finamente dispersos na matriz do material.

Outro estudo com relação à corrosão dos aços endurecidos por precipitação foi realizado por Lee, et al. (2011). Eles estudaram a resistência à CST do aço Custom $465 \AA$ em meio de $0,6 \mathrm{M} \mathrm{NaCl}, \mathrm{pH} 7,3$, utilizando a técnica RST (Rising Step Load), para amostras nas condições solubilizada, envelhecida na condição $\mathrm{H} 1000$, trabalhada a frio e envelhecida nas temperaturas de $482^{\circ} \mathrm{C}$ a $552^{\circ} \mathrm{C}$ por 4 horas. No entanto, o trabalho limita-se a apresentar os resultados dos experimentos, sem detalhar os mecanismos responsáveis pelo desempenho.

Por outro lado, neste trabalho de Lee et al. (2011), encontram-se resultados de análises por Difração de Elétrons de Área Selecionada (SADP) de amostras de Custom $465 \AA$ trabalhadas a frio e envelhecidas a $538^{\circ} \mathrm{C}$ por 4 horas: os resultados indicaram a presença de placas hexagonais de carboneto de molibdênio dentro das ripas de martensita. No entanto, os autores não relacionaram estes resultados com o desempenho quanto à CST.

O trabalho de Stavros e Paxton (1972) realizado em aços maraging $18 \% \mathrm{Ni}$ e $25 \% \mathrm{Ni}$ em meios de $1 \mathrm{~N} \mathrm{H}_{2} \mathrm{SO}_{4}$ e $3 \% \mathrm{NaCl}$ também tentou explicar a influência do tratamento térmico na resistência à corrosão. Em seu trabalho foi observado que em meio de $3 \% \mathrm{NaCl}$ o material não apresentou comportamento ativo-passivo, somente foi observado trecho ativo. Já em meio de $1 \mathrm{~N} \mathrm{H}_{2} \mathrm{SO}_{4}$, o material apresentou trecho ativo e passivo, sendo que para a menor temperatura de envelhecimento, $482^{\circ} \mathrm{C}$, 
observou-se maior densidade de corrente passiva. Nas temperaturas mais altas de tratamento térmico foram encontradas melhores resistências à corrosão (medidas através da densidade de corrente passiva). Segundo Stavros e Paxton (1972) isso se deve à formação de austenita retida e competição entre dissolução dos precipitados $\mathrm{Ni}_{3} \mathrm{Mo}$ e precipitação de $\mathrm{Fe}_{2} \mathrm{Mo}$; estas transformações, segundo Stavros e Paxton (1972) levam ao aumento do teor de níquel em solução sólida, dando origem a um material de melhor resistência à corrosão. No entanto, as curvas de polarização apresentadas pelos autores possuem trechos passivos com densidades de corrente muito próximas (da mesma ordem de grandeza), o que pode ser uma evidência fraca para inferir que a resistência à corrosão esteja de fato melhorando com o superenvelhecimento.

Deste modo, a partir dos relatos apresentados, observa-se que não há uma clara explicação da influência da temperatura e tempo de envelhecimento sobre a resistência à corrosão dos aços endurecidos por precipitação.

\subsubsection{Sulfato como inibidor de corrosão por pite}

Estudos (LECKIE; UHLIG, 1966; SATO, 1971) mostram que existe um potencial crítico abaixo do qual não é observada a presença de pites em meio contendo cloreto. Deste modo, aumentando a concentração de cloreto tem-se a mudança do potencial para valores mais ativos. No entanto, os estudos de Leckie e Uhlig (1966) mostraram que o potencial crítico pode ser direcionado para valores mais nobres com a presença de alguns ânions, como $\mathrm{ClO}_{4}^{-}, \mathrm{SO}_{4}^{-2}, \mathrm{NO}_{3}^{-} \mathrm{e} \mathrm{OH}^{-}$. Em seu estudo para o aço $18 \mathrm{Cr}-8 \mathrm{Ni}$, a adição de sulfato eleva o potencial para valores mais nobres, e na concentração da solução de $0,1 \mathrm{M} \mathrm{NaCl}+0,15 \mathrm{M} \mathrm{Na} \mathrm{SO}_{4}$, a adição chega a inibir totalmente a formação do pite (Figura 21). 


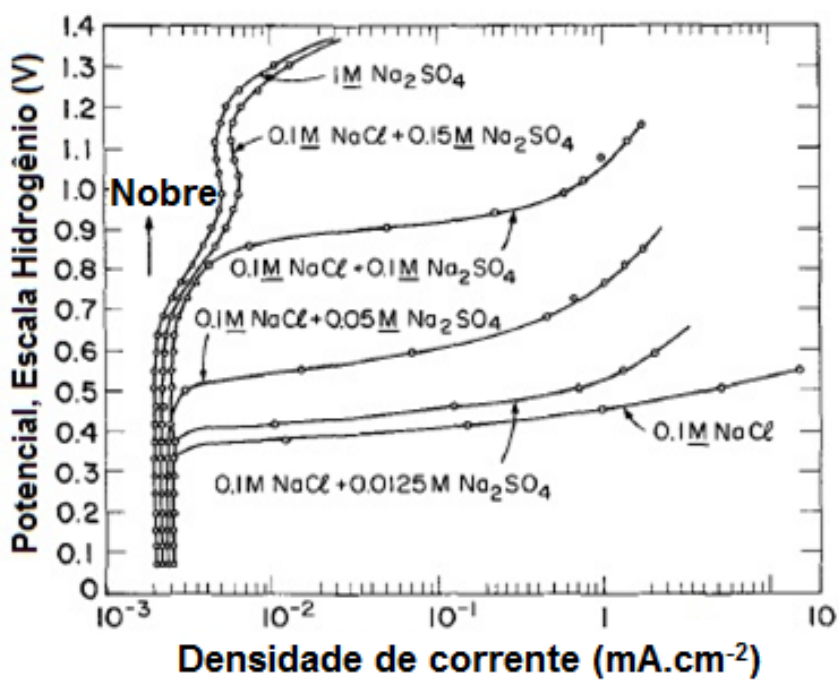

Figura 21: Curvas de polarização em $0,1 \mathrm{M} \mathrm{NaCl}$ mostrando o aumento do potencial de pite com a adição de $\mathrm{Na}_{2} \mathrm{SO}_{4}, 2^{\circ} \mathrm{C}$. (Modificado. LECKIE; UHLIG, 1966)

A quantidade de ânions que deve ser adicionada para se obter a completa inibição da formação do pite depende de cada tipo de ânion e da composição do material, mas como regra geral, quanto maior a concentração de cloreto no meio, maior deve ser a concentração de inibidor adicionado. Alguns estudos (LECKIE; UHLIG, 1966; HOAR; JACOB, 1967; SZLARSKA-SMIALOWSKA, 1971) mostram que os ânions $\mathrm{ClO}_{4}^{-}, \mathrm{SO}_{4}^{-2}, \mathrm{NO}_{3}, \mathrm{OH}^{-}$agem por mecanismo de adsorção competitiva entre estes ânions e o cloreto. Essa competição requer a mudança do potencial para valores mais nobres e deste modo, uma maior quantidade de íon cloreto deve se mover para a dupla camada elétrica, até que atinja uma concentração crítica para deslocar o oxigênio e ser adsorvido na superfície do metal. Quanto maior a afinidade e facilidade de adsorção dos ânions no filme passivo, mais efetivamente ele excluirá o íon $\mathrm{Cl}^{-}$e inibirá o pite.

No presente trabalho para o aço Custom $465 \AA$, escolheu-se avaliar a resistência à corrosão por pite na presença do íon inibidor sulfato. $O$ teor máximo de inibidor

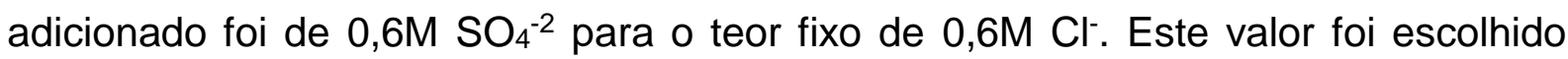
baseado em estudos realizados para os aços austeníticos 304L e 298 (CALDERÓNHERNÁNDEZ, 2012; LECKIE; UHLIG, 1966 e SZLARSKA-SMIALOWSKA, 1971), onde foi observado que houve a inibição da formação do pite nessas concentrações e também devido a dificuldade de se encontrar estudos semelhantes realizados com aços endurecidos por precipitação. 


\section{MATERIAIS E MÉTODOS}

Neste capítulo estão apresentados os materiais e procedimentos experimentais utilizados para a caracterização das propriedades mecânicas (dureza e resistência à tração) e para o estudo da resistência à corrosão por pite do aço Custom $465 \AA$.

\subsection{MATERIAL DE ESTUDO}

Para o presente estudo foi utilizada uma barra redonda de 1 polegada de diâmetro $(\Phi=25,4 \mathrm{~mm})$ do aço Custom $465 \AA$ adquirido na condição solubilizada. A Tabela 4 apresenta a composição química da barra.

Tabela 4: Composição química do aço inoxidável Custom $465 \AA$ (\% em massa).

\begin{tabular}{lccc}
\hline \multirow{2}{*}{ Elemento } & \multicolumn{2}{c}{$\begin{array}{c}\text { Especificação } \\
\text { AMS 5963,2007) }\end{array}$} & \multirow{2}{*}{ Valor encontrado (\%) } \\
\cline { 2 - 3 } & MíNIMO (\%) & MÁXIMO (\%) & \\
\hline Carbono & -- & 0,02 & 0,005 \\
Manganês & -- & 0,25 & 0,02 \\
Silício & -- & 0,25 & 0,04 \\
Fósforo & -- & 0,015 & 0,003 \\
Enxofre & -- & 0,010 & 0,0005 \\
Cromo & 11,00 & 12,50 & 11,63 \\
Níquel & 10,75 & 11,25 & 11,02 \\
Molibdênio & 0,75 & 1,25 & 0,94 \\
Titânio & 1,50 & 1,80 & 1,59 \\
Nitrogênio & -- & 0,01 & 0,002 \\
\hline
\end{tabular}

\subsection{TRATAMENTO TÉRMICO E ENSAIOS MECÂNICOS}

O Custom $465 \AA$, na condição solubilizada, foi envelhecido em duas condições de temperatura: $510^{\circ} \mathrm{C}\left(950^{\circ} \mathrm{F}\right)$ e $538^{\circ} \mathrm{C}\left(1000^{\circ} \mathrm{F}\right)$ ambos por 4 horas, tratamentos conhecidos respectivamente como $\mathrm{H} 950$ e $\mathrm{H} 1000$. Os tratamentos térmicos, realizados conforme especificado na AMS 5963, foram conduzidos em forno a ar Brasimet tipo $\mathrm{FCA} 80 / 1-0-750^{\circ} \mathrm{C}$. A Figura 22 apresenta o tratamento térmico aplicado para o Custom $465 \AA$. 


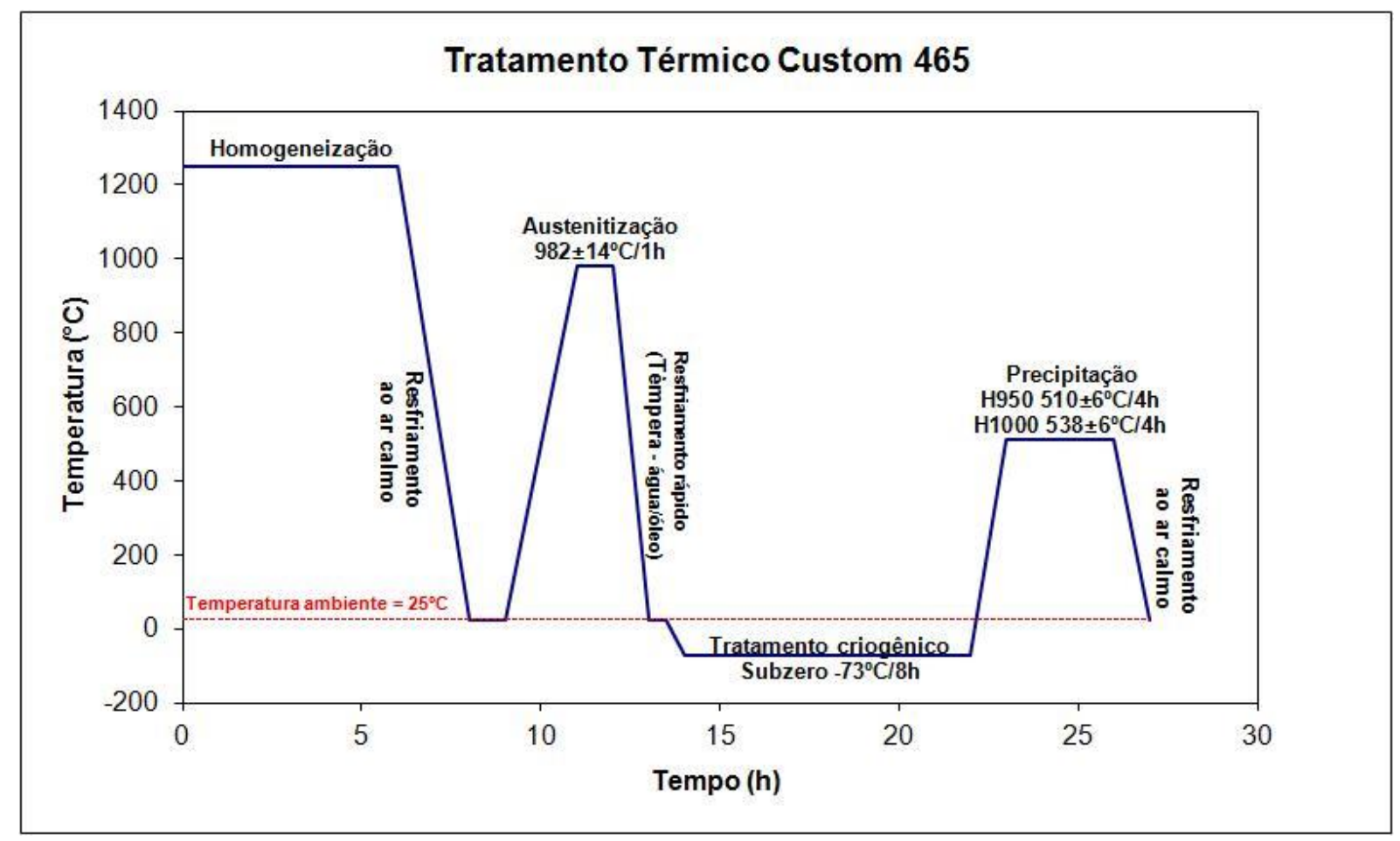

Figura 22: Tratamento térmico do aço Custom $465 \AA$.

Todo o material disponível foi tratado termicamente nas condições H950 e H1000. No entanto, no decorrer desta pesquisa, foi verificada a necessidade de se comparar os resultados de resistência à corrosão com a condição solubilizada. Havia duas opções: utilizar uma barra, de mesmas dimensões, mas de corrida diferente, ou solubilizar parte do material já tratado nas condições H950 e H1000. Como a composição química da barra de nova corrida apresentava diferenças em alguns dos elementos, escolheu-se solubilizar uma parte do material já tratado na condição $\mathrm{H} 1000$. O tratamento foi realizado no mesmo forno mencionado anteriormente, utilizando os seguintes parâmetros: austenitização realizada a $982^{\circ} \mathrm{C}$ por 60 minutos seguido de resfriamento em água; tratamento criogênico a $-73^{\circ} \mathrm{C}$ por 8 horas seguido de aquecimento em ar até a temperatura ambiente (aproximadamente $\left.25^{\circ} \mathrm{C}\right)$.

Após o endurecimento por precipitação as propriedades mecânicas foram verificadas por meio de ensaio de tração realizado em equipamento Wolpert Tipo 20TUZ 750 e a dureza em equipamento Pantec Modelo RBS. Para cada condição de envelhecimento foram confeccionados 6 corpos de prova (CDP) de tração de tamanho reduzido com seção reta circular conforme ASTM E8/E8M (ASTM E8/E8M, 
2011). As dimensões e o formato do corpo de prova estão apresentados na Tabela 5 e Figura 23. Neste ensaio os CDP's foram deformados até a fratura, com a carga de tração sendo aplicada constante e uniaxialmente ao longo do eixo do CDP. Foi utilizado extensômetro eletrônico Panantec de base de medida 25 mm.

Os valores de força medidos com relação à deformação (tensão) foram registrados através do software Panantec ATMI. Para determinação do limite de escoamento, a velocidade de teste utilizada foi de 6,89 até $68,9 \mathrm{~N} . \mathrm{mm}^{-1}$, considerando um nível de pré-deformação de 0,002. O limite de resistência foi obtido utilizando a mesma velocidade de teste aplicada para o limite de escoamento. $\mathrm{O}$ alongamento foi medido pela razão da variação do comprimento $\left(\Delta \mathrm{L}=\mathrm{L}_{\text {final }}-\mathrm{L}_{\text {inicial }}\right)$ pelo comprimento inicial (Linicial), considerando Linicial de 5 vezes o diâmetro inicial do CDP. O módulo de elasticidade, que é o coeficiente da porção elástica da curva tensão-deformação, não foi medido neste estudo.

Tabela 5: Dimensão do corpo de prova de tração. (ASTM E8/E8M, 2011)

\begin{tabular}{|l|c|}
\hline \multicolumn{1}{|c|}{ Parâmetros } & Dimensões (mm) \\
\hline Comprimento útil $(\mathrm{G})$ & $30,0 \pm 0,1$ \\
\hline Diâmetro (D) & $6,0 \pm 0,1$ \\
\hline Raio mínimo $(\mathrm{R})$ & 6 \\
\hline Comprimento mínimo da seção reduzida $(\mathrm{A})$ & 36 \\
\hline
\end{tabular}

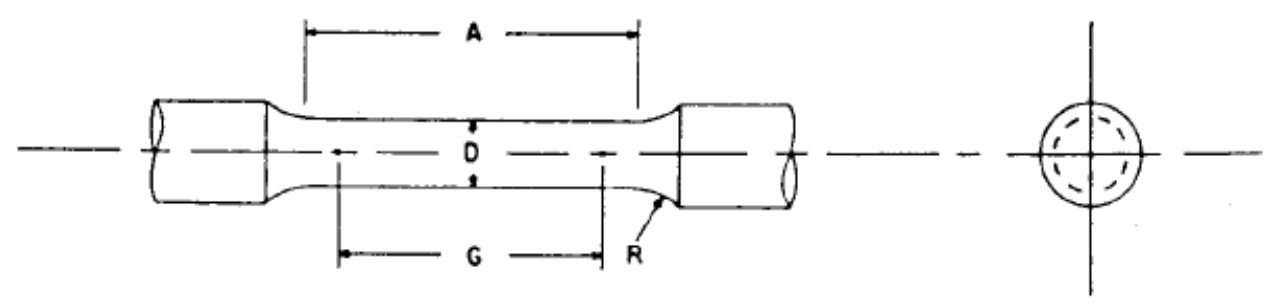

Figura 23: Corpo de prova de tração. (ASTM E8/E8M, 2011)

Para cada condição de tratamento térmico, foram realizadas 3 medições de dureza do tipo Rockwell C (HRC) diretamente na seção transversal da barra tratada, conforme ASTM A370 (ASTM A370, 2012). Neste ensaio primeiramente foi aplicada uma carga de menor intensidade (pré-carga), $10 \mathrm{~kg}$, resultando em uma identação inicial, que ajusta o penetrador no material. Posteriormente, foi aplicada uma carga de maior intensidade, onde para o tipo C, esta carga é de $150 \mathrm{~kg}$. O penetrador utilizado é um cone de diamante. A leitura da dureza foi realizada diretamente no aparelho. 


\subsection{POLARIZAÇÃO POTENCIODINÂMICA}

As amostras na condição solubilizada e tratadas termicamente foram cortadas na seção transversal da barra gerando discos de $24 \mathrm{~mm}$ de diâmetro e $6 \mathrm{~mm}$ de altura; em seguida as faces a serem ensaiadas foram lixadas até grana \#600. A célula eletroquímica utilizada (célula plana) expõe ao eletrólito $1 \mathrm{~cm}^{2}$ de superfície.

Os ensaios de corrosão e o registro dos dados foram realizados em célula plana (Figura 24), por meio de polarização potenciodinâmica utilizando o potenciostato/galvanostato da PAR (Princeton Applied Research) modelo 273A (Figura 25) e software 352 SoftCorr III, disponível no Departamento de Engenharia Metalúrgica e de Materiais da Escola Politécnica da USP (PMT/USP). O eletrodo de referência utilizado foi o prata-cloreto de prata $(\mathrm{Ag} / \mathrm{AgCl})$. Como contra eletrodo empregou-se uma tela de platina quadrada de $25 \mathrm{~mm}$ de lado. O eletrodo de trabalho era o próprio CDP que foi fixado mecanicamente na célula preenchida com eletrólito.

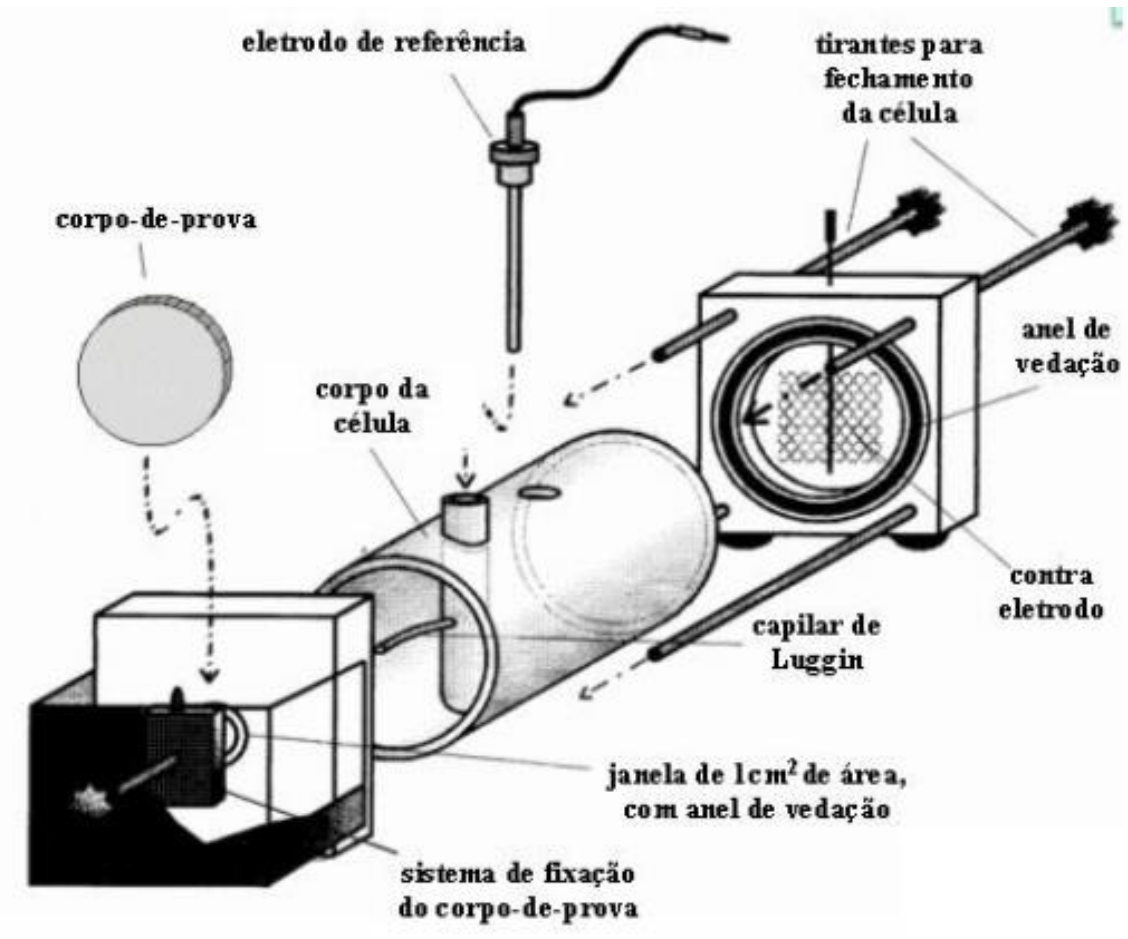

Figura 24: Representação esquemática da célula plana. (CORDEIRO, 2001). 


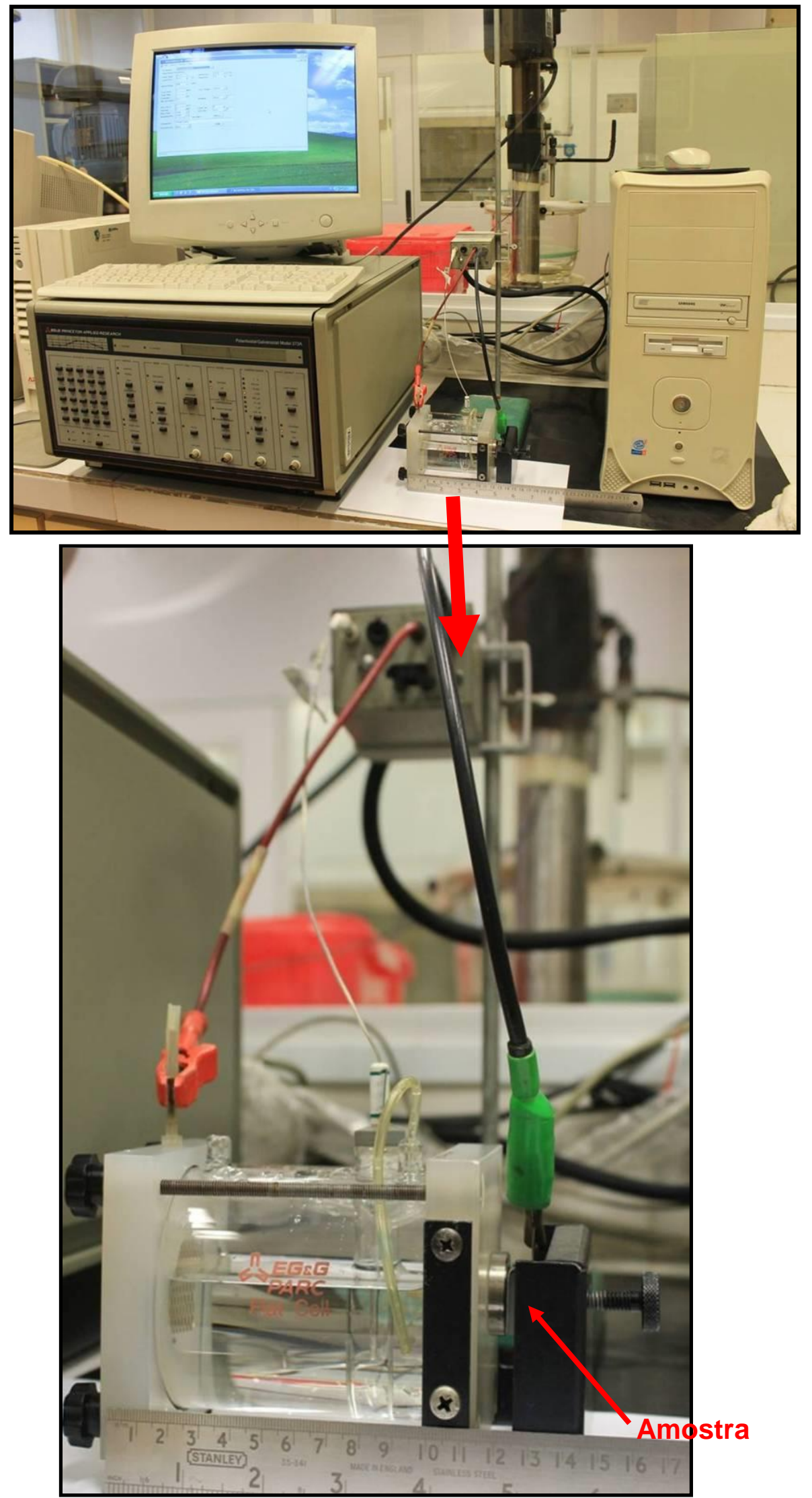

Figura 25: Representação esquemática do potenciostato e célula utilizados. 
Para todos os ensaios realizados, os CDP's foram expostos ao eletrólito durante 5 minutos antes do início da polarização. Após este tempo, iniciava-se a polarização com uma sobretensão catódica de $250 \mathrm{mV}$, seguida de varrimento de potencial, com velocidade de varredura de $1 \mathrm{mV} . \mathrm{s}^{-1}$, até que fosse atingida a densidade de corrente de $10^{-3} \mathrm{~A} . \mathrm{cm}^{-2}$. Nesse tipo de ensaio é obtida uma curva de polarização com trecho catódico, seguida de trecho passivo, que se prolonga até que pelo menos um pite seja nucleado e apresente crescimento constante. Quando se tem a nucleação de pite, ocorre um aumento acentuado da densidade de corrente, a qual aumenta praticamente sem alteração do potencial de eletrodo, atingindo densidades de corrente $10^{3}$ vezes maior. O potencial onde ocorre esse aumento acentuado de densidade de corrente é o potencial de pite, Ep, o qual é lido diretamente na curva de polarização.

\subsection{ATIVIDADE DO ÍON CLORETO}

Os ensaios de polarização potenciodinâmica foram realizados nos eletrólitos mostrados na Tabela 6, na condição naturalmente aerada (sem aeração forçada). Conforme mencionado no item da Revisão Bibliográfica, a adição de sulfato a eletrólitos contendo cloreto causam efeito inibidor à corrosão por pite, em alguns materiais, como por exemplo, o aço UNS S30403 e aços inoxidáveis austeníticos $\mathrm{Cr}$ Ni-Mn, conhecidos como série 200 (CALDERÓN-HERNÁNDEZ, 2012; LECKIE; UHLIG, 1966 e SZLARSKA-SMIALOWSKA, 1971). Assim, para o presente estudo foram feitas adições crescentes de sulfato com o objetivo de diminuir a agressividade do meio e também de estudar a formação de pites no aço Custom $465 \AA$.

Tabela 6: Concentração dos eletrólitos estudados.

\begin{tabular}{c}
\hline Concentração dos eletrólitos \\
\hline $0,6 \mathrm{M} \mathrm{Cl}\left(\mathrm{NaCl}^{2}\right)$ \\
$0,6 \mathrm{M} \mathrm{Cl}^{-}(\mathrm{NaCl})+0,06 \mathrm{M} \mathrm{SO}_{4}^{2-}\left(\mathrm{Na}_{2} \mathrm{SO}_{4}\right)$ \\
$0,6 \mathrm{M} \mathrm{Cl}^{-}(\mathrm{NaCl})+0,3 \mathrm{M} \mathrm{SO}_{4}^{2-}\left(\mathrm{Na}_{2} \mathrm{SO}_{4}\right)$ \\
$0,6 \mathrm{M} \mathrm{Cl}^{-}(\mathrm{NaCl})+0,6 \mathrm{M} \mathrm{SO}_{4}{ }^{2-}\left(\mathrm{Na}_{2} \mathrm{SO}_{4}\right)$ \\
\hline
\end{tabular}

As soluções foram preparadas com reagentes padrão analítico ( $\mathrm{NaCl}$ e $\mathrm{Na}_{2} \mathrm{SO}_{4}$ ), água destilada e deionizada. Os eletrólitos foram trocados a cada cinco ensaios para 
evitar contaminações. Para cada condição, tratamento térmico e eletrólito, foram realizados no mínimo 10 ensaios, permitindo o cálculo do valor médio e desvio padrão do Ep.

Após cada ensaio eletroquímico, os CDP's foram retirados da célula eletroquímica, lavados em água, secos com acetona ou álcool e jato de ar e observados em microscópio ótico (MO) e microscópio eletrônico de varredura (MEV) para verificação da morfologia de corrosão (os microscópios utilizados estão descritos no item Caracterização Microestrutural).

\subsection{CARACTERIZAÇÃO MICROESTRUTURAL}

A avaliação microestrutural, em cada etapa do trabalho, foi realizada em MO e MEV. Também foi realizada análise por Espectroscopia de Energia Dispersiva (EDS) para identificação das fases.

Para investigação da microestrutura foram utilizados os seguintes reagentes:

- Vilella, para revelar as fases presentes (carbonetos, fase sigma, ferrita delta) e a microestrutura martensítica. Tempo de imersão aplicado foi de 15 a 30 segundos.

- Fry, utilizado para aços martensíticos e endurecido por precipitação, que é o caso do aço em estudo (Custom 465®). Tempo de imersão aplicado foi de 15 a 30 segundos.

- Ácido oxálico, utilizado em ataque eletrolítico dissolve carbonetos de cromo, revela fase $\sigma$ e contornos de grão. Foi aplicado com $6 \mathrm{~V}$ e tempo variando de 40 a 60 segundos.

Os três reagentes químicos foram utilizados na temperatura ambiente.

A composição química dos reagentes está indicada na Tabela 7.

Tabela 7: Composição química dos reagentes. (BENSCOTER, 1985)

\begin{tabular}{|c|c|c|}
\hline Vilella & Fry & Ácido Oxálico \\
\hline $\begin{array}{c}1 \mathrm{~g} \text { ácido pícrico } \\
5 \mathrm{~mL} \mathrm{HCl} \\
\text { 100mL etanol }\end{array}$ & $\begin{array}{c}5 \mathrm{~g} \mathrm{CuCl}_{2} \\
33 \mathrm{~mL} \mathrm{HCL} \\
33 \mathrm{~mL} \text { etanol } \\
33 \mathrm{~mL} \mathrm{H} \mathrm{H}_{2} \mathrm{O}\end{array}$ & $\begin{array}{c}\text { 10g Ácido oxálico } \\
\text { 100mL H } \mathrm{H}_{2} \mathrm{O}\end{array}$ \\
\hline
\end{tabular}




\subsubsection{Microscopia ótica}

O exame da microestrutura (e da morfologia dos pites) do aço Custom $465 \AA$ foi realizado em MO Pantec (Capturador de Imagem UMIAS 2006) e Heicherter - Jung POLYVAR. Para o exame da microestrutura, as amostras foram lixadas e polidas em equipamento automatizado, Met Prep 4TM da Allied High Tech Products, Inc. O lixamento foi realizado nas lixas de carboneto de silício granulometria \#180 e \#320 (força aplicada $=22 \mathrm{~N}$; rotação $=300 \mathrm{rpm}$; tempo $=3$ minutos). Para $\circ$ polimento foram utilizadas as suspensões de diamante de $9 \mu \mathrm{m}, 6 \mu \mathrm{m}$ e $1 \mu \mathrm{m}$ (força aplicada = $22 \mathrm{~N}$; rotação $=150 \mathrm{rpm}$; tempo $=4$ minutos).

\subsubsection{Microscopia eletrônica de varredura}

Complementando os exames realizados em MO, foram realizados exames em MEV modelo Jeol JSM-6490LV. Foram obtidas imagens de elétrons retroespalhados e secundários das amostras polidas e atacadas conforme indicado acima. Realizaramse também análises por EDS das fases e inclusões encontradas.

\subsubsection{Difração de raios $X$}

A identificação dos microconstituintes das amostras solubilizada, condição de envelhecimento $\mathrm{H} 950$ e H1000 foram realizadas por meio de análise de difratometria de raios $X$. As análises foram realizadas utilizado radiação Cu-Ka (comprimento de onda de $1,5418 \mathrm{~nm}$ ), a $30 \mathrm{kV}$ e corrente de $30 \mathrm{~mA}$, no difratômetro Shimatzu XRD7000, pertencente ao Departamento de Engenharia de Materiais - Centro Universitário da FEl. A velocidade de varredura utilizada foi de $2 \%$ min e passo de $0,04^{\circ}$. 


\section{RESULTADOS EXPERIMENTAIS}

Neste capítulo serão apresentados os resultados encontrados nos ensaios e exames realizados. Primeiramente apresenta-se a caracterização do material quanto às propriedades mecânicas e sua microestrutura. Posteriormente, estão apresentados os resultados dos ensaios eletroquímicos, em especial os valores de Ep, e a morfologia da corrosão encontrada.

\subsection{ENSAIOS MECÂNICOS}

A média dos resultados dos ensaios de tração, alongamento e dureza estão apresentadas na Tabela 8, Figura 26 e Figura 27. Para as duas condições de envelhecimento, $\mathrm{H} 950$ e $\mathrm{H} 1000$, os valores do limite de escoamento $\left(\sigma_{e}\right)$, limite de resistência $\left(\sigma_{R}\right)$, alongamento $(A L)$ e dureza estão acima dos valores mínimos especificados na AMS 5963 (AMS 5963, 2007). A Figura 28 apresenta curvas típicas do Custom 465® obtidas no ensaio de tração para cada condição de envelhecimento.

Tabela 8: Média (de seis ensaios) dos resultados encontrados no ensaio de tração.

\begin{tabular}{|c|c|c|c|c|}
\hline Tratamento térmico & $\boldsymbol{\sigma}_{\mathbf{R}}(\mathbf{M P a})$ & $\boldsymbol{\sigma}_{\mathbf{e}}(\mathbf{M P a})$ & $\mathbf{A L}(\%)$ & $\begin{array}{c}\text { Dureza } \\
\text { (HRC) }\end{array}$ \\
\hline $\begin{array}{c}\text { H950 } \\
( \pm \text { desvio padrão) }\end{array}$ & $1881 \pm 21$ & $1836 \pm 22$ & $10 \pm 0,5$ & $52 \pm 1$ \\
\hline $\begin{array}{c}\text { H1000 } \\
( \pm \text { desvio padrão) }\end{array}$ & $1702 \pm 14$ & $1676 \pm 15$ & $12 \pm 0,9$ & $49 \pm 3$ \\
\hline
\end{tabular}




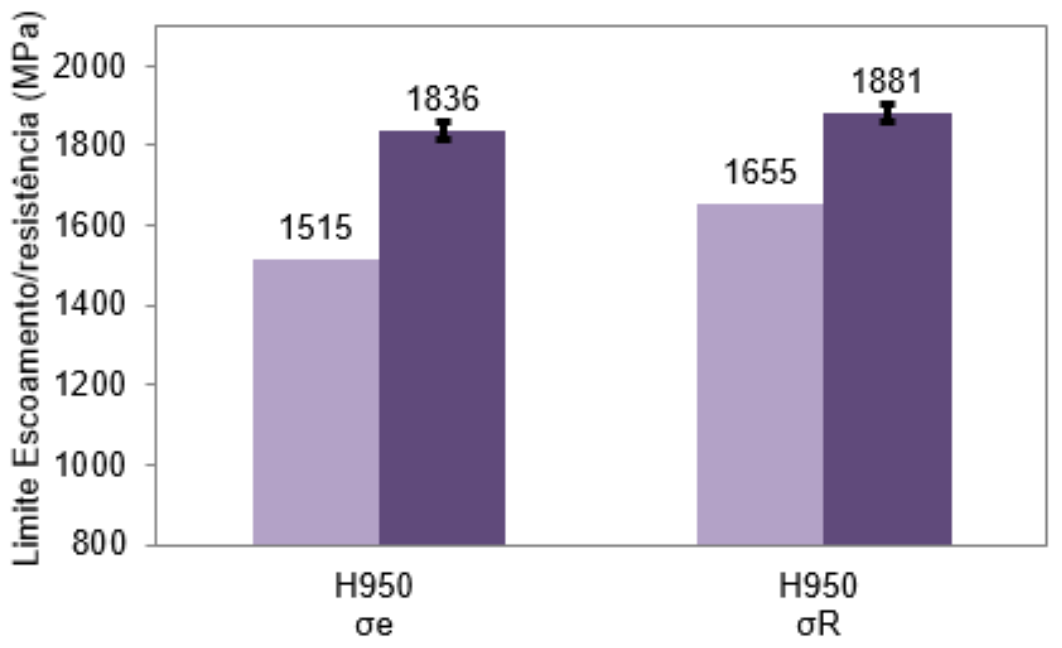

\section{H950}

- Valores mínimos especificados

- Valores encontrados

(a)

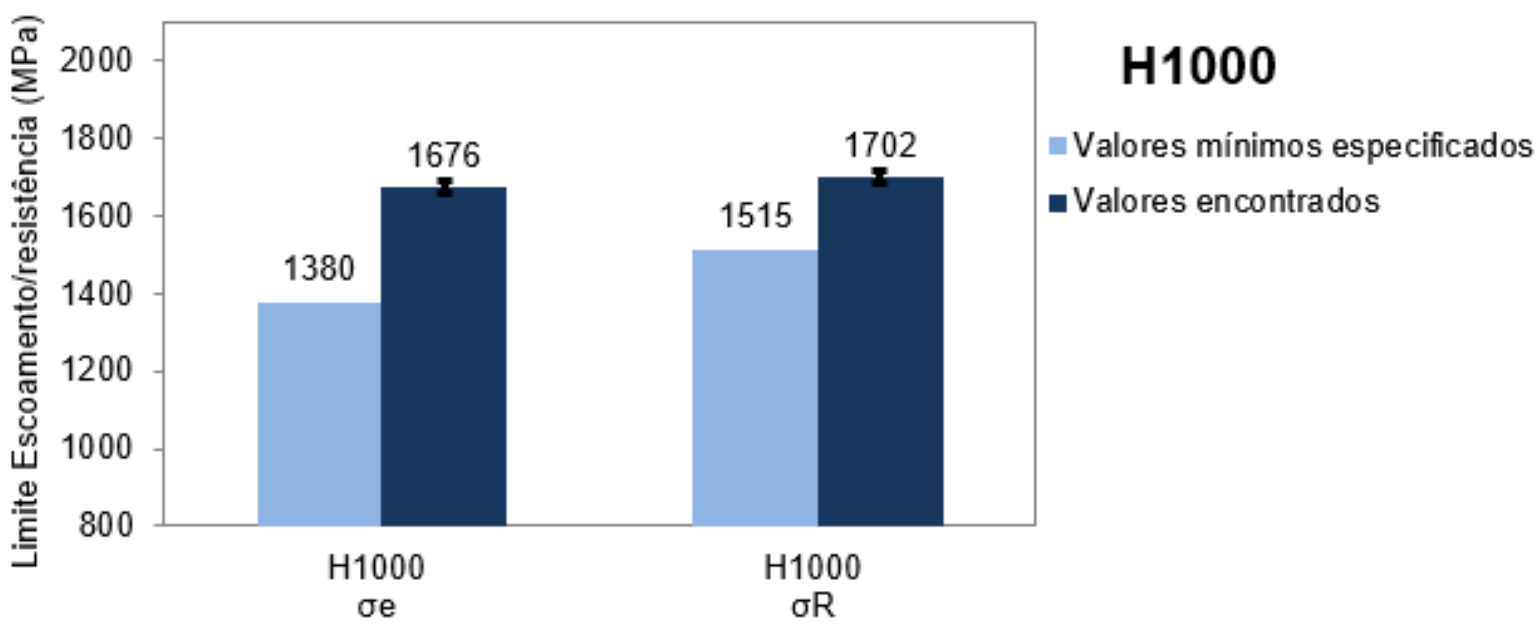

(b)

Figura 26: Propriedades mecânicas encontradas após ensaio de tração; os valores medidos são a média de 6 ensaios de tração. 


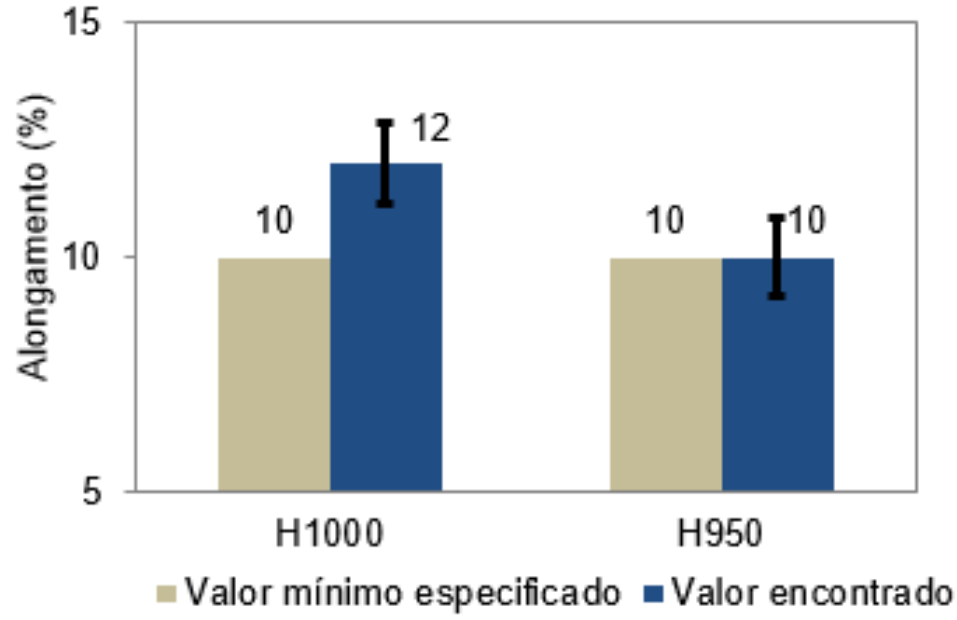

(a)

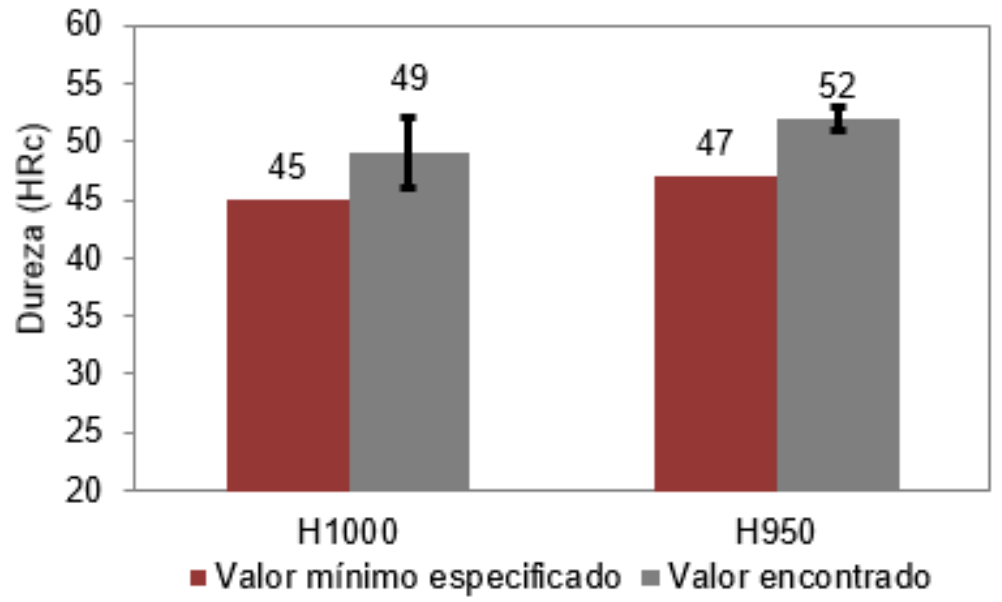

(b)

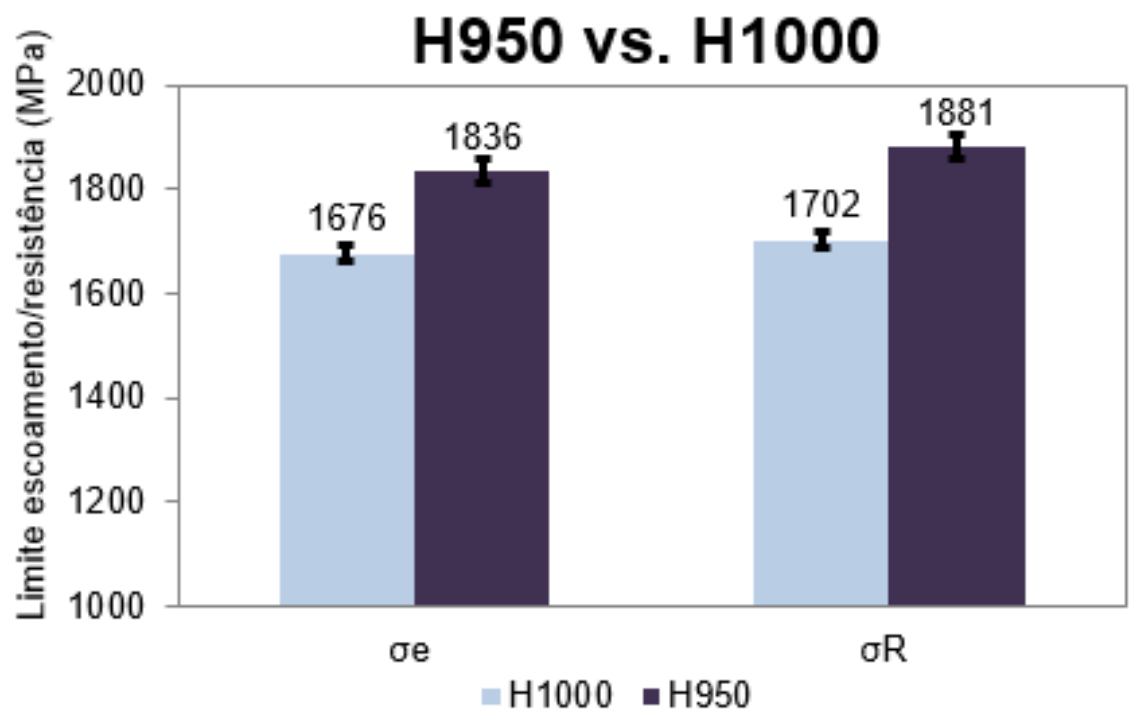

(c)

Figura 27: Comparação das propriedades mecânicas nas condições H950 e H1000 obtidas no presente trabalho. 


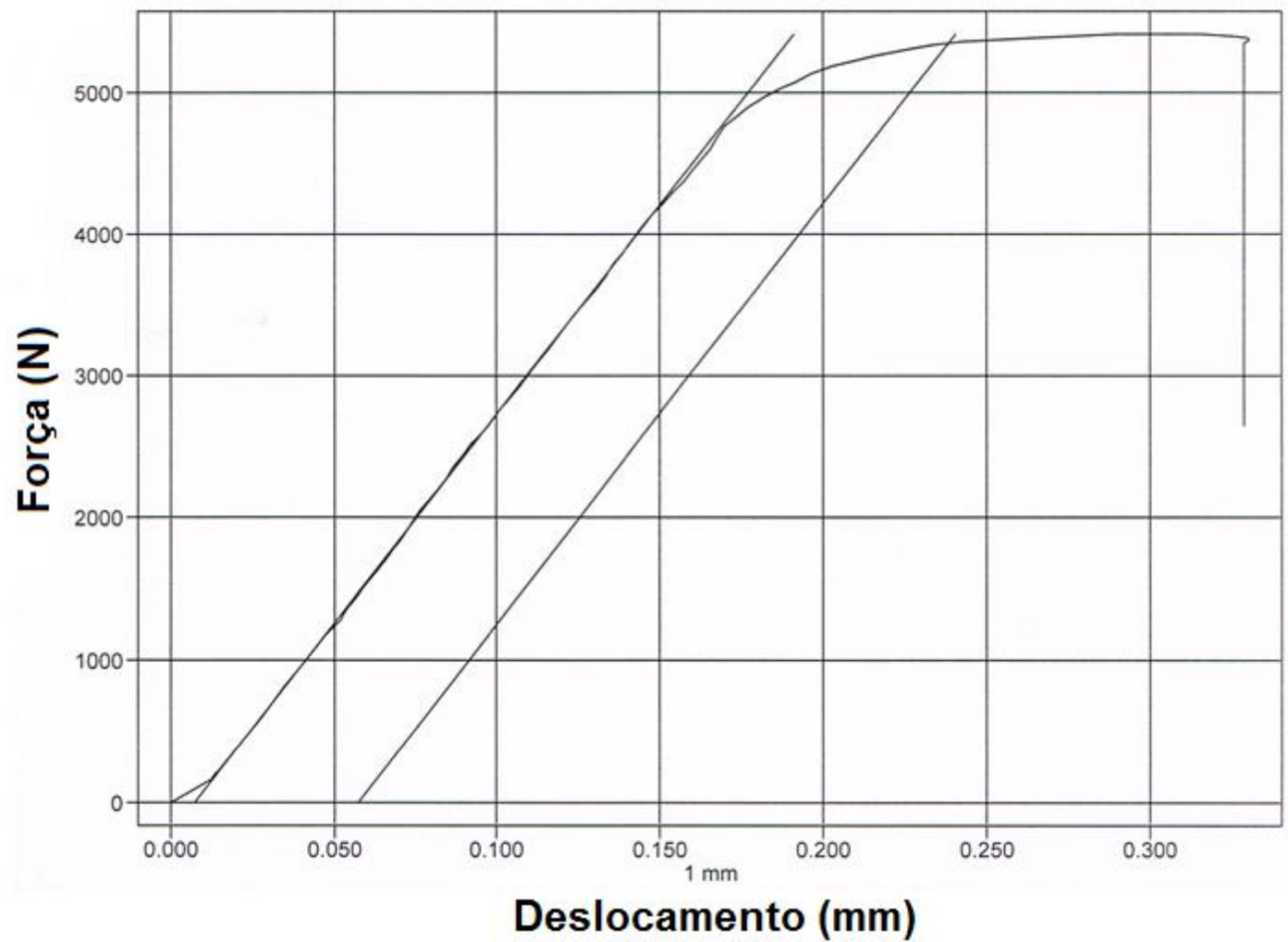

(a)

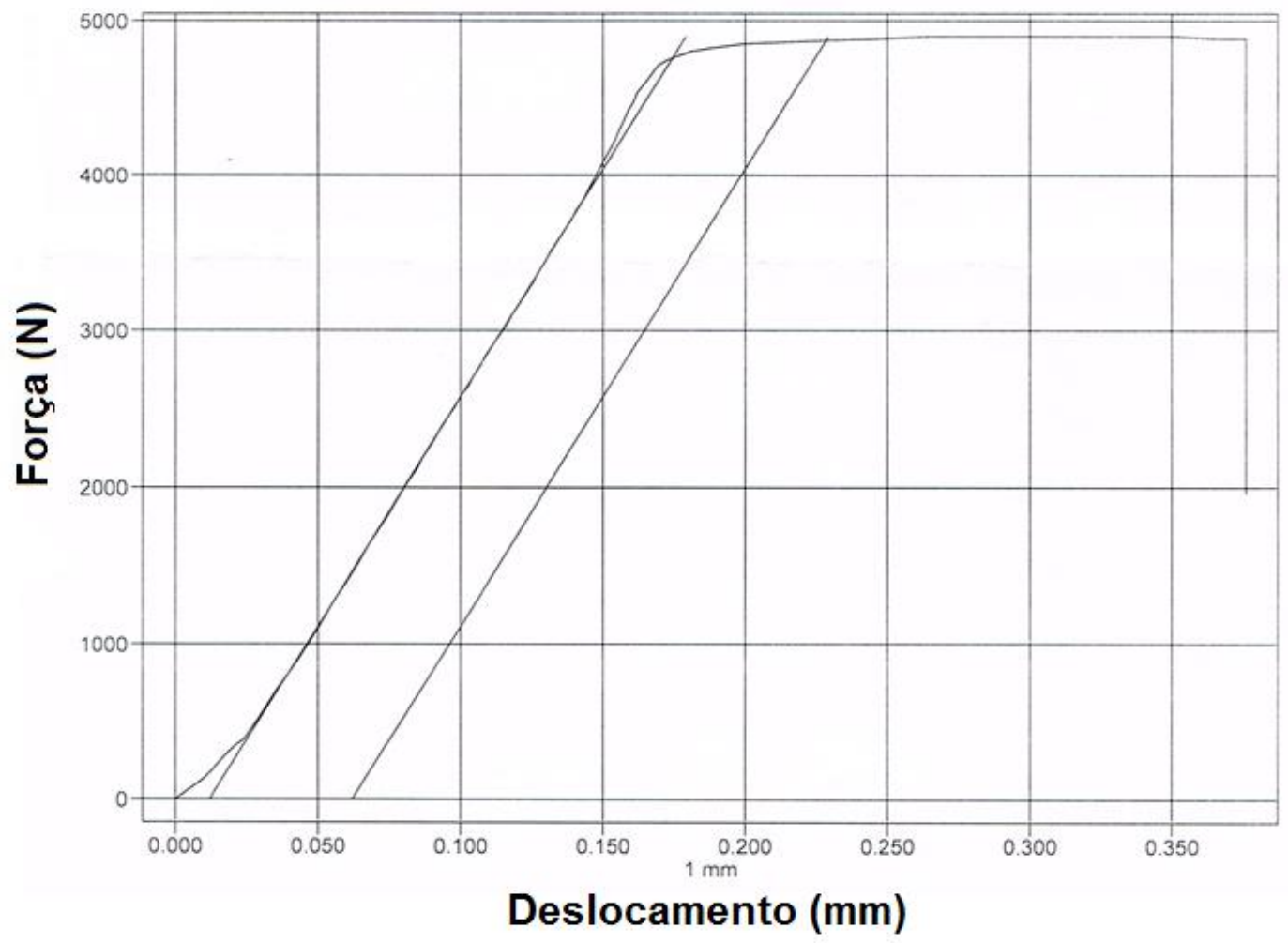

(b)

Figura 28: Curvas típicas de tração encontradas para o Custom $465 \AA$ nas condições (a) $H 950$ (Área $=28,56 \mathrm{~mm}^{2} ; \mathrm{D}=6,03 \mathrm{~mm} ; \mathrm{L}_{0}=30 \mathrm{~mm} ; \mathrm{L}_{\mathrm{f}}=33,04 \mathrm{~mm}$; $\sigma_{\mathrm{R}}=1859,35 \mathrm{MPa} ; \sigma_{\mathrm{e}}=1836,7 \mathrm{MPa}$ ) e (b) $\mathrm{H} 1000$ (Área=28,18 mm²; $\mathrm{D}=5,99 \mathrm{~mm}$; $\left.L_{0}=30 \mathrm{~mm} ; \mathrm{L}_{\mathrm{f}}=33,13 \mathrm{~mm} ; \sigma_{\mathrm{R}}=1703,6 \mathrm{MPa} ; \sigma_{\mathrm{e}}=1697,16 \mathrm{MPa}\right)$. 
Os resultados dos ensaios mecânicos encontrados para o Custom 465® concordam com os resultados observados por Xiang, et al. (2011), que estudou o efeito do envelhecimento nas propriedades mecânicas do aço inoxidável endurecido por precipitação $17-4 \mathrm{PH}$. Em seu trabalho tratamentos térmicos realizados nas temperaturas de $550^{\circ} \mathrm{C}, 580^{\circ} \mathrm{C}$ e $620^{\circ} \mathrm{C}$, mostraram que com o aumento da temperatura de envelhecimento o limite de escoamento, limite de resistência e dureza diminuíram, enquanto que o alongamento, a redução de área e a tenacidade à fratura aumentaram.

O aço Custom 465® deve ser aplicado na condição envelhecida (DEPARTMENT OF DEFENSE, 2003). Por esse motivo ensaios de tração e dureza não foram realizados para o material na condição solubilizada.

\subsection{EXAMES MICROESTRUTURAIS}

As análises microestruturais foram realizadas nas condições solubilizada e envelhecida, H950 e H1000. Inicialmente as amostras foram examinadas após polimento (Figura 29). O aspecto inicial era de um material com inclusões dispersas. No entanto, como estão mostradas logo a seguir, as partículas observadas em MO tinham em sua composição química elevados teores de Ti. Concluiu-se daí, que se tratavam de precipitados ricos em $\mathrm{Ti}$. 


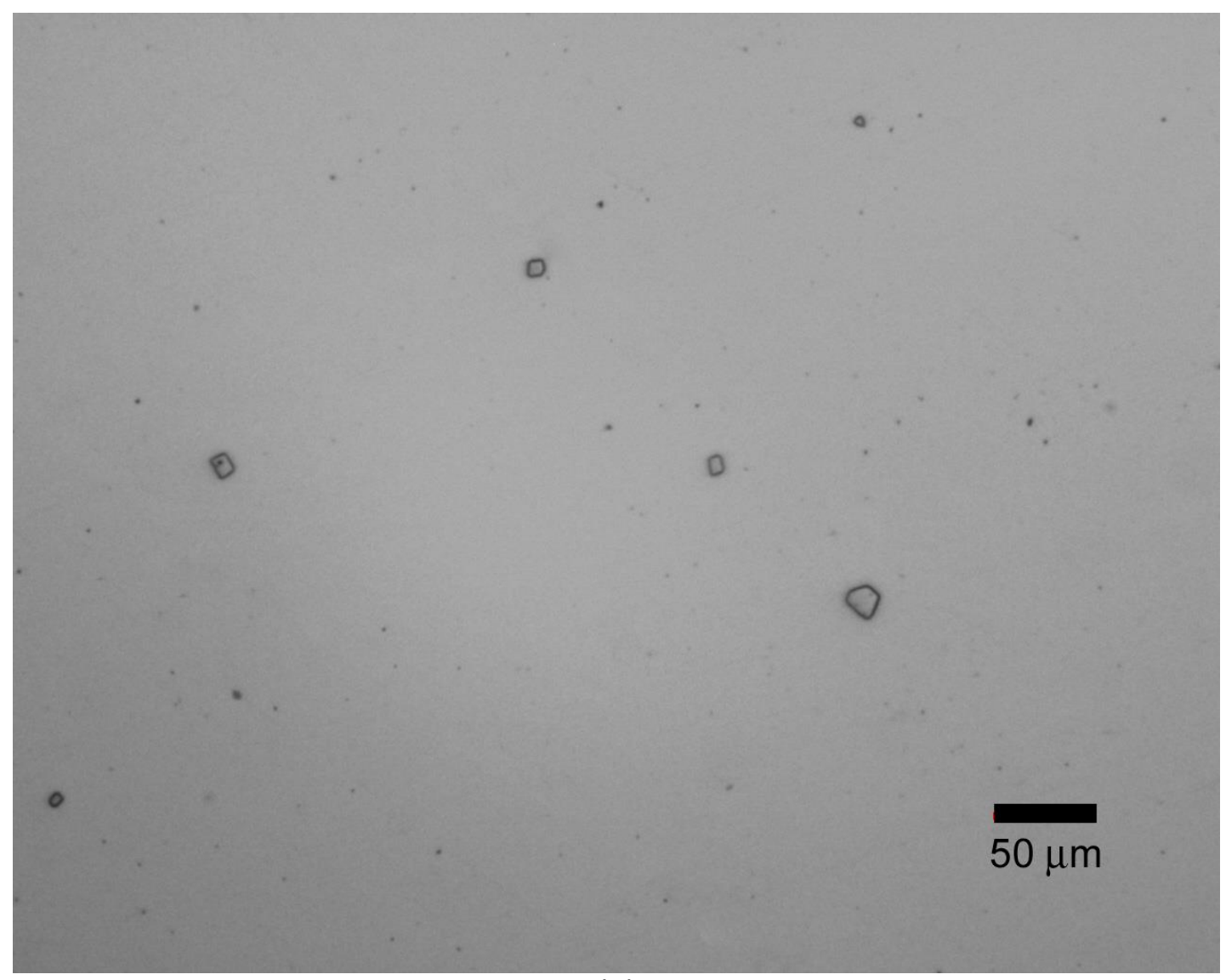

(a)

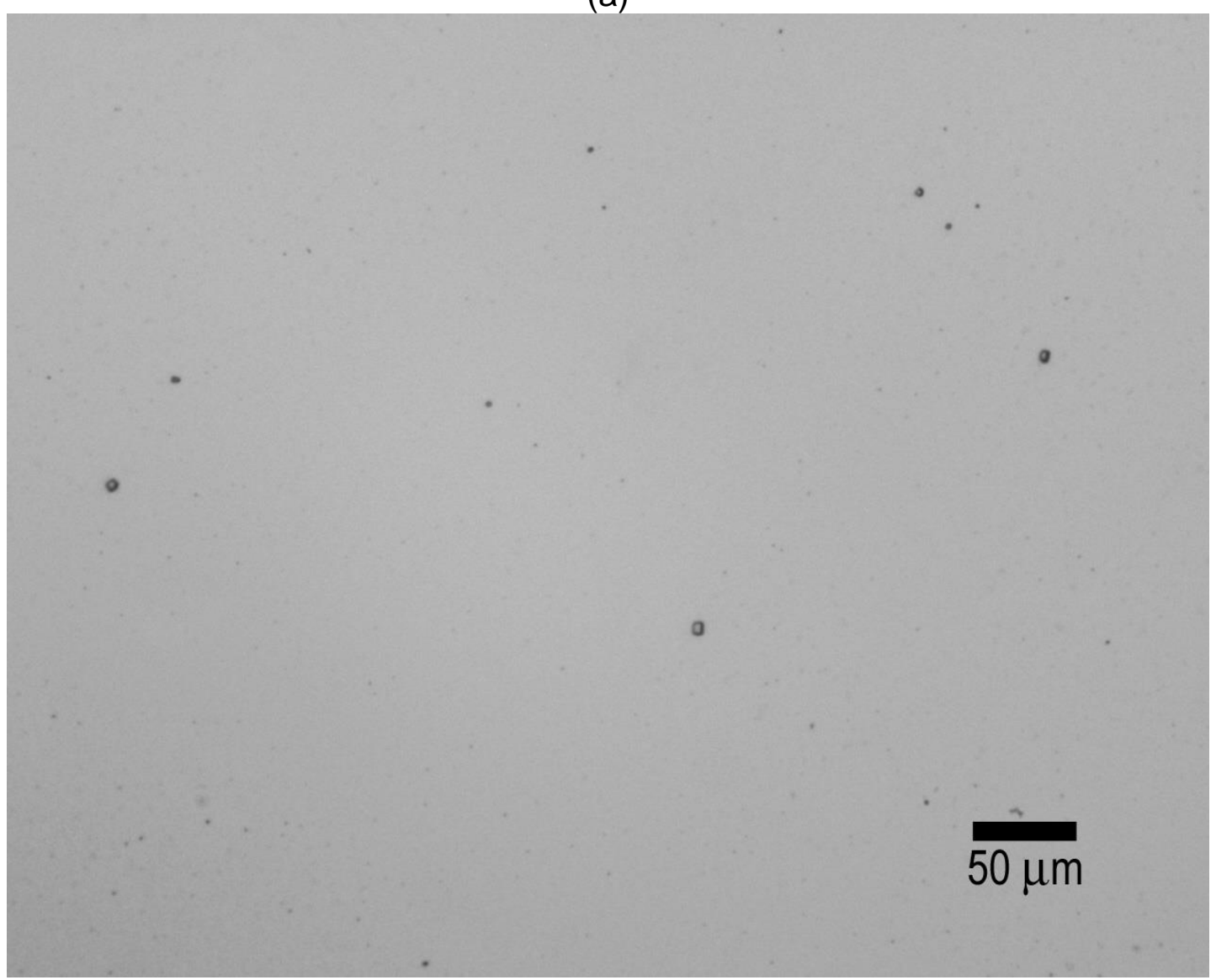

(b) 


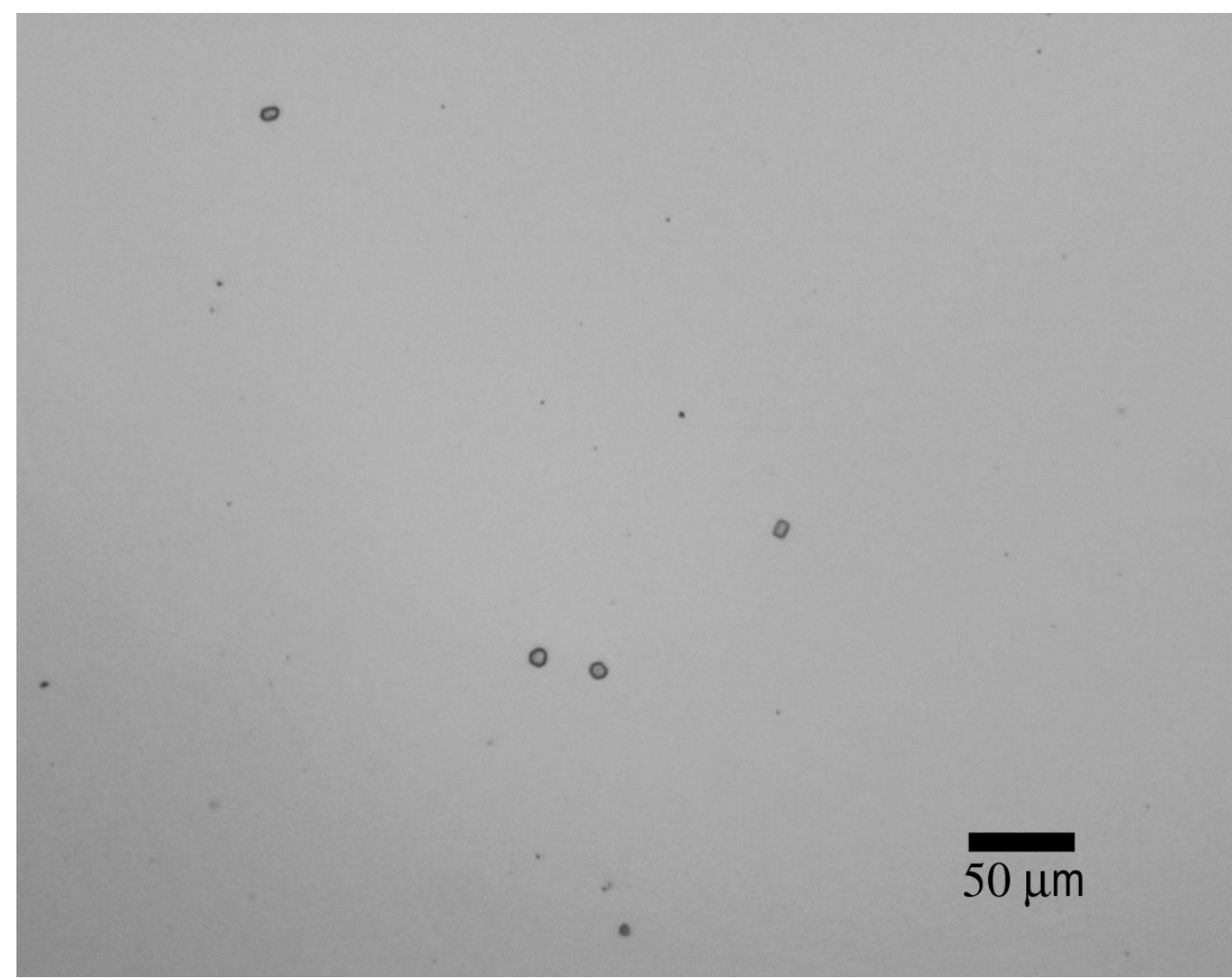

(c)

Figura 29: Imagens em MO das amostras polidas até $1 \mu \mathrm{m}$ : (a) solubilizada; (b) H950 e (c) H1000, todas com aumento de 50x.

Após exames em MO, essas amostras foram examinadas em MEV, onde foi utilizada a análise por EDS para verificação da composição química dos precipitados (Figura 30). Conforme indicado nos espectros obtidos por EDS, os precipitados são compostos principalmente de Ti. O EDS da matriz apresenta os principais elementos que compõe o aço Custom 465® $(\mathrm{Cr}, \mathrm{Ni}$, Ti e $\mathrm{Fe})$; e pelos valores obtidos estão próximos dos valores encontrados na análise da composição química do material (Tabela 4).

Resultados semelhantes foram encontrados nas amostras examinadas nas condições solubilizada e H1000.

Apesar da quantificação do teor de N por análise de EDS não ser precisa, o espectro não deixa dúvida de sua presença nessa fase, confirmando tratar-se de partículas de nitreto de titânio. 


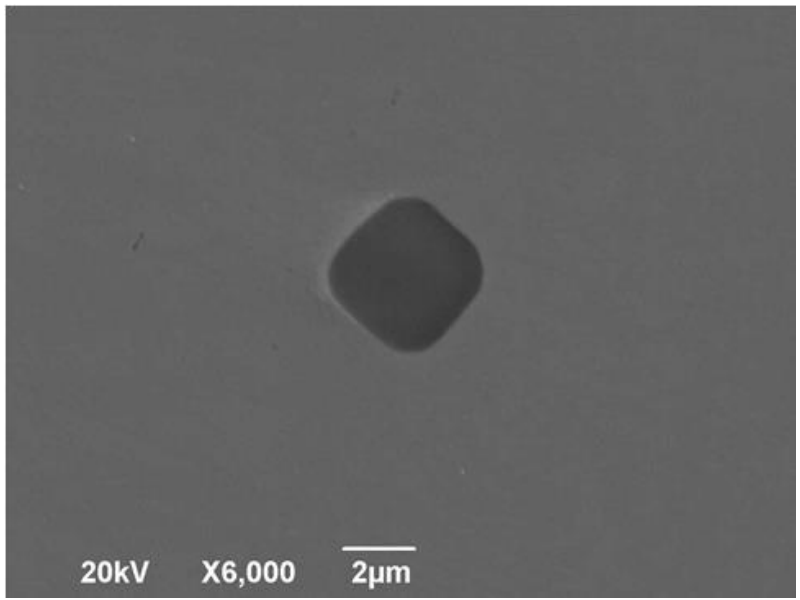

(a)

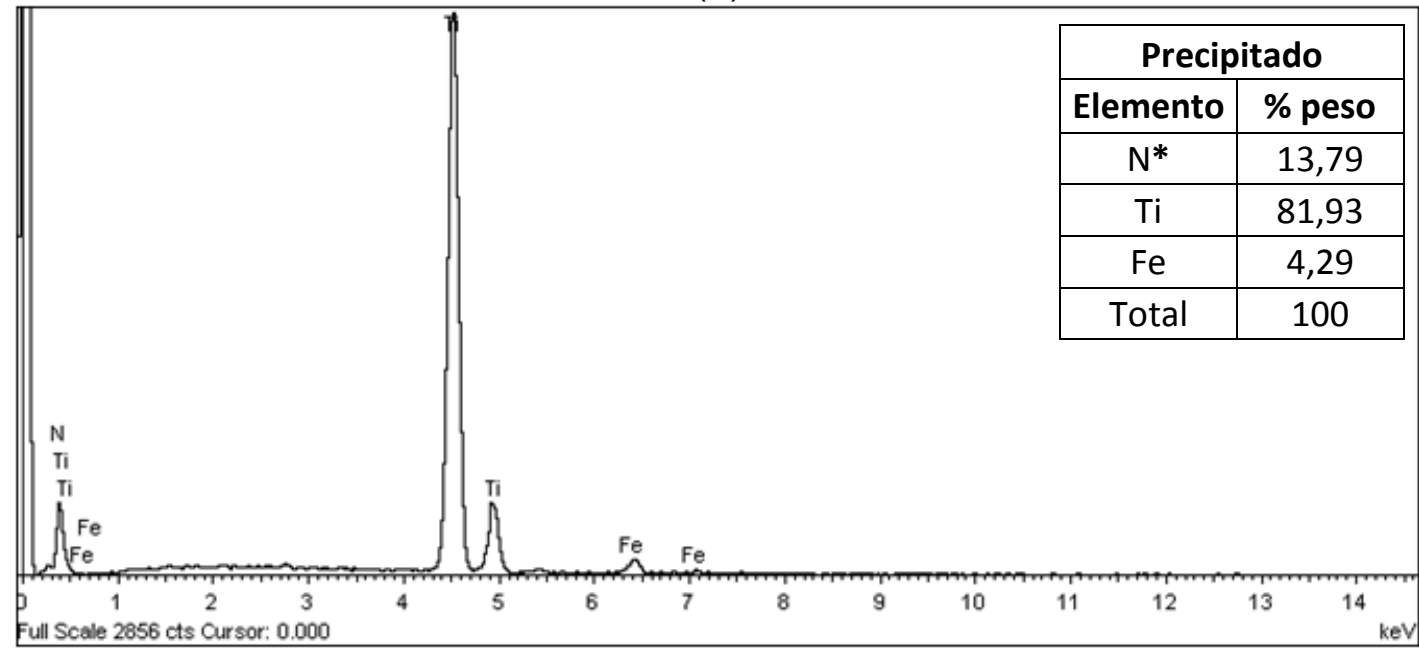

(b)

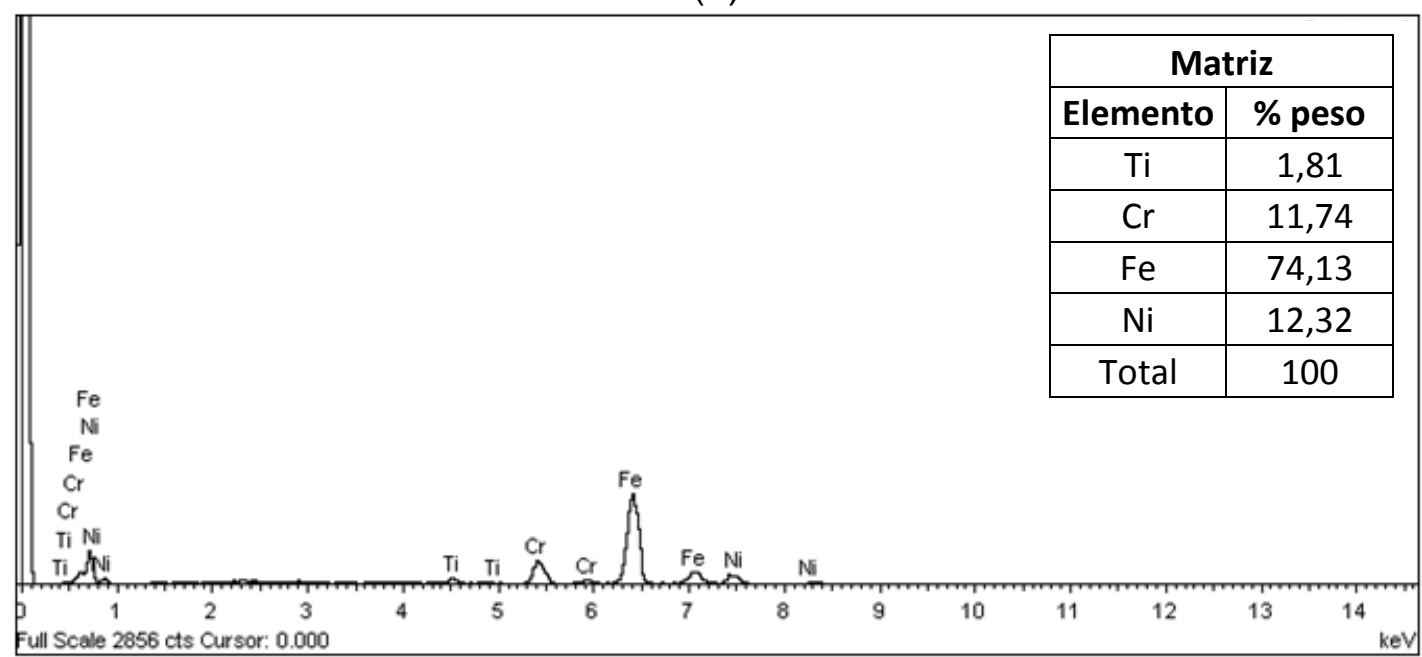

(c)

Figura 30: (a) Imagem de elétrons secundários da amostra na condição H950, polida, mostrando o precipitado; (b) e (c) resultados dos EDS's realizados no precipitado e na matriz.

$\left.{ }^{*}\right)$ O teor de $N$ não é preciso, pois a melhor análise é a de Espectrometria por Dispersão de Comprimento de Onda (WDS). A análise de EDS realizada mostra apenas que o $N$ está presente. 
A Figura 31 apresenta a micrografia óptica das amostras atacadas com Vilella. Assim como no trabalho de Lee et al. (2011), a microestrutura encontrada é tipicamente martensítica, sendo possível observar os contornos de grão da antiga austenita e as ripas de martensita dentro dos grãos. Os precipitados de Ti que foram observados nas amostras polidas apresentaram melhor definição após o ataque metalográfico. Nota-se que a condição solubilizada apresenta maior tamanho de grão austenítico do que as condições H950 e H1000. Isso é devido ao tratamento de solubilização (austenitização) que foi realizado numa amostra já tratada para a condição $\mathrm{H} 1000$, conforme comentado no item 4.4 Tratamento térmico e ensaios mecânicos.

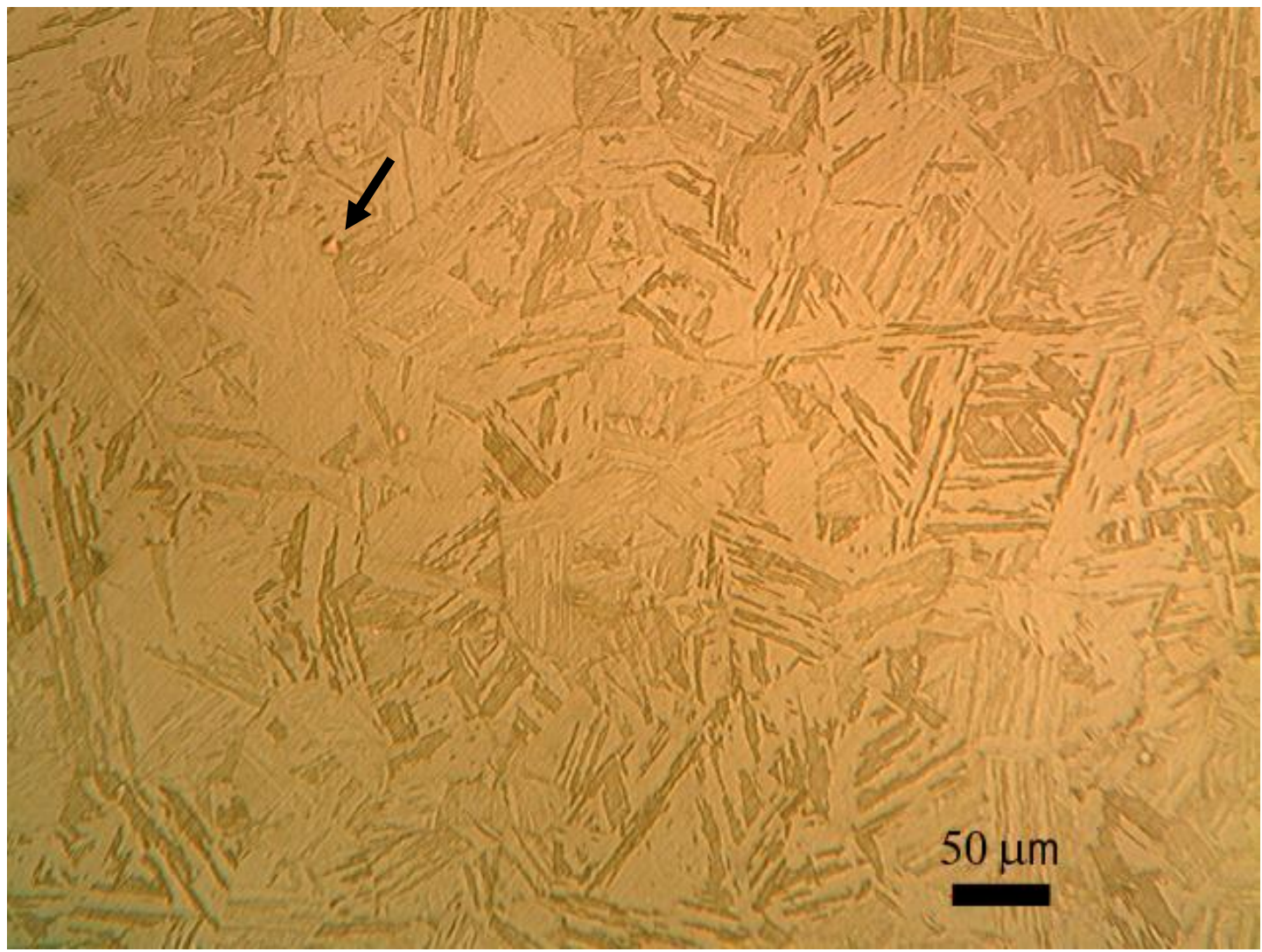

(a) 


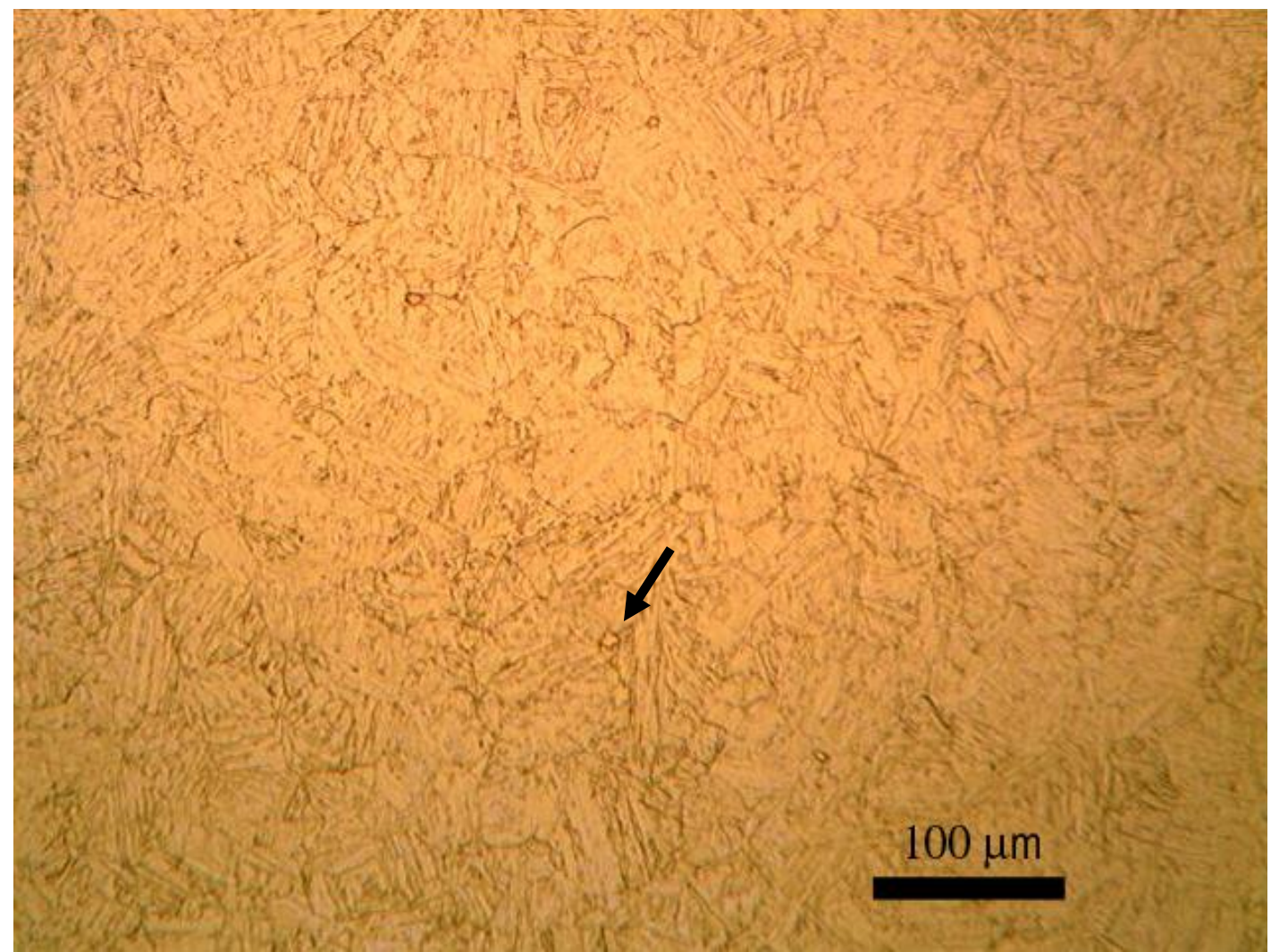

(b)

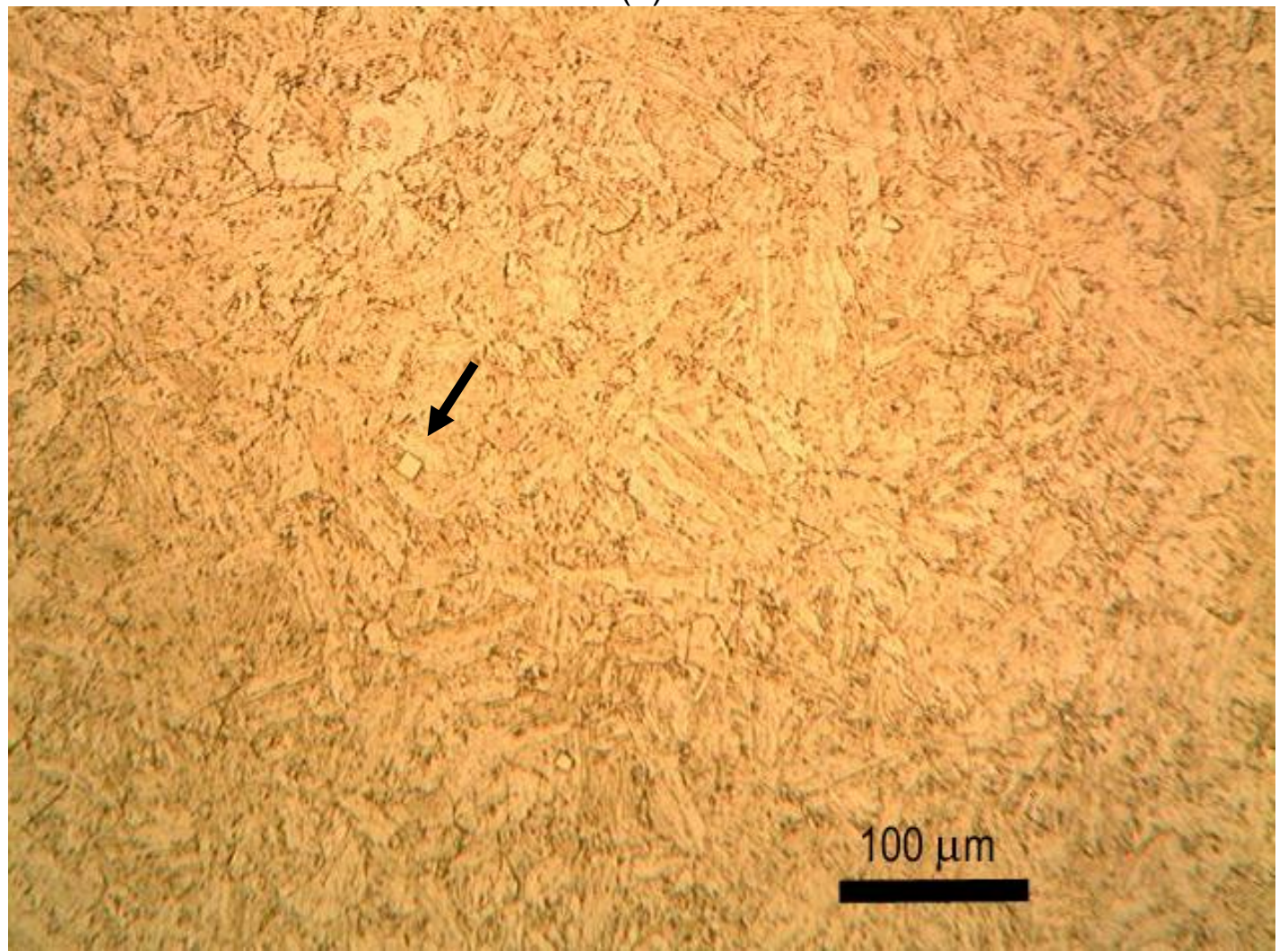

(c)

Figura 31: Imagens em MO na condição (a) solubilizada; (b) H950 e (c) H1000; todas com aumento de $200 x$, ataque Vilella. As setas indicam os precipitados de TiN. 
Os exames realizados em MEV (Figura 32, Figura 33 e Figura 34) mostram mais claramente as diferenças microestruturais das três condições (solubilizada, H950 e H1000).

Avaliando-se a mesma condição de tratamento térmico, observa-se que para a amostra solubilizada os diferentes ataques metalográficos não revelaram diferenças na microestrutura quanto à quantidade e distribuição dos precipitados e fases. Já para as amostras envelhecidas nas condições $\mathrm{H} 950$ e H1000, observou-se que o ataque com Vilella acentuou mais os contornos de grãos austeníticos e os contornos das ripas de martensita, além dos precipitados revelados no interior dos grãos e nos contornos de grãos.

Após ataque com reagente Fry as ripas de martensita não foram tão evidenciadas e a matriz apresentou uma série de pites devido ao ataque metalográfico (isso se justifica pela presença de $\mathrm{CuCl}_{2}$ nesse reagente).

Ainda foram realizados ataques eletrolíticos em ácido oxálico (10\%). Nesse caso, as amostras não reagiram ao ataque, as superfícies permaneceram inalteradas, não revelando qualquer microconstituinte. Isso é uma indicação de que não existem precipitados ricos em $\mathrm{Cr}$, uma vez que as condições de potencial de eletrodo nesse ataque provocam a dissolução dessas fases (carbonetos de cromo, fase sigma e outras). (BENSCOTER, 1985) 


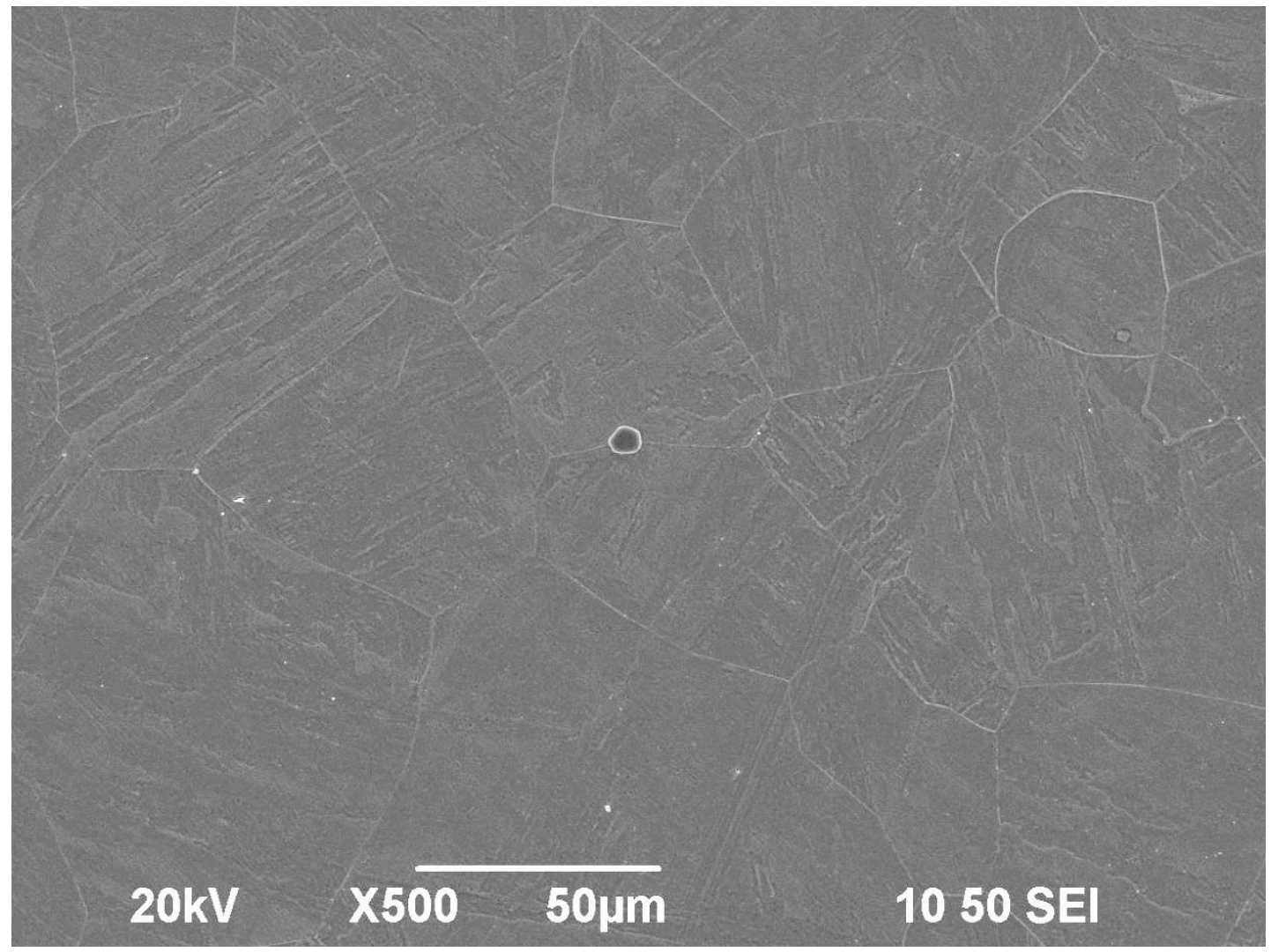

(a)

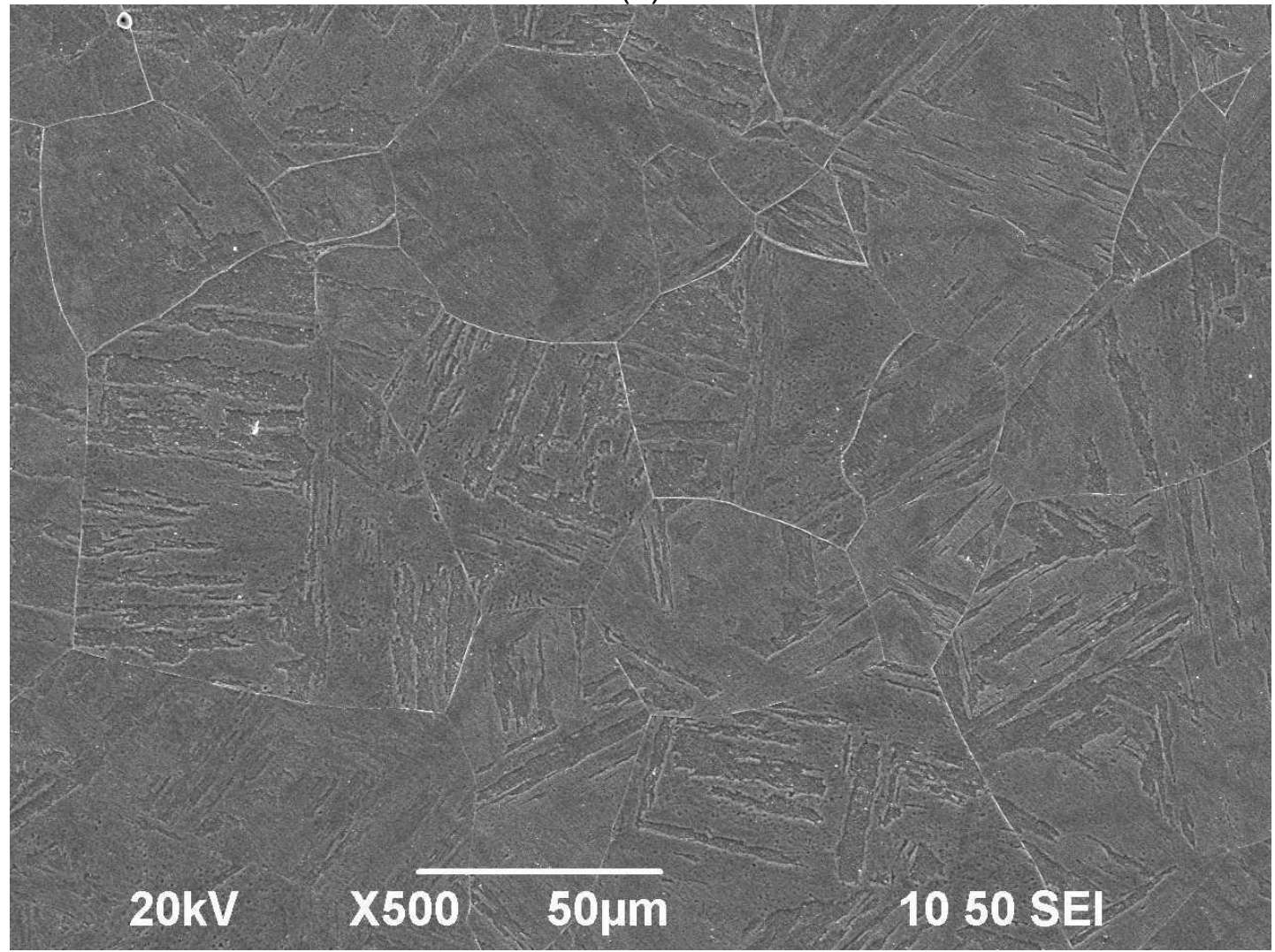

(b)

Figura 32: Imagens de elétrons secundários na condição solubilizada: (a) ataque com Vilella e (b) ataque com Fry. 


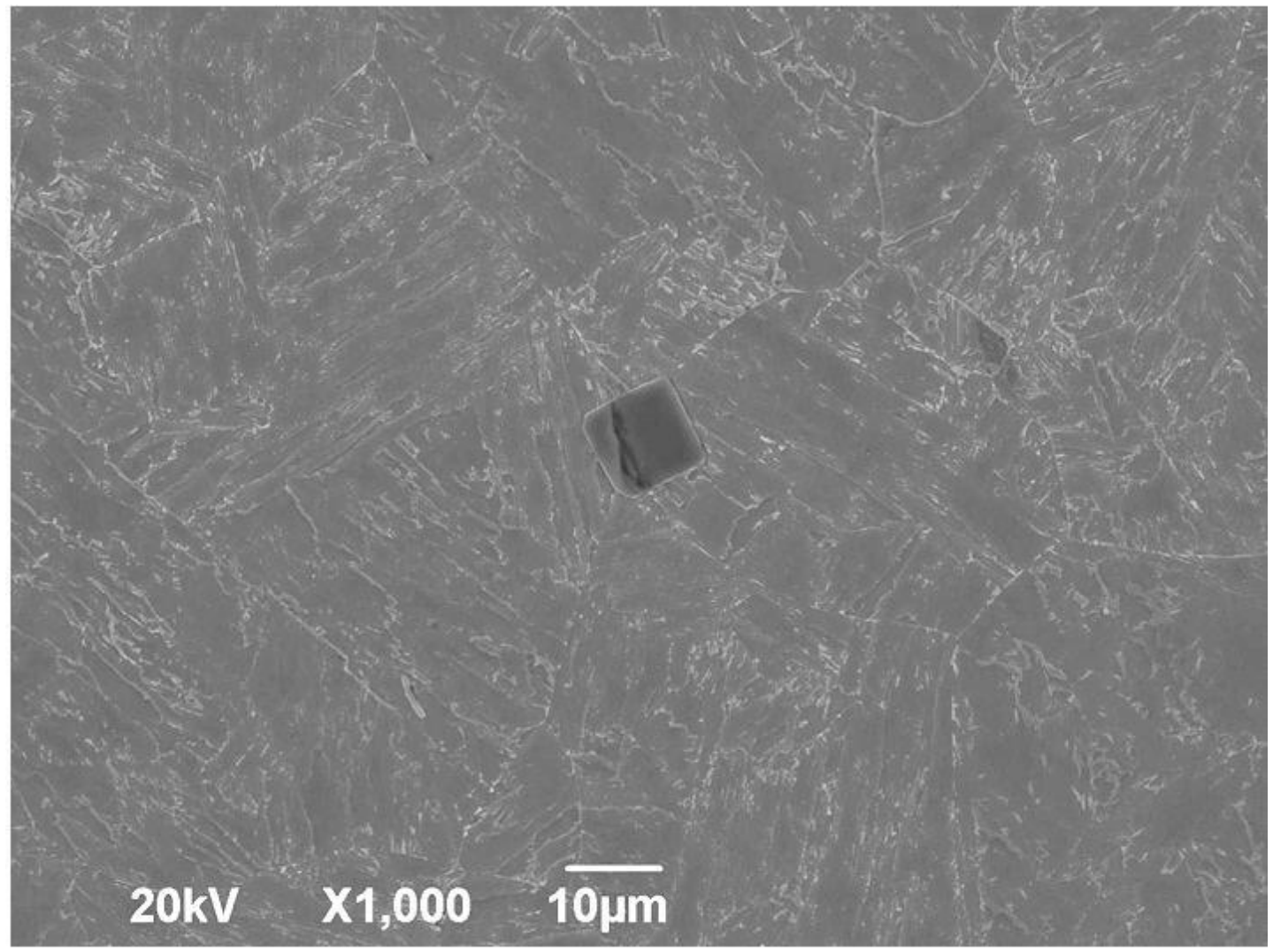

(a)

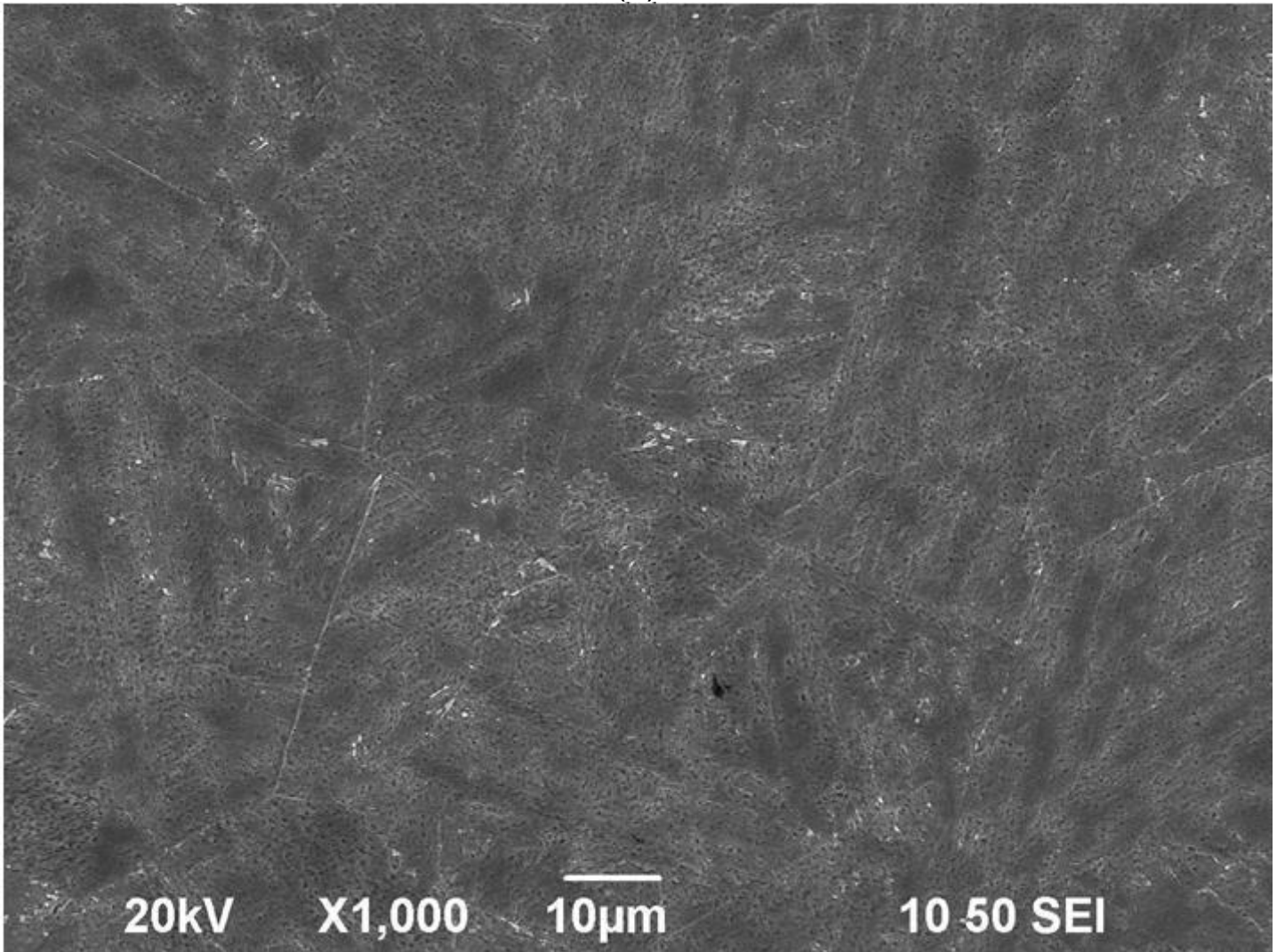

(b)

Figura 33: Imagens de elétrons secundários na condição H950: (a) ataque com Vilella e (b) ataque com Fry. 


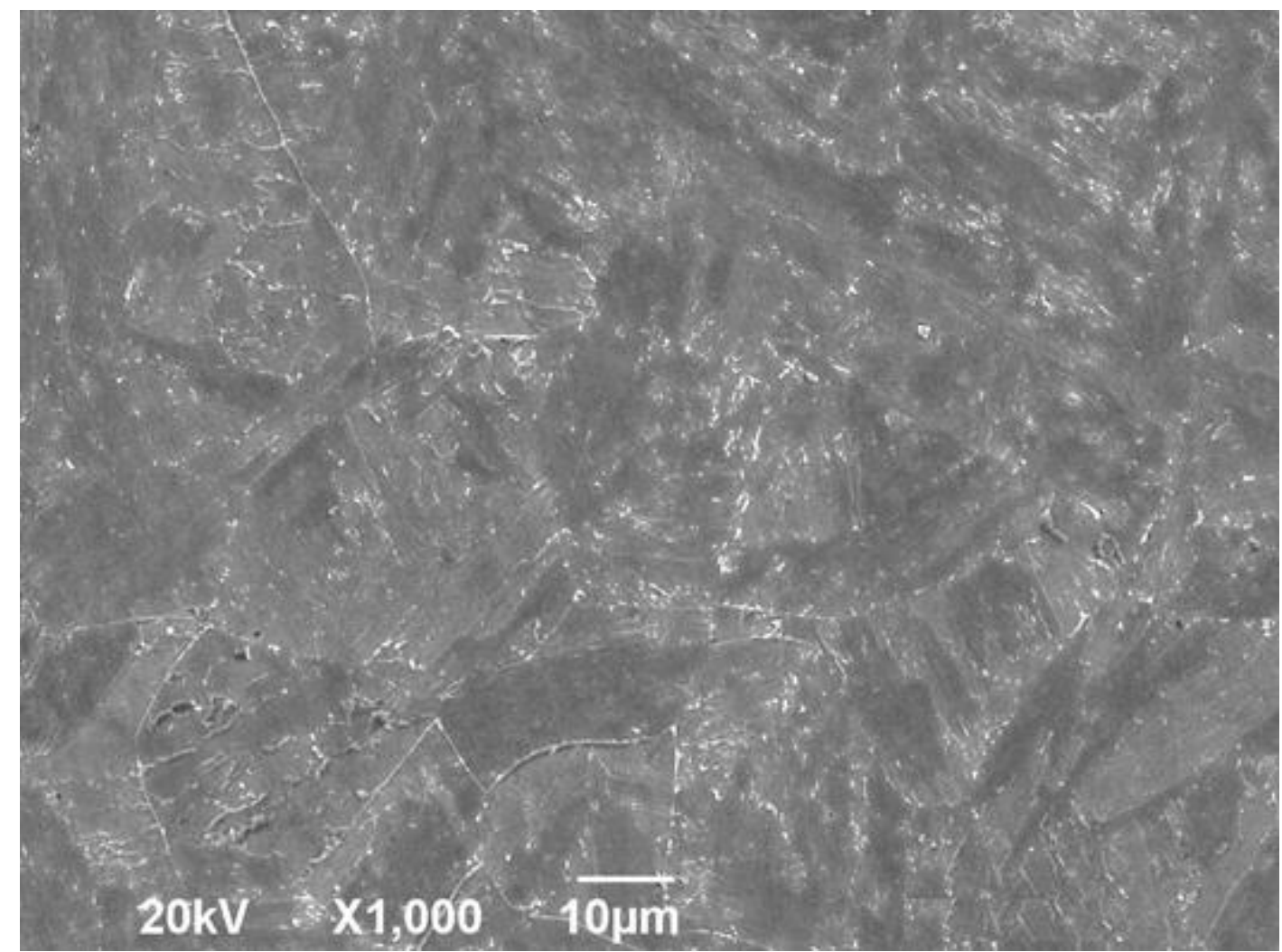

(a)

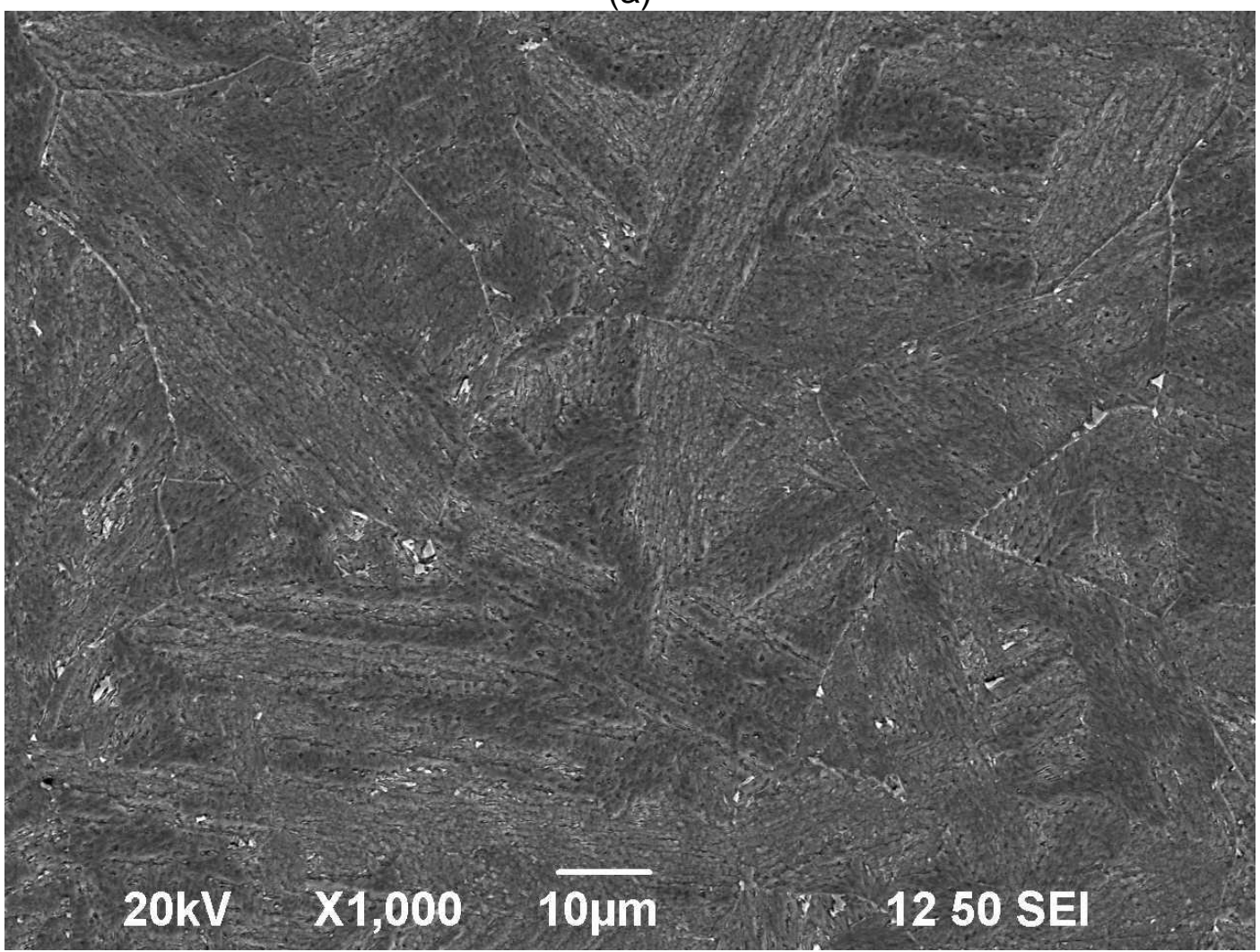

(b)

Figura 34: Imagens de elétrons secundários na condição H1000: (a) ataque com Vilella e (b) ataque com Fry. 
A comparação dos exames microestruturais entre as três condições de tratamento térmico (solubilizada, H950 e H1000) revelaram que existe uma maior quantidade de precipitados (pontos claros observados nas micrografias) nas amostras envelhecidas do que na amostra solubilizada. A Figura 35 realizada com maior aumento apresenta a diferença na quantidade de precipitados observados entre as amostras H950 e H1000. Análises por EDS indicaram que os precipitados (pontos claros) são fases ricas em Mo e Ti (Figura 36).

Assim como observado nos exames anteriores (Figura 29 e Figura 30) as partículas angulosas e escuras foram aqui novamente analisadas por EDS. Os resultados confirmaram tratar-se de partículas ricas em $\mathrm{Ti}$ e $\mathrm{N}$ confirmando a hipótese de serem, nitretos de titânio, como pode ser observado na Figura 37.

Não foi observada a presença de austenita retida, tanto nos exames em MO quanto em MEV. Vale mencionar que, mais adiante, estão apresentados os resultados da análise por Thermo-Calc, que mostraram a presença de austenita nos tratamentos $\mathrm{H} 950$ e H1000.

Nos exames, MO e MEV, realizados não foi possível observar a presença dos precipitados, $\mathrm{Ni}_{3} \mathrm{Ti}$, citados na Revisão Bibliográfica como sendo os principais responsáveis pelo endurecimento do material. Assim como observado no trabalho de Kim e Wayman (1990), somente é possível observar esses precipitados por exame em MET. Igualmente, aos casos anteriores, mais adiante, está apresentado na análise por Thermo-Calc que os tratamentos térmicos realizados levam a formação de precipitados $\mathrm{Ni}_{3} \mathrm{Ti}$. 


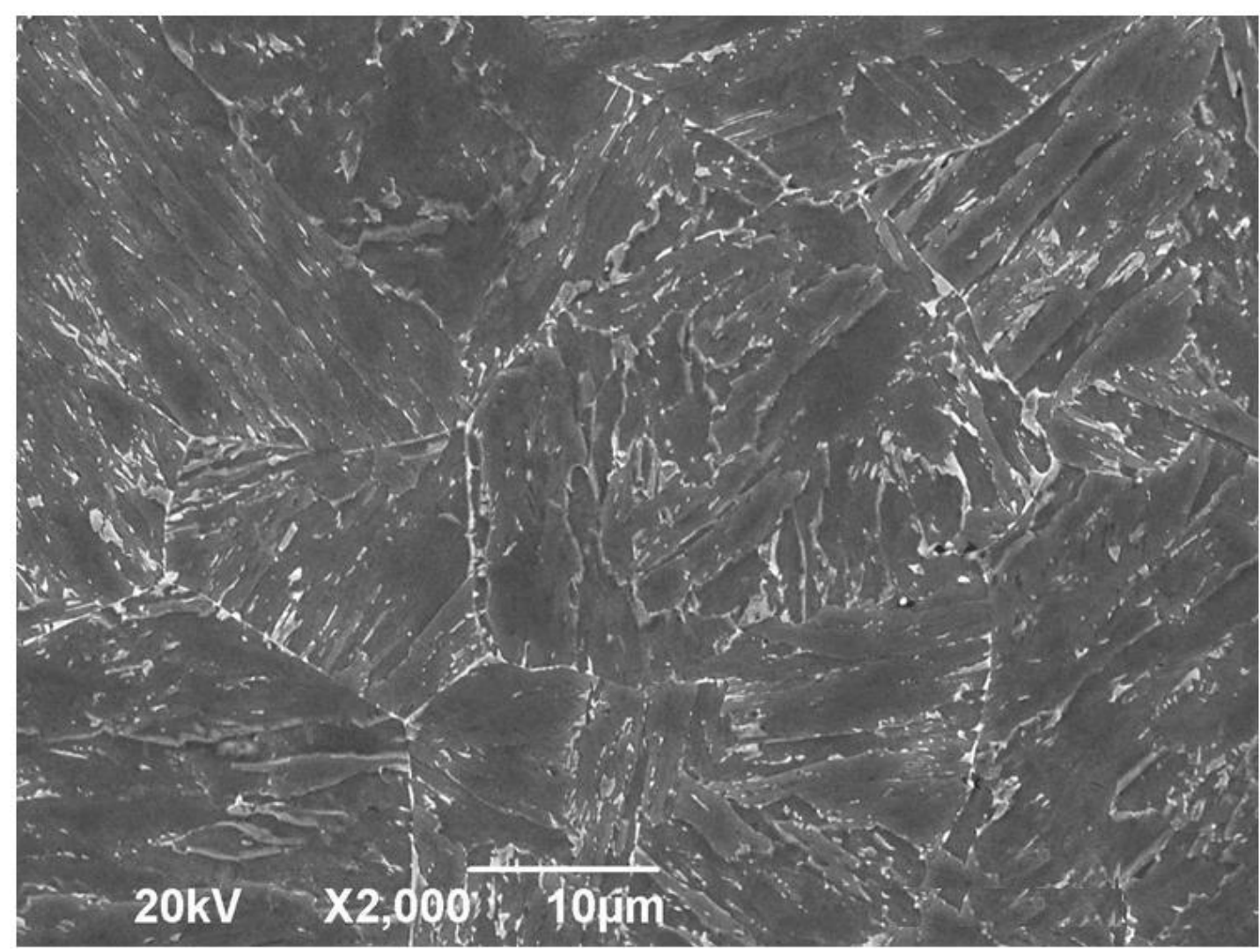

(a)

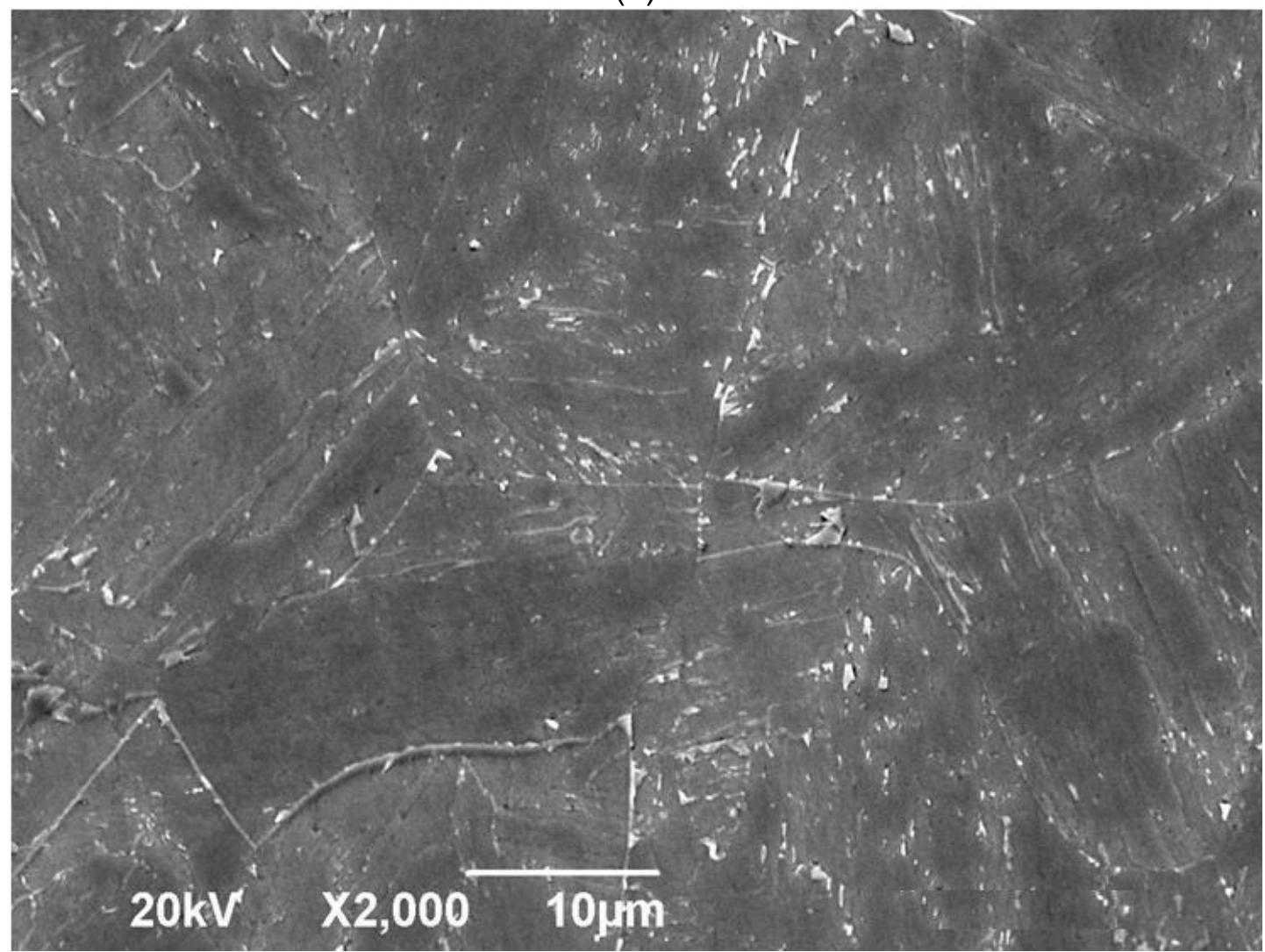

(b)

Figura 35: Imagens de elétrons secundários nas condições: (a) $\mathrm{H} 950$ e (b) H1000, ataque com Vilella, mostrando a diferença na quantidade de precipitados observados e no tamanho de grão. 


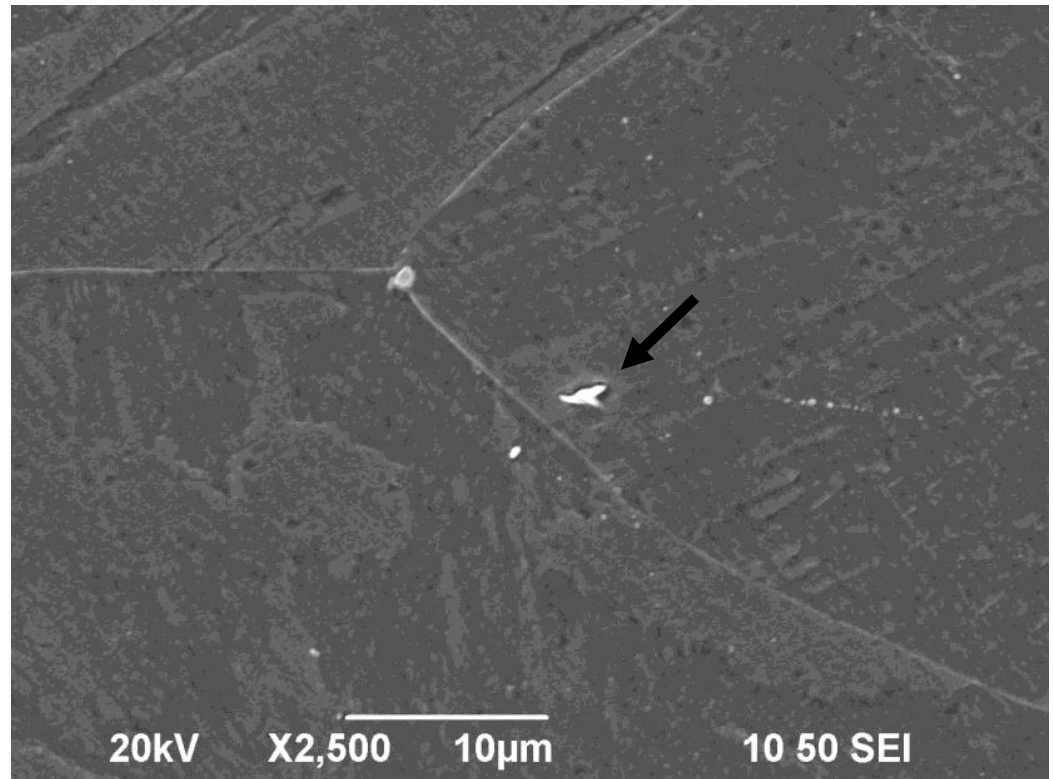

(a)

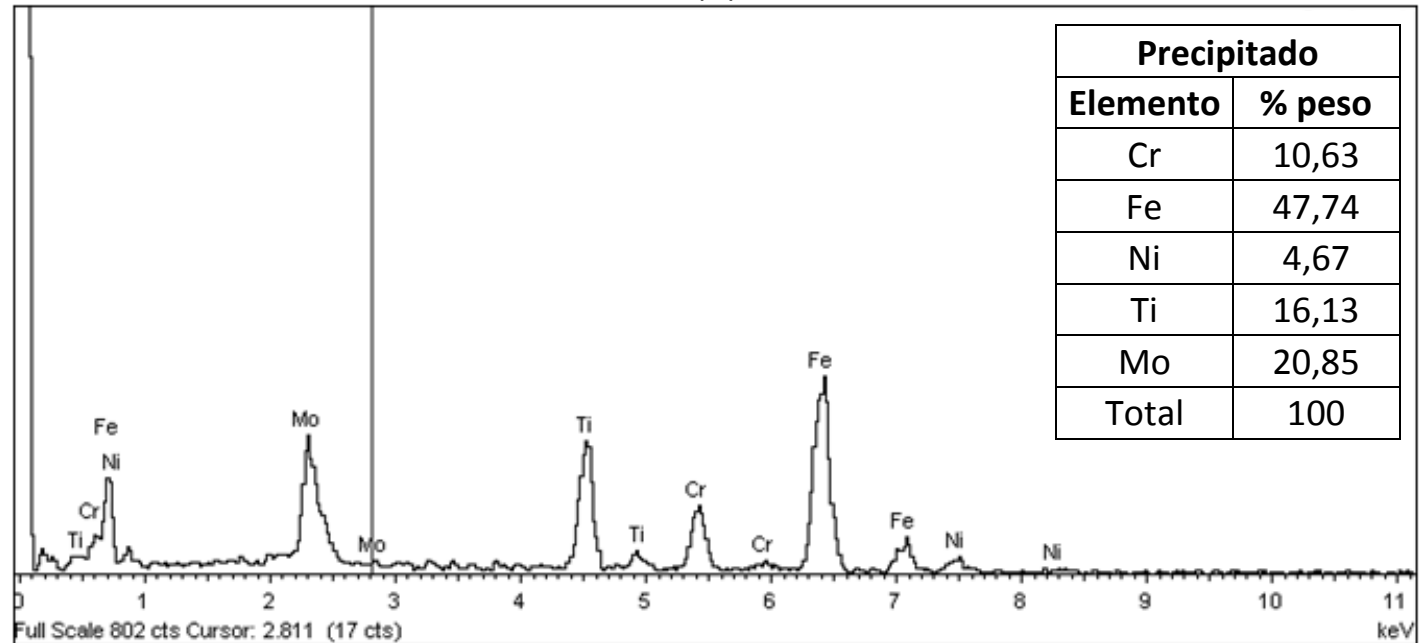

(b)

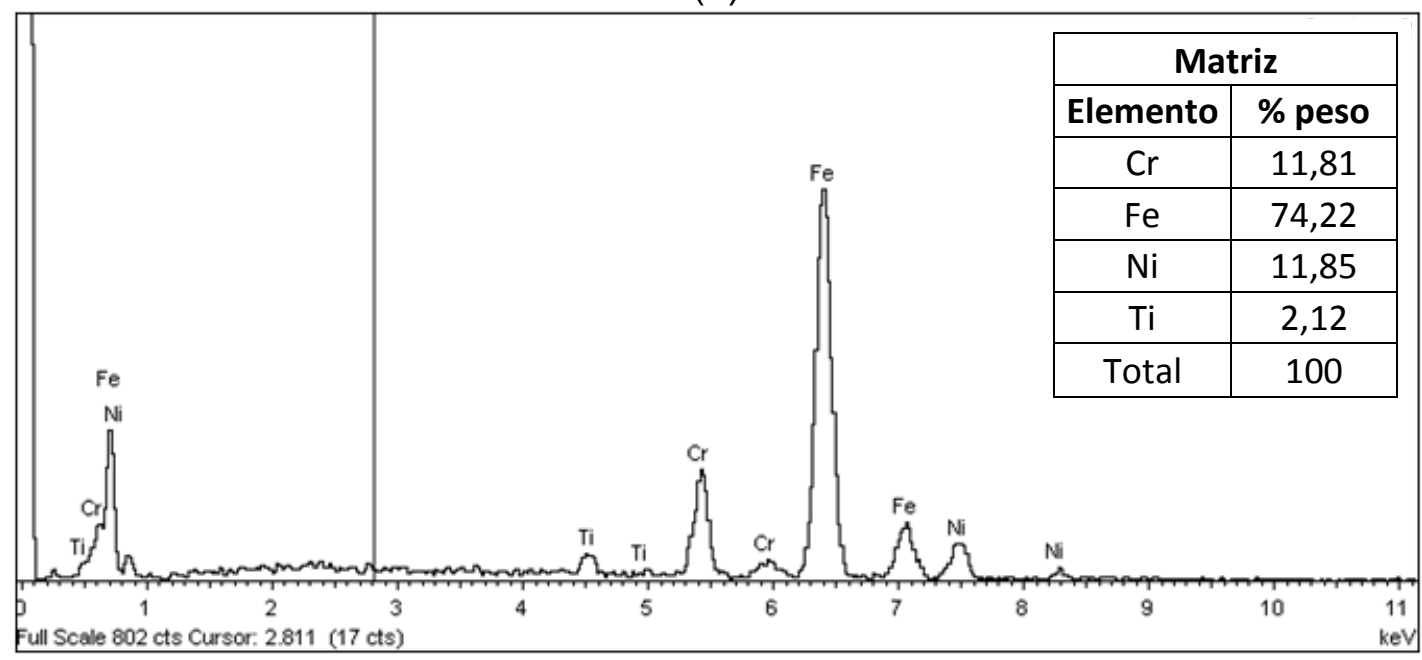

(c)

Figura 36: Imagem de elétrons secundários na condição solubilizada e análise por EDS, mostrando que o precipitado (indicado pela seta) é rico em Mo e Ti (ataque com Vilella). 


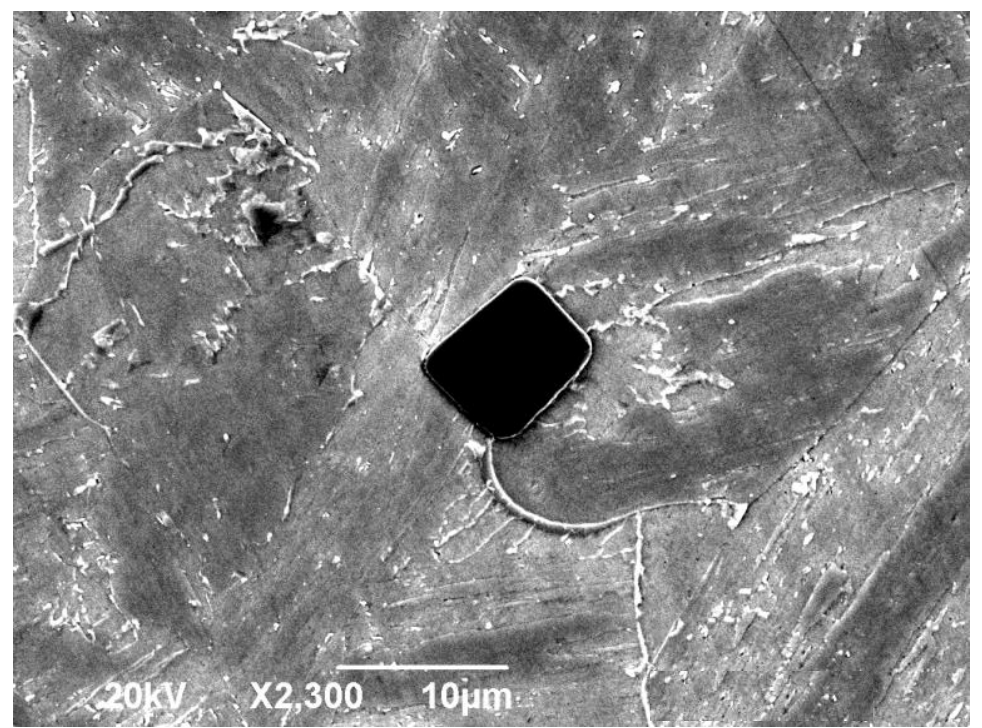

(a)

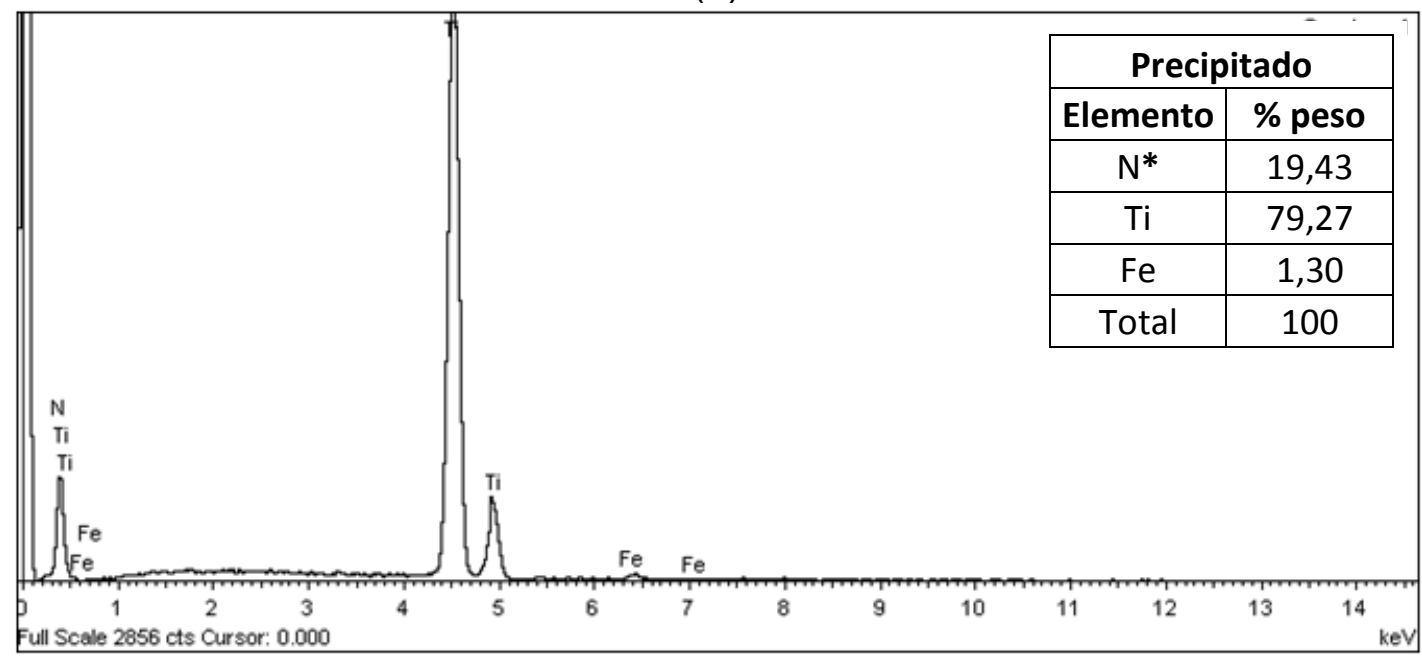

(b)

Figura 37: Imagem de elétrons secundários da amostra na condição H1000 e análise por EDS, mostrando que as partículas escuras são ricas em Ti (nitreto de titânio) (ataque com Vilella).

${ }^{*}$ ) O teor de $N$ não é preciso, pois a melhor análise é a de Espectrometria por Dispersão de Comprimento de Onda (WDS). A análise de EDS realizada mostra apenas que o $N$ está presente.

\subsection{DIFRAÇÃO DE RAIOS $X$}

Complementando os exames de MO e MEV, as amostras foram submetidas a análise por difração de raios $X$. As análises das amostras nas três condições de tratamento térmico, solubilizada, $\mathrm{H} 950$ e $\mathrm{H} 1000$ (Figura 38) indicaram a presença das fases: ferrita [picos (110), (211), (220)] e chi [pico (600)]. A fase ferrita corresponde, no presente caso, à fase martensita. 


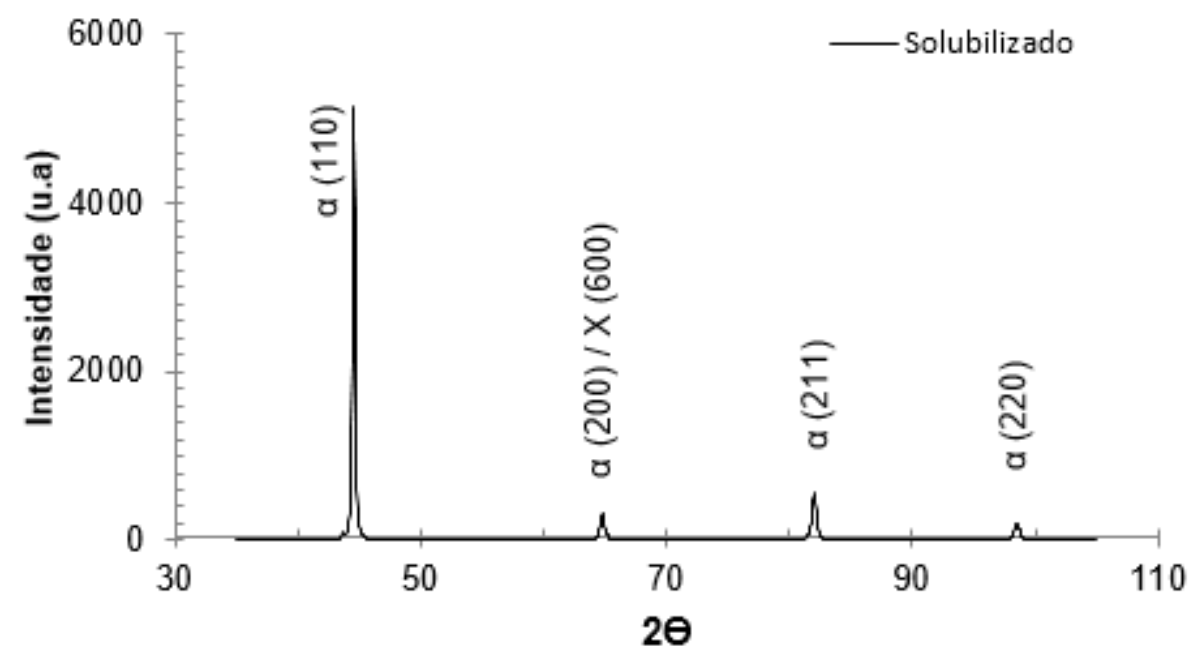

(a)

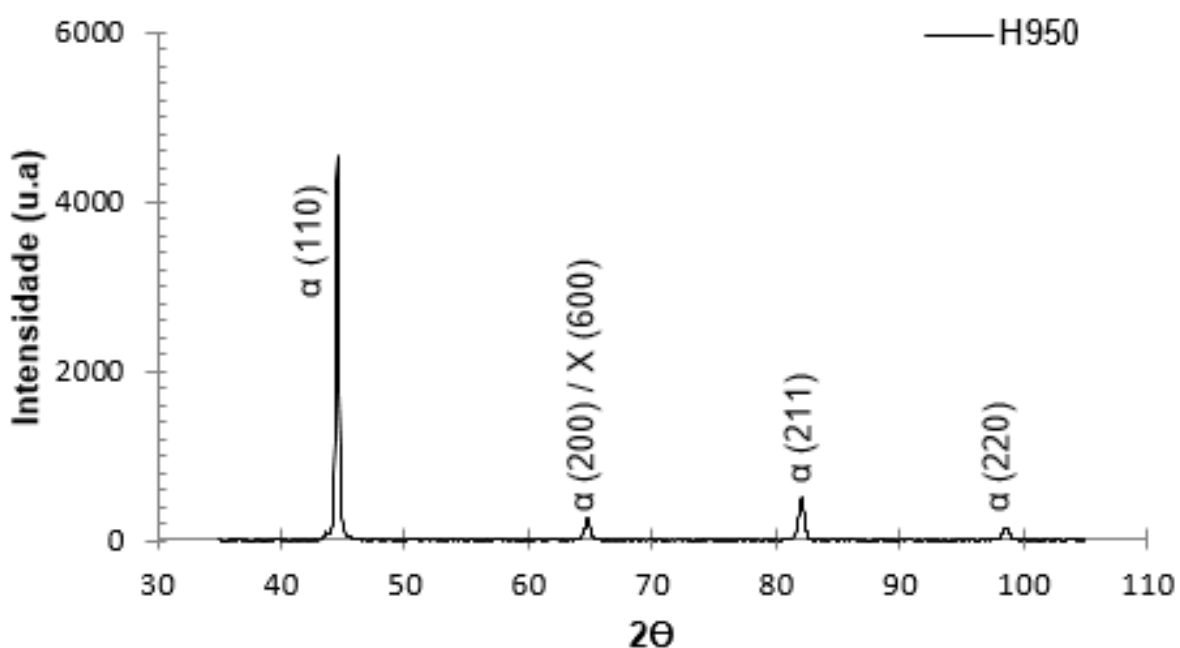

(b)

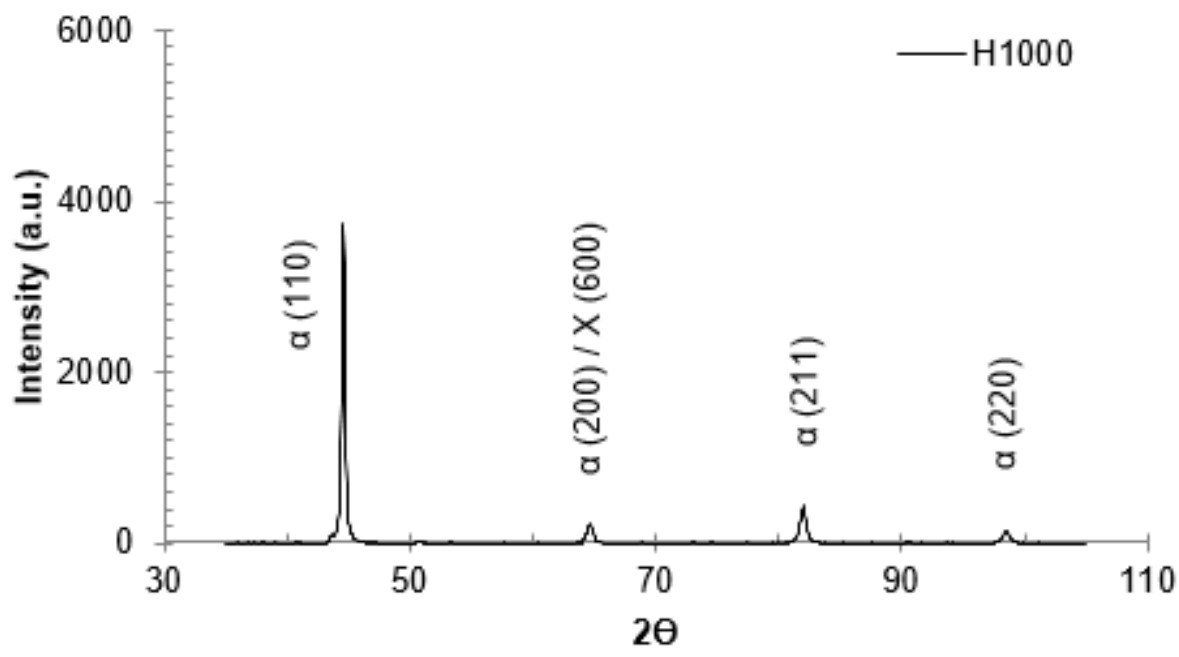

(c)

Figura 38: Espectro de difração de raios $X$ das amostras: (a) solubilizada; (b) H950 e (c) H1000. (fases: $\alpha=$ ferrita; $X=$ chi). 
Além dos exames microestruturais e análise por difração de raios $X$, foi realizada análise utilizando o software Thermo-Calc, base de dados TCFE6, disponibilizados no Departamento de Engenharia de Materiais - Centro Universitário da FEI. No diagrama são apresentadas as fases que podem ser encontradas quando o material está em equilíbrio termodinâmico. O Thermo-Calc utiliza somente os valores da composição química do material.

O resultado do Thermo-Calc para o Custom 465® está apresentado na Figura 39.

Lembrando que os tratamentos $\mathrm{H} 950$ e $\mathrm{H} 1000$ ocorrem nas temperaturas de $510^{\circ} \mathrm{C}$ e $538^{\circ} \mathrm{C}$, a Figura 39 indica que são possíveis as seguintes fases:

- Fase BCC, que é a ferrita cúbica de corpo centrado, e que no presente caso, por motivos cinéticos, fica impedida de ocorrer e em seu lugar tem-se a estrutura martensítica da matriz.

- Fase $\mathrm{Ni}_{3} \mathrm{Ti}$, que são os precipitados responsáveis pelo endurecimento do material. Não foram encontradas evidências experimentais de sua ocorrência, apesar da literatura (WRIGHT; JUNG, 2011) mencionar a presença dessas partículas. Acredita-se que o endurecimento e propriedades de resistência à tração e alongamento devem-se a uma fina e bem distribuída precipitação desses intermetálicos. Sua identificação só seria possível com recursos de microscopia eletrônica de maior resolução e de uma pesquisa mais especializada nesse assunto, o que seria inviável no presente trabalho.

- Fase chi que é segundo a literatura (BECHTOLD; VACHER, 1957) uma fase rica em Fe, Cr e Mo (Tabela 2), foi observada nas análises por difração de raios $X$ nas duas condições de tratamento térmico.

- Fase FCC, que é a austenita cúbica de face centrada; conforme mencionado anteriormente, não foi possível observar austenita retida nos exames em MO e MEV, mas é um microconstituinte mencionado nos trabalhos da literatura (SCHNITZER, et al., 2010), como representado na Figura 9. 
THERMO-CALC (2013.06.06:10.12) :

DATABASE:TCFE6

$P=1.01325 E 5, W(C R)=0.1163, W(N I)=0.1102, W(M O)=9.4 E-3, W(T I)=1.59 E-2$, $\mathrm{W}(\mathrm{N})=2 \mathrm{E}-5, \mathrm{~B}=100$;

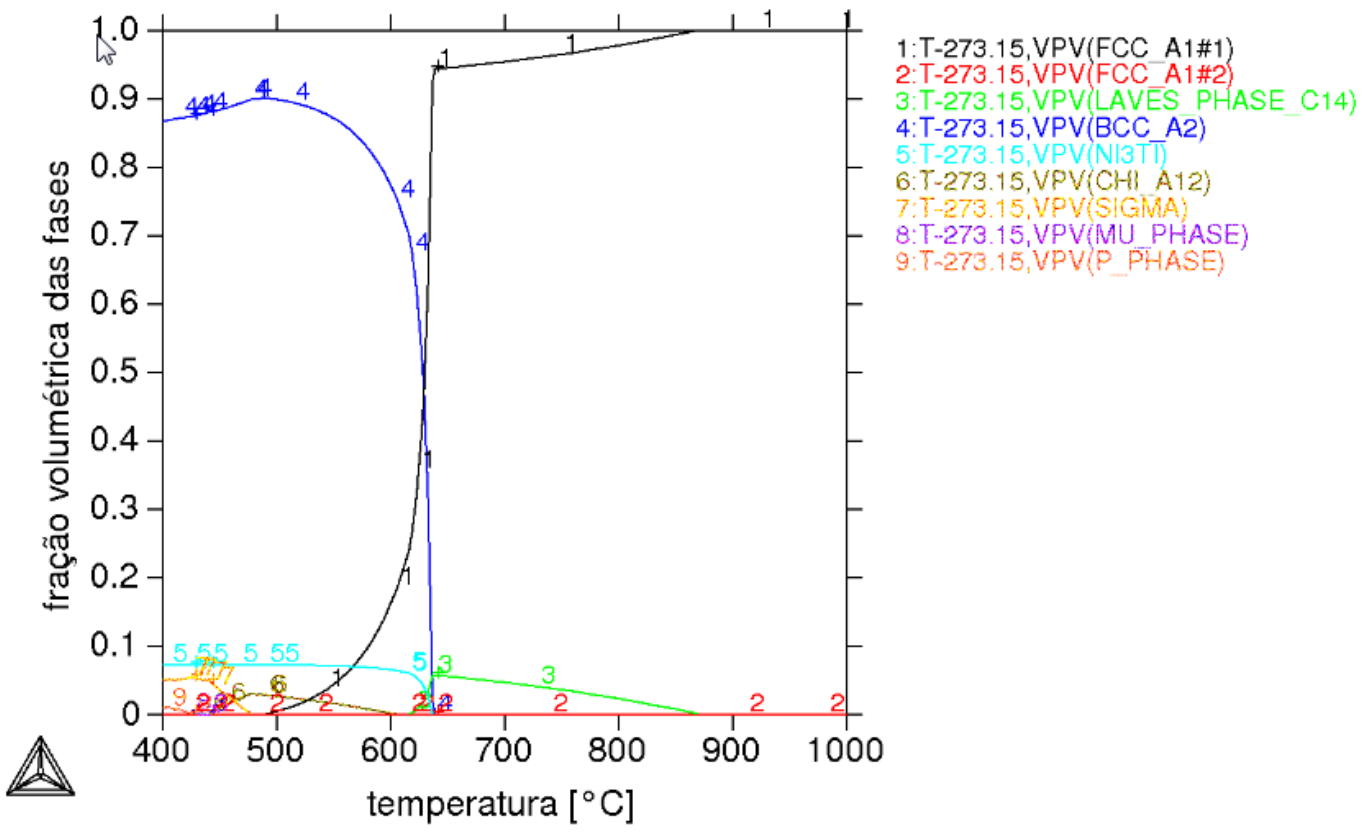

(a)

THERMO-CALC $(2013.06 .06: 10.17)$ :

$\mathrm{P}=1.01325 \mathrm{E} 5, \mathrm{~W}(\mathrm{CR})=0.1163, \mathrm{~W}(\mathrm{NI})=0.1102, \mathrm{~W}(\mathrm{MO})=9.4 \mathrm{E}-3, \mathrm{~W}(\mathrm{TI})=1.59 \mathrm{E}-2$, $W(N)=2 E-5, B=100$;

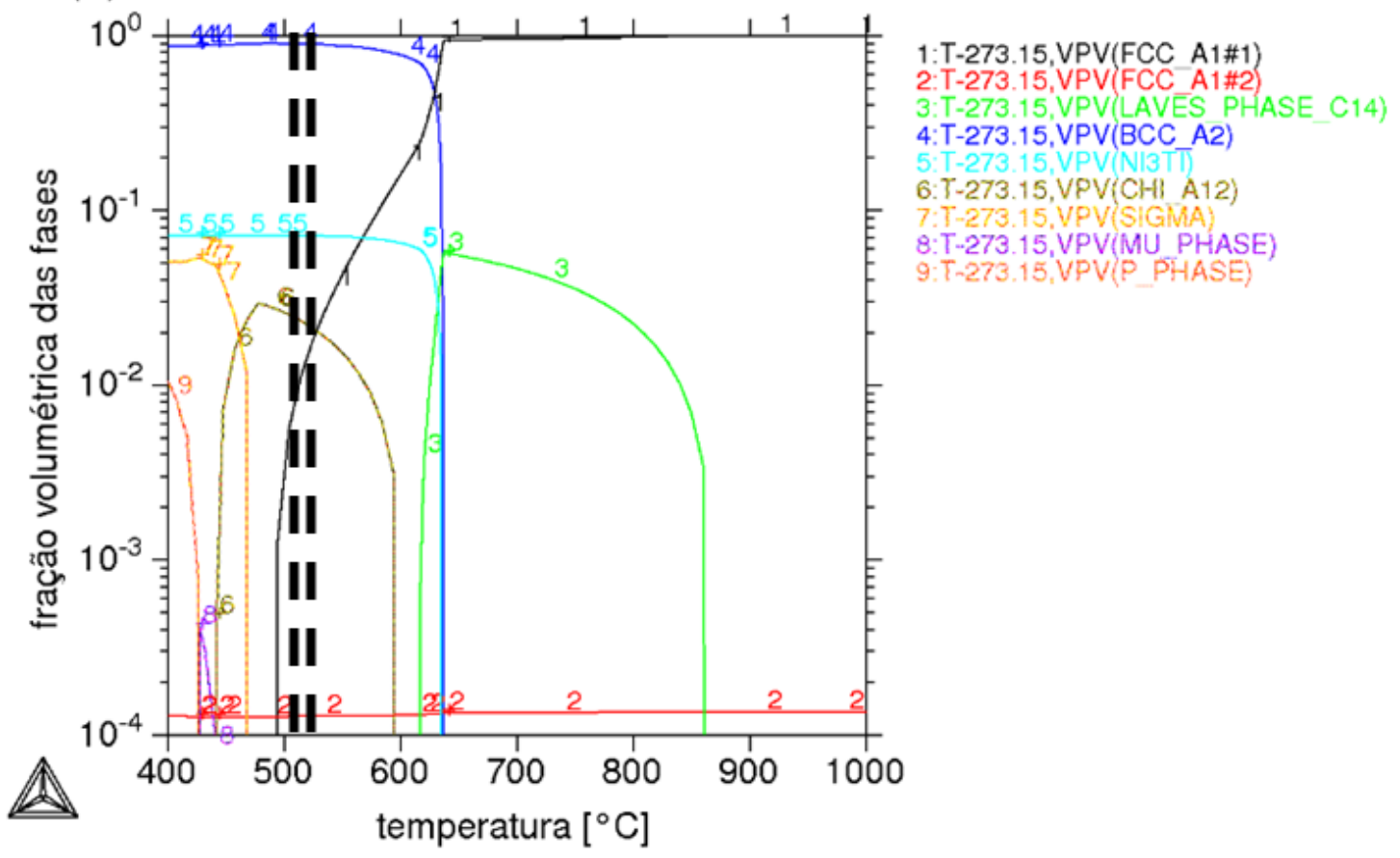

(b)

Figura 39: Resultado do Thermo-Calc para o Custom 465® (composição química Tabela 4) mostrando as fases que podem ser encontradas no equilíbrio. As linhas tracejadas indicam as temperaturas de tratamento $\mathrm{H} 950$ $\left(510^{\circ} \mathrm{C}\right)$ e $\mathrm{H} 1000\left(538^{\circ} \mathrm{C}\right)$. 
A análise quantitativa do Thermo-Calc indicou que a principal diferença entre a condição de tratamento térmico $\mathrm{H} 950$ e H1000 está na porcentagem volumétrica de austenita e de fase chi presente no material, como é possível observar na Tabela 9.

Tabela 9: Fases determinadas no Thermo-Calc.

\begin{tabular}{|c|c|c|}
\hline Fases & H950 (\% volume) & $\mathbf{H 1 0 0 0}$ (\% volume) \\
\hline $\mathrm{BCC}$ & 89,2 & 87,8 \\
\hline $\mathrm{Ni}_{3} \mathrm{Ti}$ & 7,4 & 7,3 \\
\hline $\mathrm{chi}$ & 2,6 & 2,0 \\
\hline $\mathrm{FCC}$ & 0,8 & 2,9 \\
\hline
\end{tabular}

Em síntese, a análise por Thermo-Calc aliada aos resultados das análises por difração de raios X, indicam que o aço Custom 465® nas condições H950 e H1000 apresentam em sua microestrutura uma matriz martensítica, partículas de $\mathrm{Ni}_{3} \mathrm{Ti}$, precipitados de fase chi e austenita. Também foram encontradas partículas de TiN nos exames microestruturais; no entanto, a fração dessa fase pode ser desprezada devido ao baixo teor de nitrogênio na composição química do aço $(0,002 \% \mathrm{~N})$.

\subsection{COMPILAÇÃO DOS RESULTADOS MICROESTRUTURAIS E PROPRIEDADES MECÂNICAS}

A Tabela 10 apresenta, de forma resumida, os principais aspectos das propriedades mecânicas e da microestrutura do aço Custom $465 \AA$ nas três condições de tratamento térmico, detectados a partir dos ensaios, exames e das análises realizados.

Tabela 10: Resumo da caracterização do aço Custom 465®.

\begin{tabular}{|c|c|c|c|c|c|c|c|}
\hline Condição & $\begin{array}{c}\sigma_{\mathrm{R}} \\
(\mathrm{MPa})\end{array}$ & $\begin{array}{c}\sigma_{\mathrm{e}} \\
(\mathrm{MPa})\end{array}$ & $\begin{array}{l}\text { dureza } \\
\text { (HRc) }\end{array}$ & $\begin{array}{l}A L \\
(\%)\end{array}$ & MO, MEV, EDS & DRX & Thermo-Calc \\
\hline Solubilizada & - & - & $30^{*}$ & & \multirow{3}{*}{$\begin{array}{c}\text { Precipitados } \\
\text { contendo Mo e Ti }\end{array}$} & \multirow{3}{*}{$\begin{array}{l}\alpha(=\mathrm{M}) \\
\text { Fase chi }\end{array}$} & - \\
\hline H950 & 1881 & 1836 & 52 & 10 & & & $\begin{array}{c}\alpha(=\mathrm{M}) \\
2,6 \% \mathrm{chi} \\
0,8 \% \mathrm{y} \\
7,4 \% \mathrm{Ni}_{3} \mathrm{Ti} \\
\end{array}$ \\
\hline H1000 & 1702 & 1676 & 49 & 12 & & & $\begin{array}{c}\alpha(=\mathrm{M}) \\
2,0 \% \mathrm{chi} \\
2,9 \% \mathrm{y} \\
7,3 \% \mathrm{Ni}_{3} \mathrm{Ti}\end{array}$ \\
\hline
\end{tabular}

$M=$ martensita; $\alpha=$ ferrita; $\gamma=$ austenita.

* Valor não apresentado no item Resultados. Somente utilizado para comparação dos resultados. 


\subsection{ENSAIOS ELETROQUÍMICOS}

Realizada a caracterização mecânica e metalográfica, o material foi submetido aos ensaios de polarização potenciodinâmica. A Figura 40 apresenta as curvas típicas de polarização encontradas para esse material em cada condição estudada.

Os resultados encontrados para o material solubilizado foram utilizados como referência para o material ensaiado nas condições envelhecidas, H950 e H1000.

As curvas de polarização obtidas mostram o trecho catódico (reação de oxigênio) seguido de região passiva em todas as condições. O potencial de pite aparece muito bem definido em todos os casos (potencial onde ocorre o aumento brusco da densidade de corrente).

A partir das curvas de polarização foram lidos os valores de Ep. A determinação foi feita no potencial onde ocorre o aumento brusco da densidade de corrente. A Tabela 11 e a Figura 41 apresentam os valores médios de Ep juntamente com o desvio padrão correspondente. Para efeito de comparação, foram acrescentados na Figura 41b os valores de Ep para o aço UNS S30403 (304L), encontrados no trabalho de Calderón-Hernández (2012). Os valores de Ep para o aço 304L foram medidos originalmente com relação ao eletrodo de calomelano saturado (ECS) e, por isso, foram convertidos para os valores do eletrodo de prata-cloreto de prata, que foi o eletrodo de referência utilizado para medir os valores de Ep do Custom $465 \AA$.

Tabela 11: Potenciais de pite do aço Custom 465® e 304L (V, Ag/AgCl).

\begin{tabular}{|c|c|c|c|c|}
\hline \multirow{2}{*}{ Amostras } & \multicolumn{4}{|c|}{ Sulfato (M) } \\
\cline { 2 - 5 } & $\mathbf{0}$ & $\mathbf{0 , 0 6}$ & $\mathbf{0 , 3}$ & $\mathbf{0 , 6}$ \\
\hline Solubilizada & $225 \pm 22$ & $293 \pm 47$ & $316 \pm 41$ & $528 \pm 31$ \\
\hline H950 & $288 \pm 25$ & $306 \pm 47$ & $376 \pm 12$ & $536 \pm 132$ \\
\hline H1000 & $238 \pm 59$ & $256 \pm 43$ & $349 \pm 56$ & $594 \pm 128$ \\
\hline
\end{tabular}

\begin{tabular}{|c|c|c|c|c|}
\hline \multirow{3}{*}{$\begin{array}{l}\text { 304L* (Calderón- } \\
\text { Hernández, 2012) }\end{array}$} & \multicolumn{4}{|c|}{ Sulfato (M) } \\
\hline & 0 & 0,06 & 0,15 & 0,6 \\
\hline & $327 \pm 41$ & $352 \pm 30$ & $386 \pm 13$ & $441 \pm 60$ \\
\hline
\end{tabular}

*Valores medidos originalmente com relação ao eletrodo de calomelano saturado e convertido para o eletrodo de $\mathrm{Ag} / \mathrm{AgCl}$. 


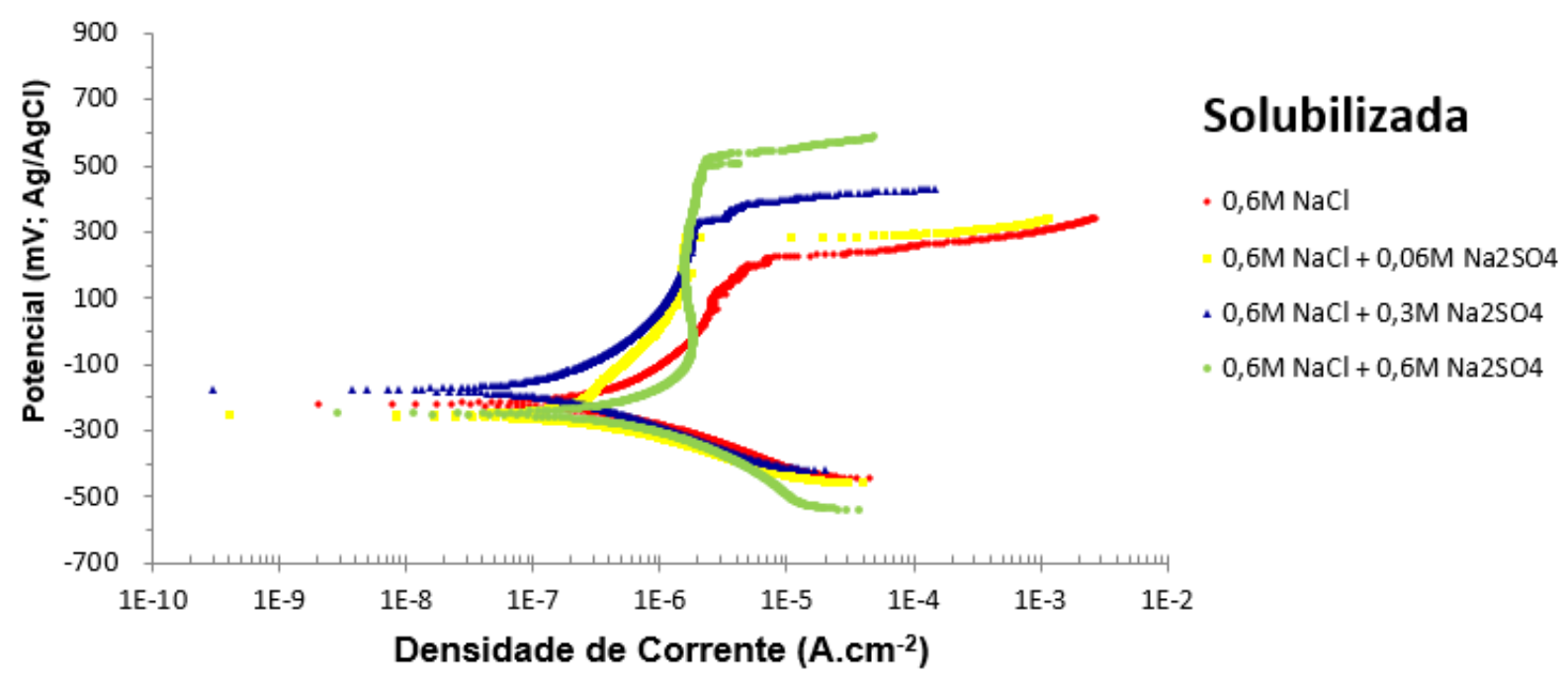

(a)

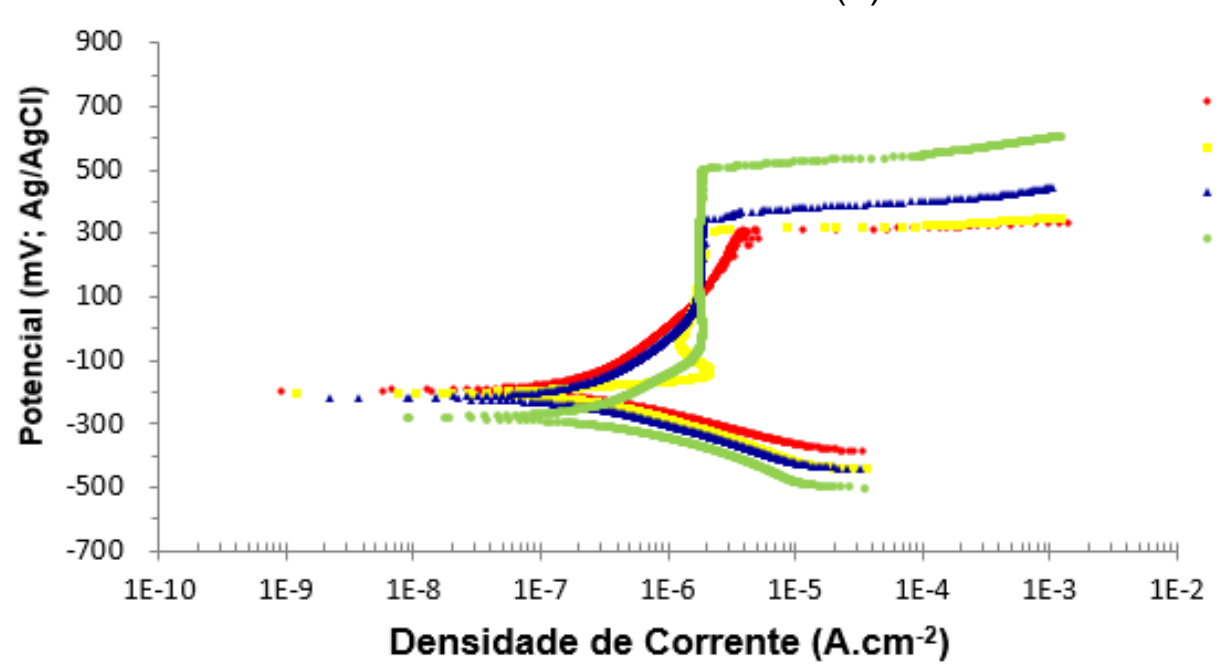

\section{H950}

$0,6 \mathrm{M} \mathrm{NaCl}$

$0,6 \mathrm{M} \mathrm{NaCl}+0,06 \mathrm{M} \mathrm{Na} 2 \mathrm{SO} 4$

. $0,6 \mathrm{M} \mathrm{NaCl}+0,3 \mathrm{M} \mathrm{Na} 2 \mathrm{SO} 4$

- $0,6 \mathrm{M} \mathrm{NaCl}+0,6 \mathrm{M} \mathrm{Na} 2 \mathrm{SO} 4$

(b)

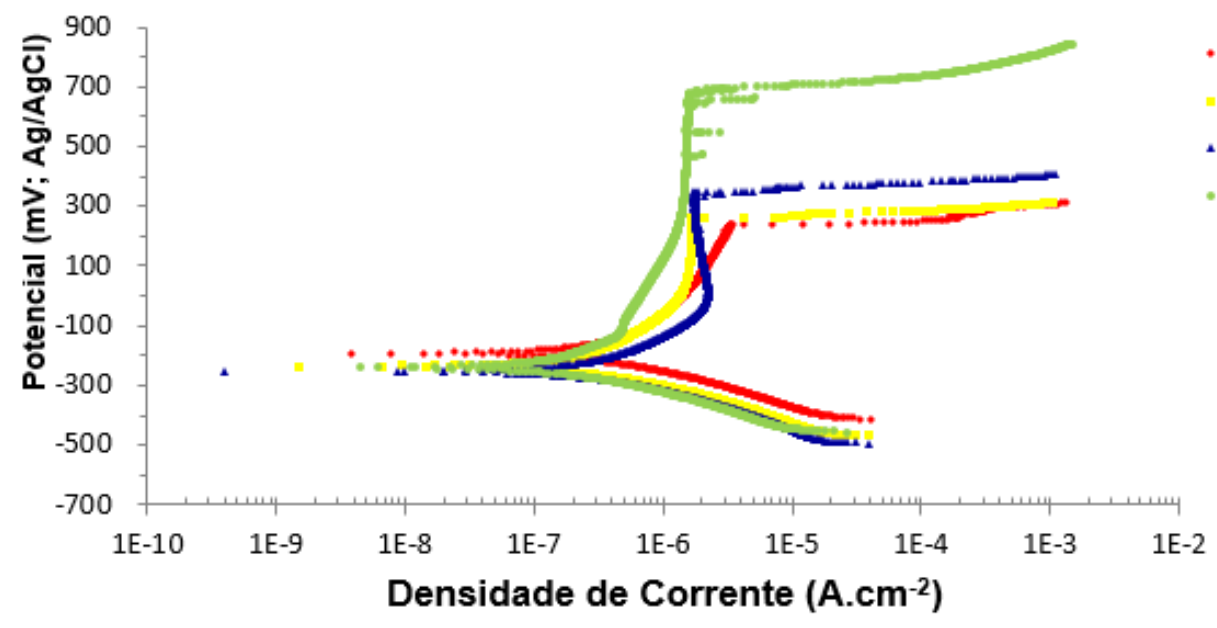

\section{H1000}

$0,6 \mathrm{M} \mathrm{NaCl}$

$0,6 \mathrm{M} \mathrm{NaCl}+0,06 \mathrm{M} \mathrm{Na} 2 \mathrm{SO} 4$

$0,6 \mathrm{M} \mathrm{NaCl}+0,3 \mathrm{M} \mathrm{Na} 2 \mathrm{SO} 4$

$0,6 \mathrm{M} \mathrm{NaCl}+0,6 \mathrm{M} \mathrm{Na} 2 \mathrm{SO} 4$

(c)

Figura 40: Curvas típicas de polarização potenciodinâmica obtidas para 0 aço Custom 465® nas condições: (a) solubilizada; (b) $\mathrm{H} 950$ e (c) H1000; com adições crescentes de sulfato $\left(\mathrm{Na}_{2} \mathrm{SO}_{4}\right)$. 


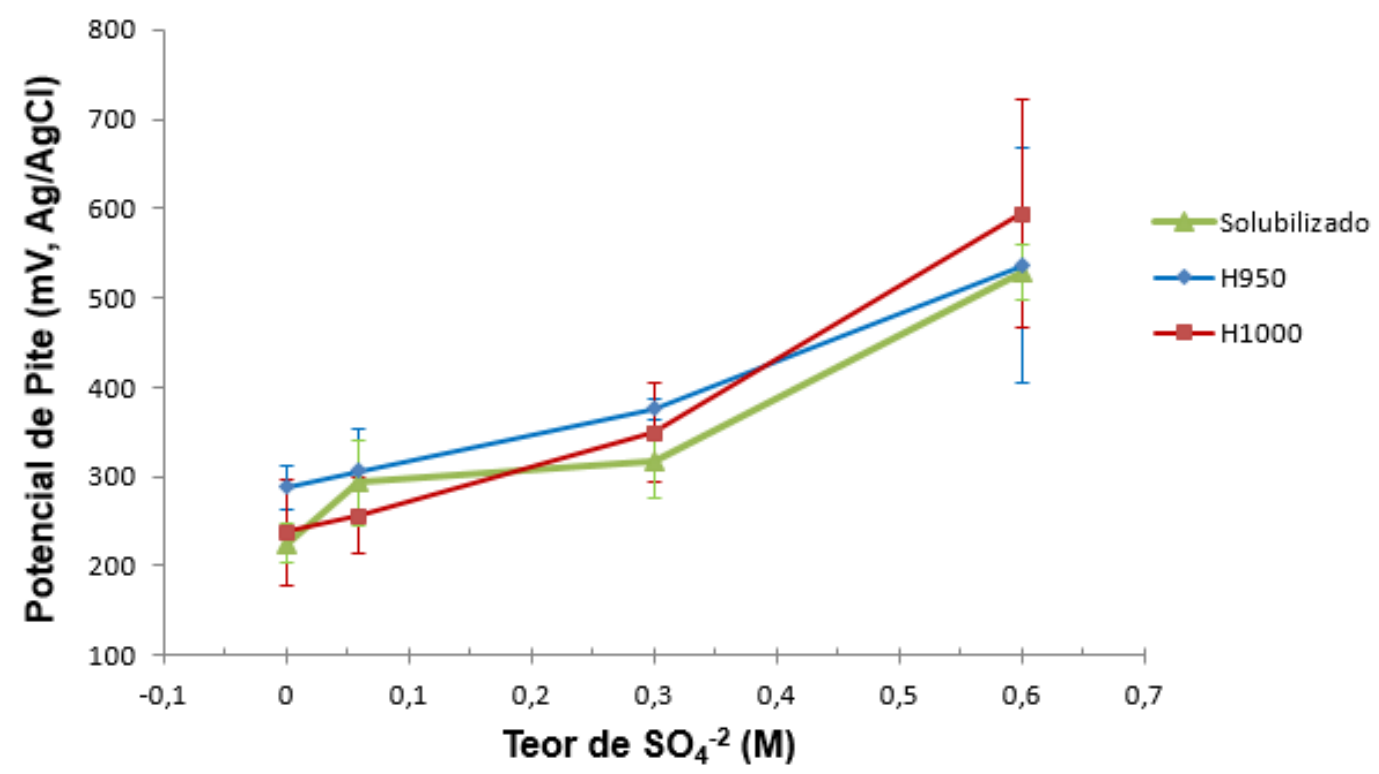

(a)

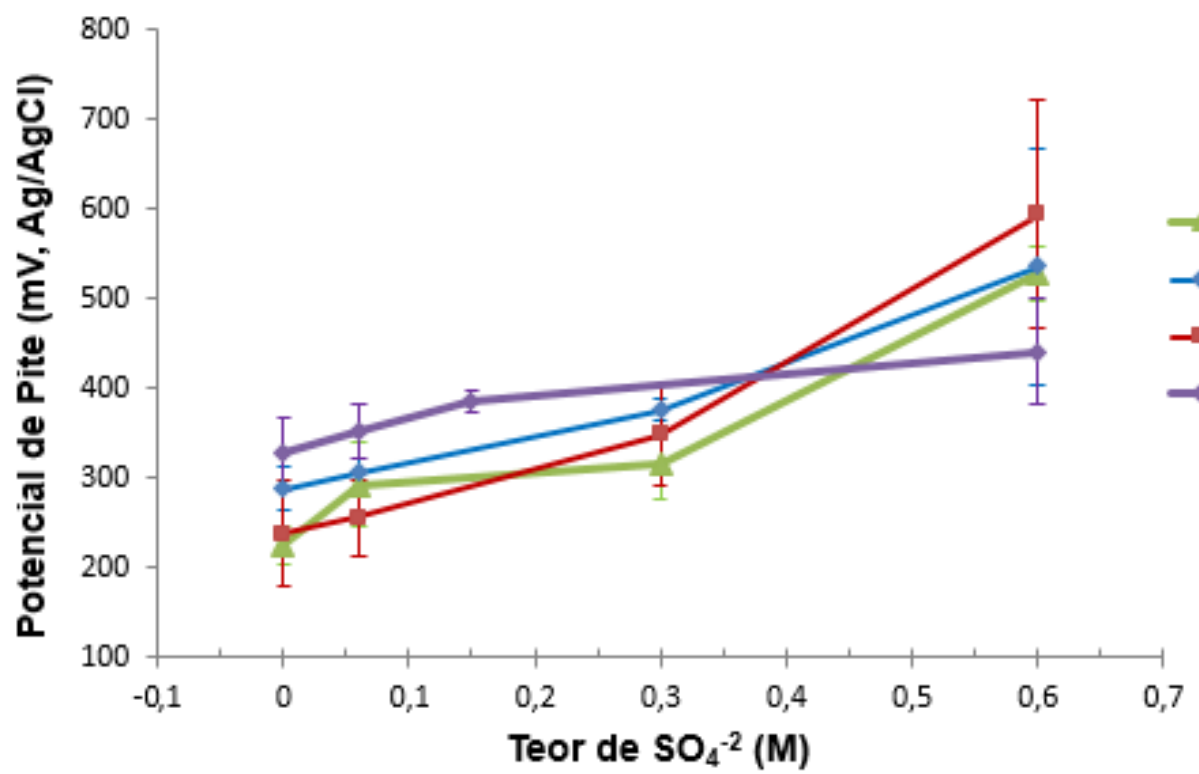

(b)

Figura 41: Potencial de pite médio (Ep): (a) para o aço Custom 465® e (b) para Custom $465 \AA$ e $304 \mathrm{~L}$. Os valores para o aço $304 \mathrm{~L}$ pertencem ao trabalho Calderón-Hernández (2012). Teor fixo de 0,6M NaCl.

A Figura 41 mostra que o aço Custom $465 \AA$ apresenta valores crescentes de potencial de pite para as duas condições de envelhecimento estudadas com 0 aumento do teor de $\mathrm{SO}_{4}{ }^{-2}$; esse comportamento é esperado, uma vez que a literatura (LECKIE; UHLIG, 1966; SATO, 1971) menciona o efeito inibidor deste íon para aços inoxidáveis. Por outro lado, observa-se que o efeito inibidor do $\mathrm{SO}_{4}{ }^{-2}$ é mais acentuado para o aço Custom $465 \AA$ comparativamente ao efeito sobre o aço 304L. 


\subsection{MORFOLOGIA DA CORROSÃO}

As amostras ensaiadas em polarização potenciodinâmica foram examinadas em MO e MEV com o objetivo de analisar a morfologia da corrosão. As Figuras 42 a 44 apresentam uma seleção das imagens obtidas. A morfologia dos pites foi a mesma para todas as condições de tratamento térmico (solubilizada, H950 e H1000) e eletrólitos estudados: os pites apresentaram-se como cavidades circulares de mesma morfologia. Além disso, as Figura 42 e Figura 43 sugerem que o diâmetro dos pites aumenta com o aumento da concentração de sulfato.

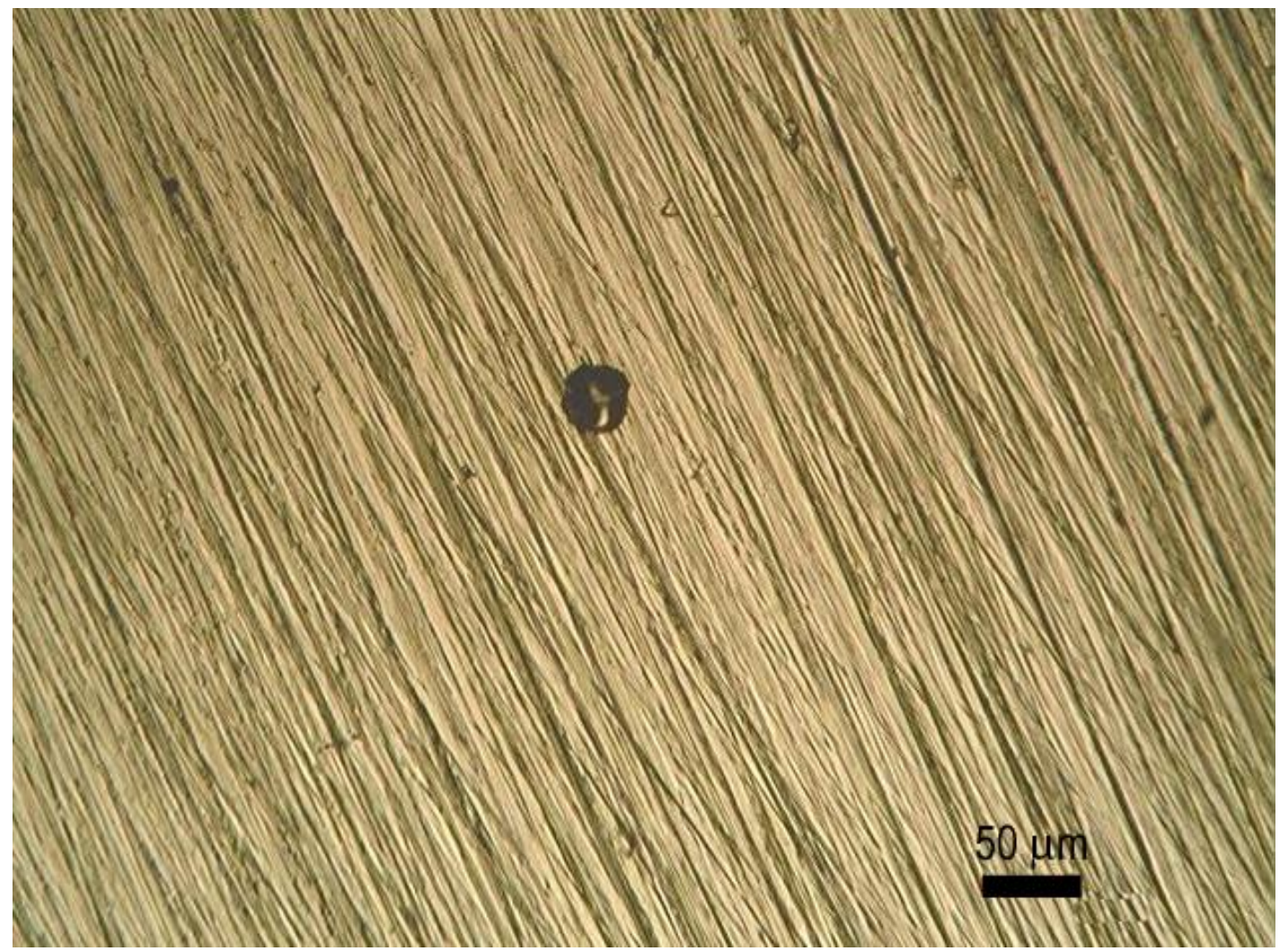

(a) 


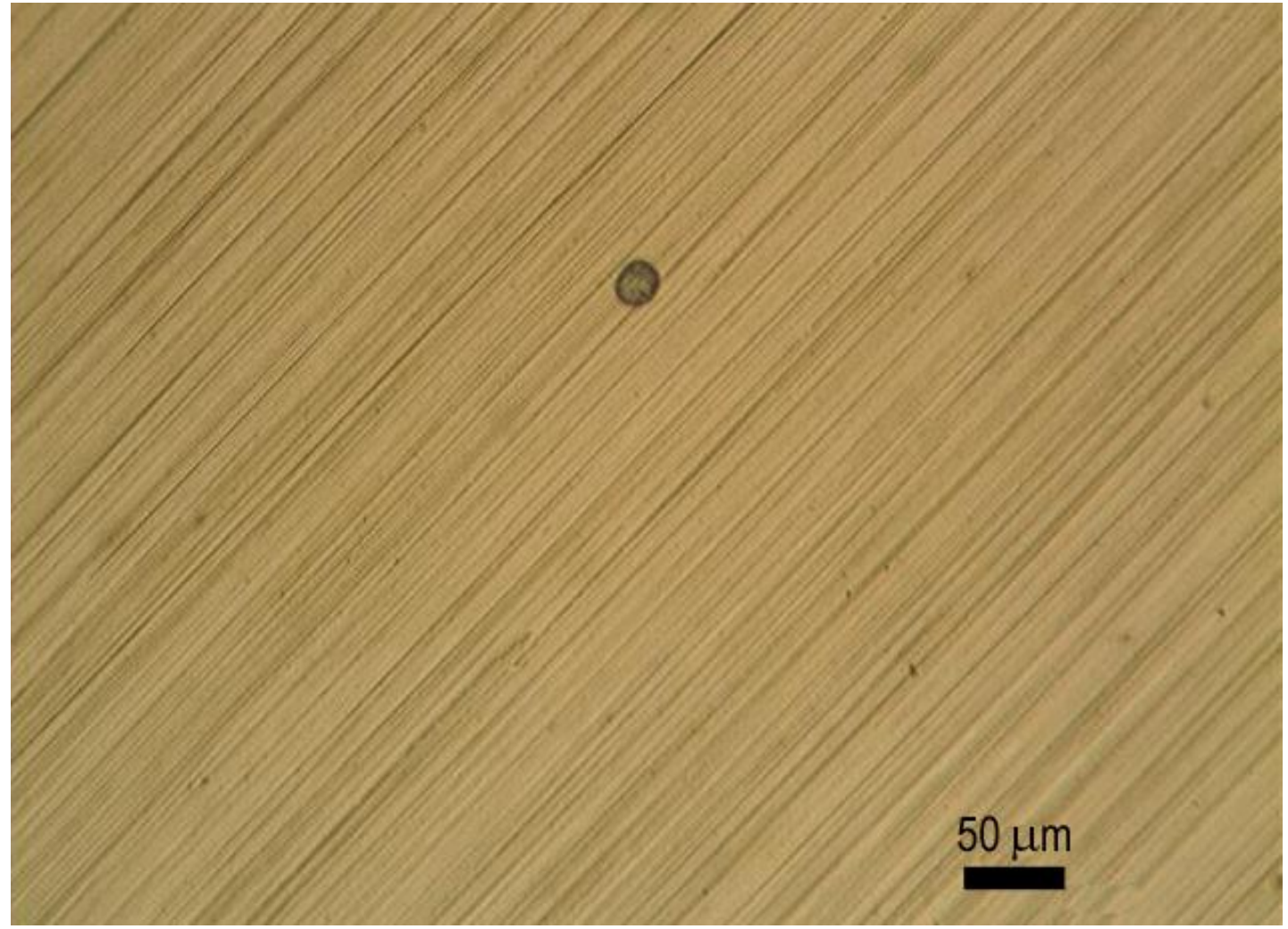

(b)

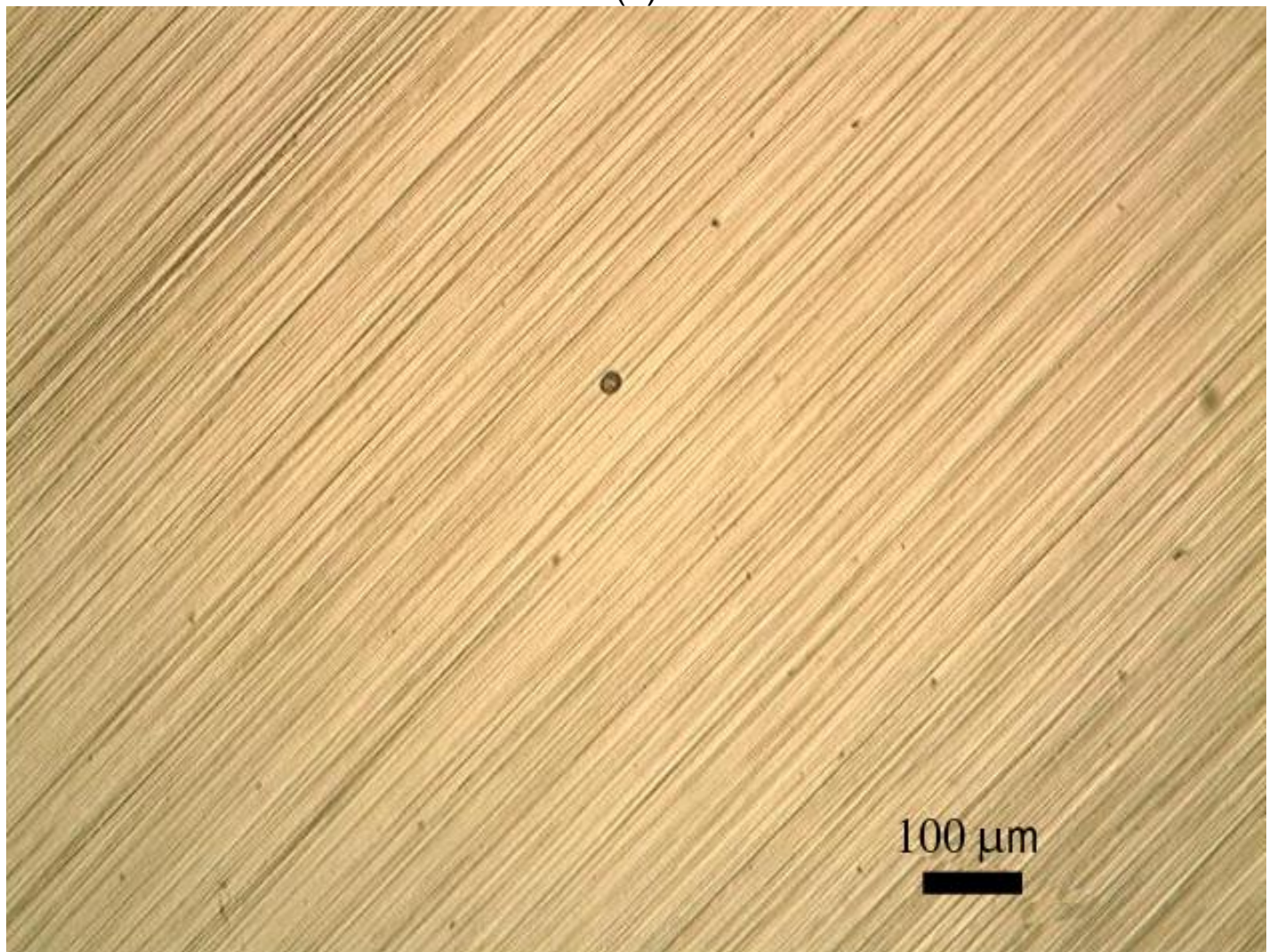

(c)

Figura 42: Imagens obtidas em MO da morfologia dos pites encontrados em ensaio de polarização potenciodinâmica, condições: (a) solubilizada; (b) H950 (c) $\mathrm{H} 1000$ em meio $0,6 \mathrm{M} \mathrm{NaCl}$. 


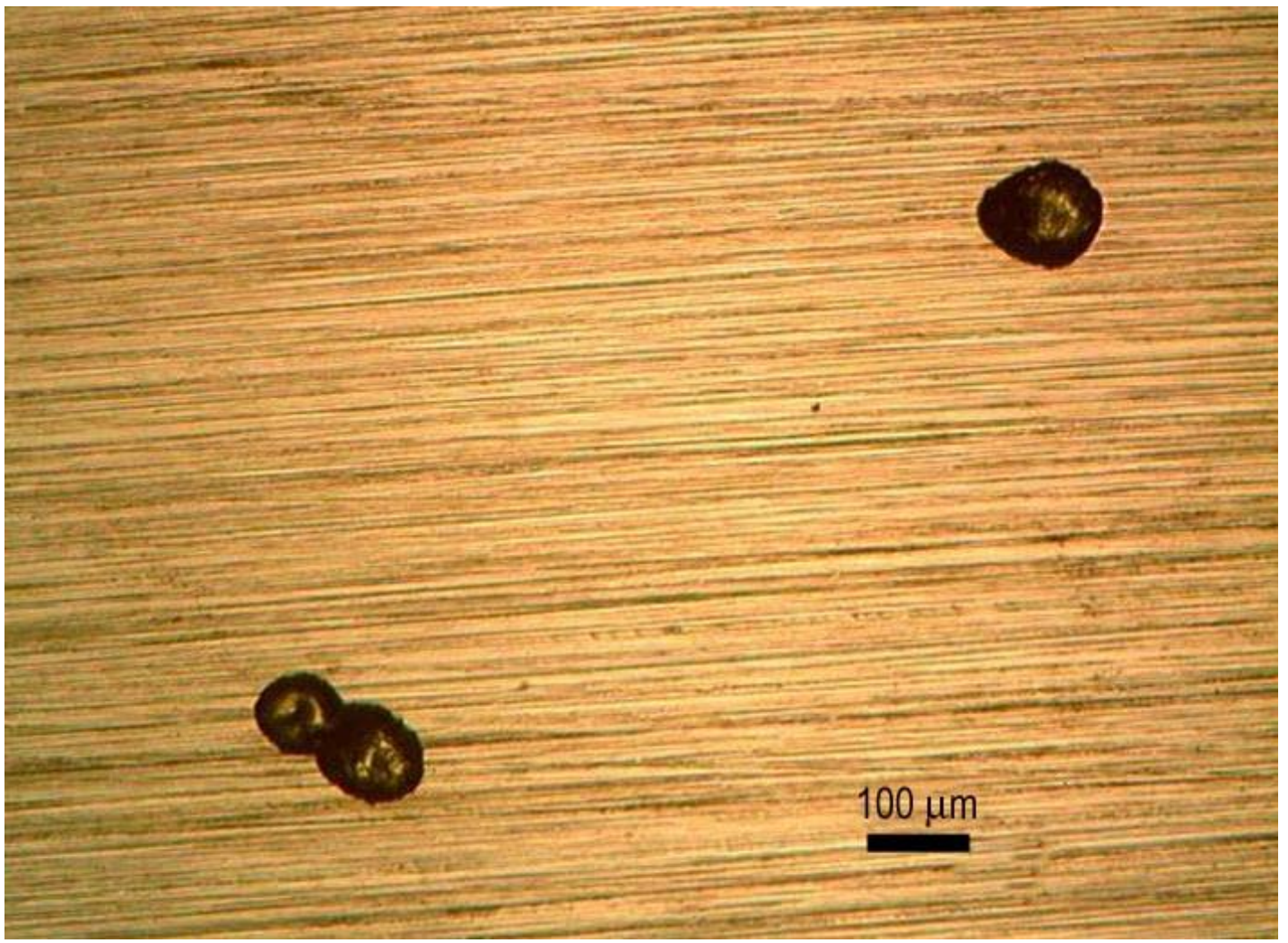

(a)

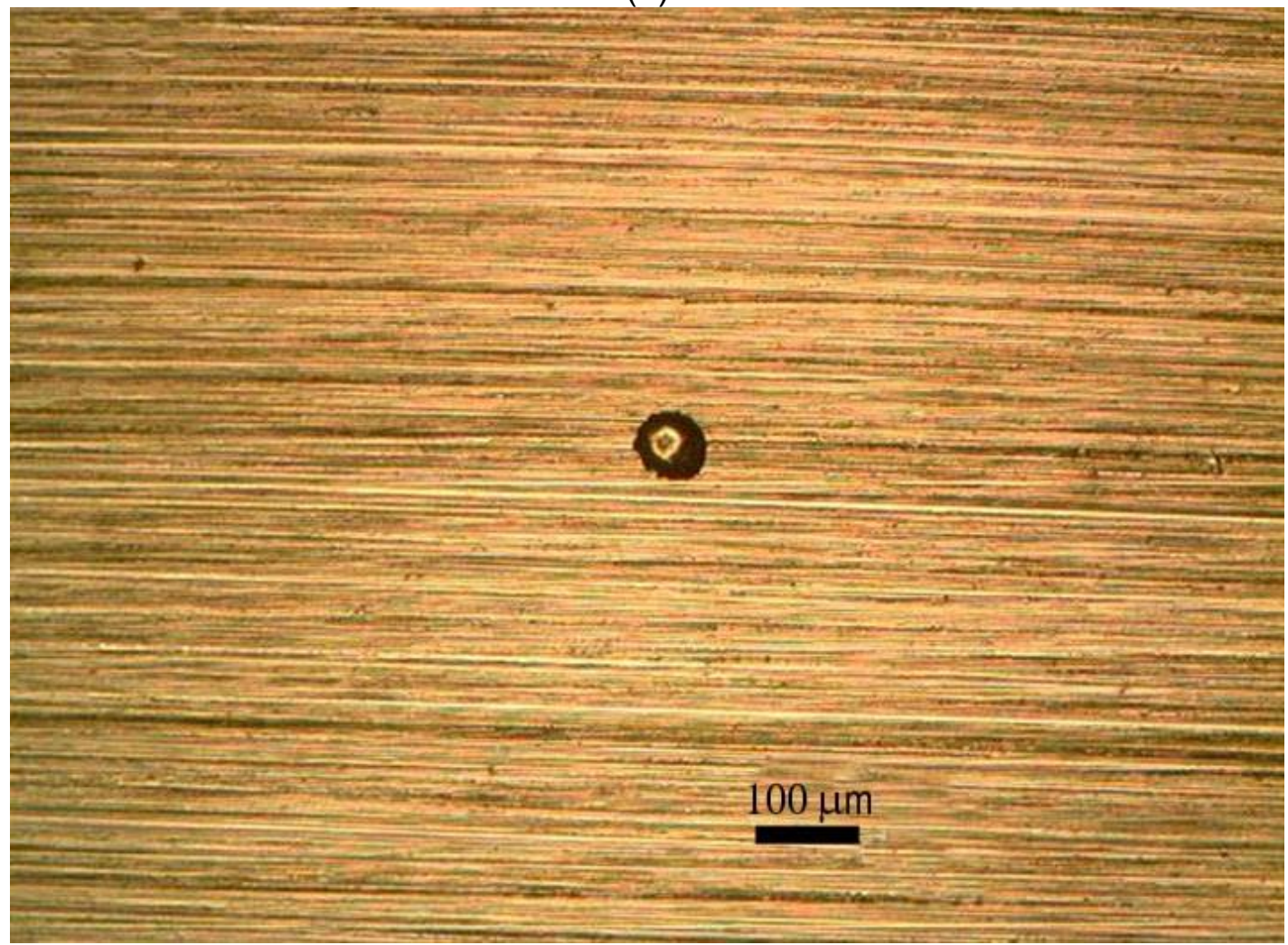

(b) 


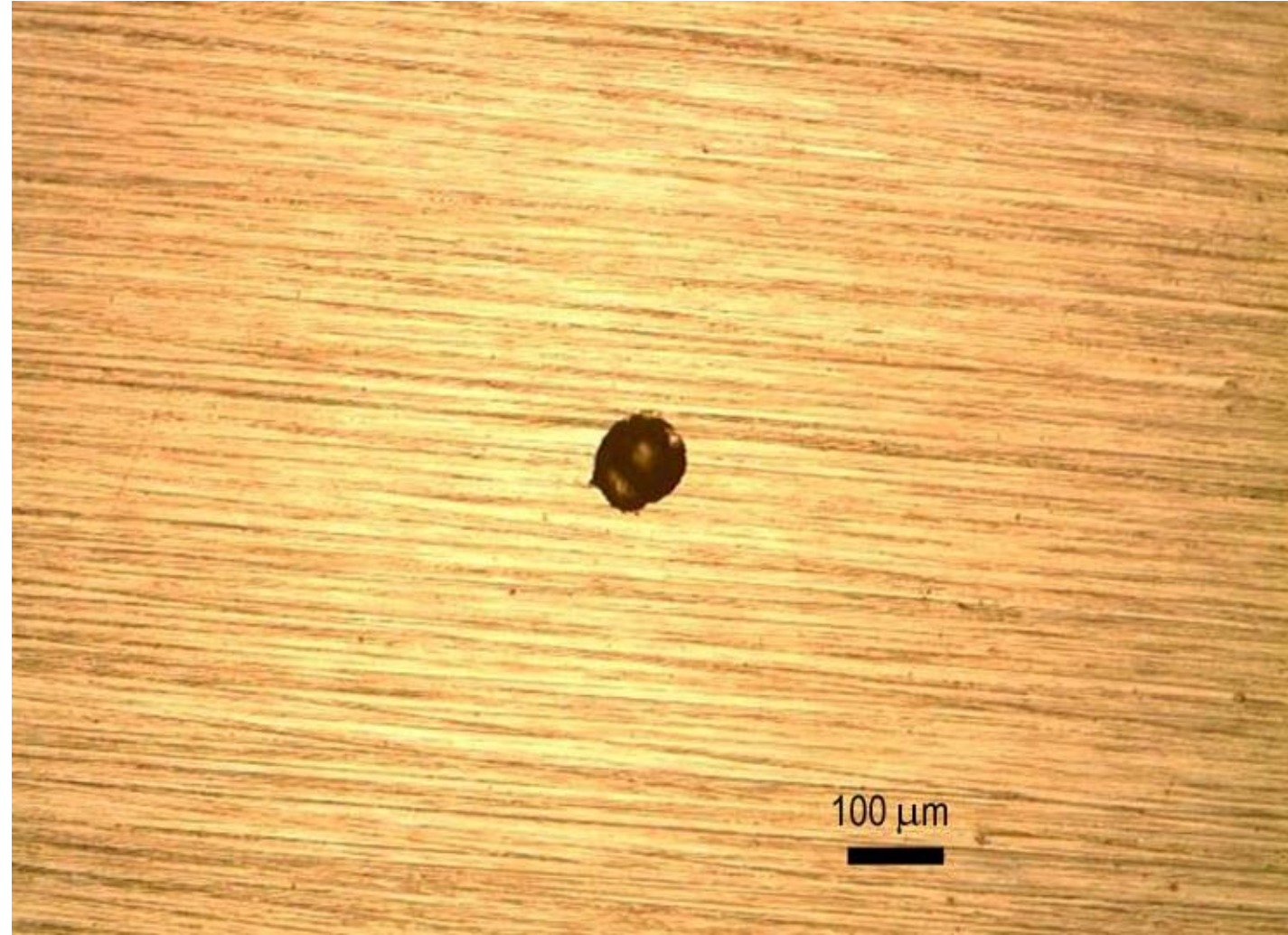

(c)

Figura 43: Imagens obtidas em MO da morfologia dos pites encontrados em ensaio de polarização potenciodinâmica, condições: (a) solubilizada; (b) H950 (c) $\mathrm{H} 1000$ em meio 0,6M NaCl + 0,06M Na $2 \mathrm{SO}_{4}$. Aumento 100x. 


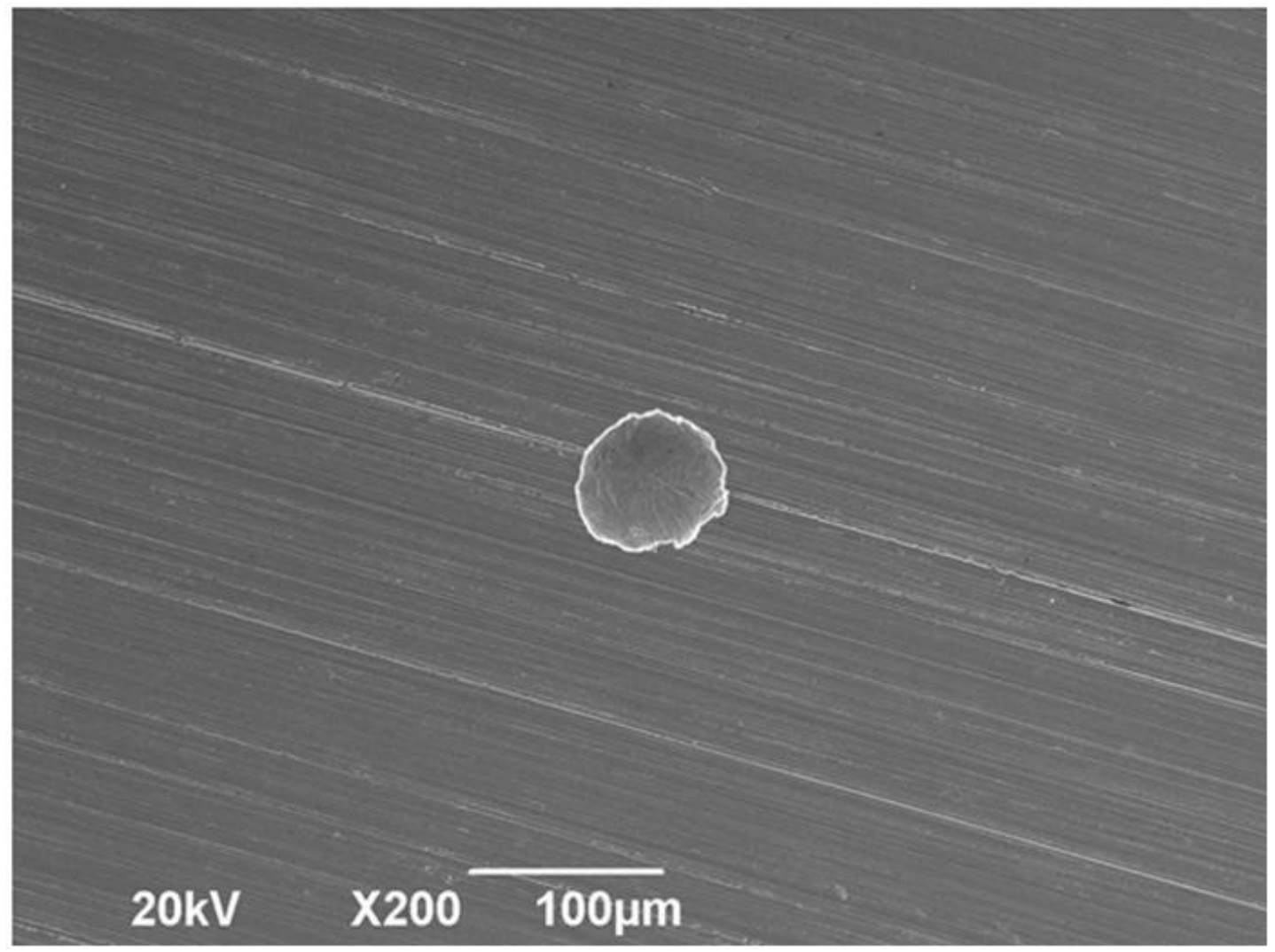

(a)

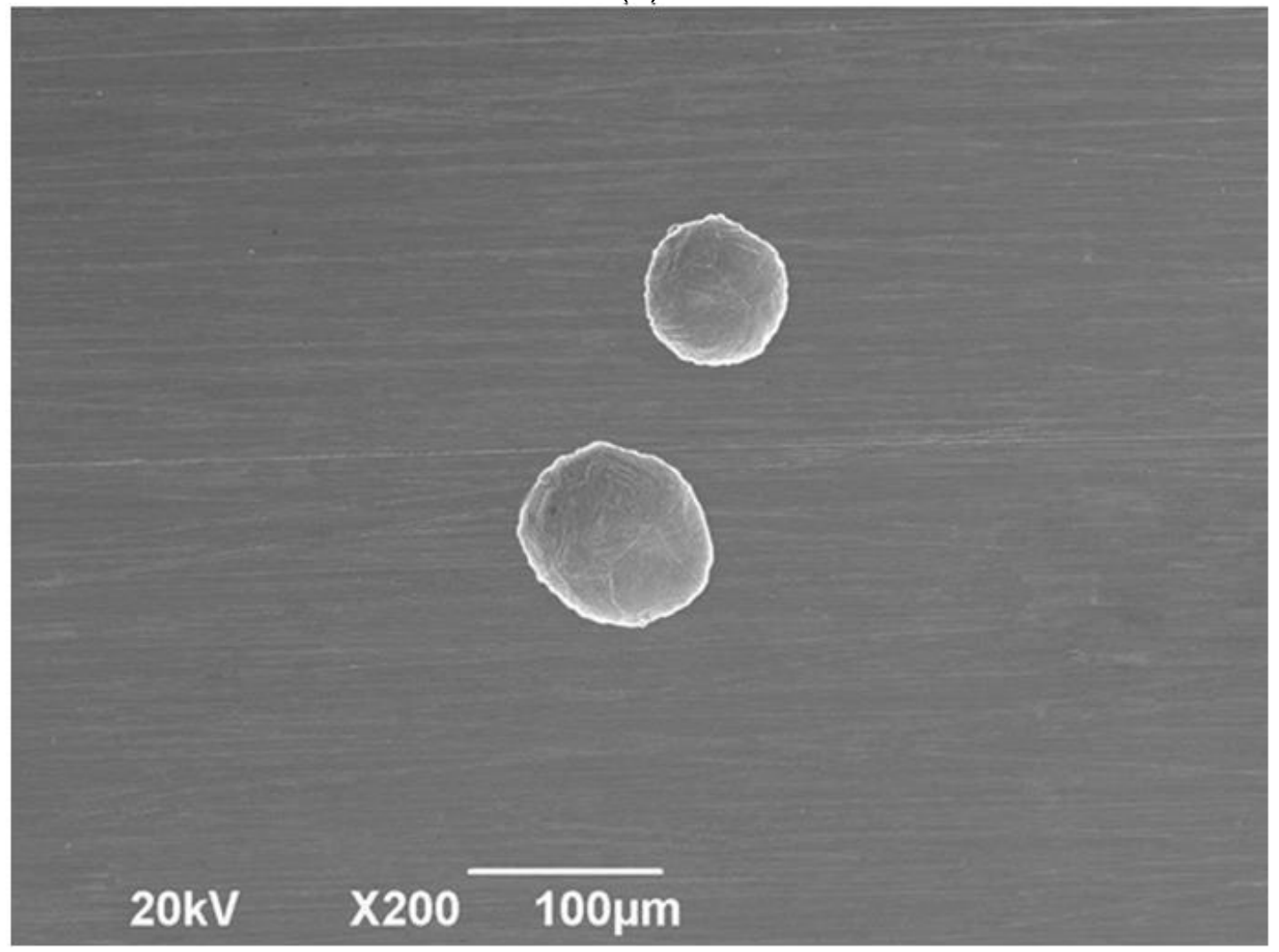

(b)

Figura 44: Imagens de em MEV da morfologia dos pites encontrados em ensaio de polarização potenciodinâmica, condições: (a) H950 e (b) H1000 em meio $0,6 \mathrm{M} \mathrm{NaCl}+0,06 \mathrm{M} \mathrm{Na} 2 \mathrm{SO}_{4}$. 


\section{DISCUSSÃO}

Neste capítulo são apresentadas as principais questões levantadas durante a pesquisa. A discussão é realizada na seguinte ordem:

- Primeiramente é discutida a presença de partículas de nitreto de titânio observadas nos exames em MO e MEV.

- Em segundo lugar é discutido o efeito das temperaturas de envelhecimento H950 e H1000 sobre as propriedades mecânicas.

- Em seguida é discutida a resistência à corrosão por pite, inclusive as razões pelas quais o efeito inibidor dos íons sulfato é mais acentuado para o Custom $465 \AA$ do que para o aço 304L.

\section{Presença de nitreto de titânio}

Os precipitados de nitreto de titânio observados nos exames de MO e MEV (Figura 29, Figura 30 e Figura 37) são formados quando o metal ainda está líquido, conforme indicado na Figura 11. Após sua precipitação, os tratamentos térmicos de envelhecimento somente promovem seu crescimento.

Esses nitretos, por serem partículas duras e frágeis, podem diminuir as propriedades mecânicas do material, principalmente a tenacidade à fratura. Conforme resultados apresentados no capítulo Ensaios Mecânicos, a presença dos nitretos de titânio não influenciou as propriedades mecânicas medidas, todos os resultados estão conforme os requisitos mínimos especificados em norma AMS 5963. Os resultados dos limites de resistência, de escoamento e alongamento tiveram valores acima dos valores mínimos especificados para o material, independentemente da condição de envelhecimento. Isso se justifica pelo fato de que a fração de nitreto de titânio, conforme já mencionado anteriormente, é muito pequena, devido ao baixo teor de nitrogênio na composição química do aço $(0,002 \% N)$.

Com relação à resistência à corrosão, a presença desses precipitados promove a estabilização do nitrogênio (e carbono, caso esteja presente), promovendo a resistência à corrosão intergranular do material, uma vez que o $\mathrm{Ti}$ evita a precipitação de nitretos e carbonetos de $\mathrm{Cr}$. 


\section{Efeito das temperaturas de envelhecimento H950 e H1000 sobre as propriedades mecânicas}

Neste estudo, os efeitos das temperaturas de envelhecimento H950 e H1000 sobre as propriedades mecânicas do aço Custom $465 \AA$ foram investigados.

Os resultados dos ensaios mecânicos mostraram que as propriedades de resistência mecânica e a ductilidade do material são fortemente dependentes do tratamento térmico aplicado.

Apesar de não terem sido observadas, nos exames microestruturais, a simulação do diagrama de fases para o Custom $465 \AA$ realizada com auxílio do Thermo-Calc indicou a presença das fases austenita e $\mathrm{Ni}_{3} \mathrm{Ti}$. Com base nos resultados obtidos é possível afirmar que quanto maior a temperatura de envelhecimento, maior quantidade de austenita é formada: foram encontrados $0,8 \%$ de austenita para o tratamento $\mathrm{H} 950$ e 2,9\% para a condição H1000 (Tabela 9). Esse resultado é semelhante ao observado por Schnitzer et al. (2010) e Nakagawa e Miyazaki (1999). Seu papel é o de diminuir a resistência à tração e aumentar o alongamento.

Ainda com os resultados do Thermo-Calc notou-se que a quantidade dos precipitados $\mathrm{Ni}_{3} \mathrm{Ti}$ não sofreu alteração com o aumento da temperatura de envelhecimento (7,4\% para H950 e 7,3\% para H1000). Esses precipitados são conhecidos por fornecer o endurecimento ao material, interagindo com as discordâncias quando fina e uniformemente distribuídos na matriz. Um estudo por microscopia eletrônica de transmissão é necessário para a verificação exata desse microconstituinte.

Schnitzer et al. (2010), em seu estudo para aço PH 13-8Mo, o qual continha precipitados de níquel-alumínio, calcularam que $40 \%$ da diminuição das propriedades mecânicas se devem a presença da austenita revertida e o restante ao coalescimento dos precipitados de níquel-alumínio. Analogamente, no presente estudo, não se deve descartar o coalescimento dos finos precipitados de $\mathrm{Ni}_{3} \mathrm{Ti}$, ou ao menos a menor taxa de nucleação dos precipitados na condição H1000, uma vez que os resultados do Thermo-Calc não indicaram diferenças no teor de $\mathrm{Ni}_{3} \mathrm{Ti}$ entre as duas condições de envelhecimento. $\mathrm{Na}$ condição $\mathrm{H} 1000$, sendo os precipitados $\mathrm{Ni}_{3} \mathrm{Ti}$ maiores e mais distantes entre si (devido ao menor número de núcleos comparativamente à condição H950), tem-se maior caminho livre para a 
movimentação das discordâncias, e deste modo, contribui para a diminuição da resistência à tração e aumento da ductilidade.

Como mostrado no item Exames Microestruturais, foram observadas diferenças nas quantidades de precipitados (pontos claros - Figura 32, Figura 33 e Figura 34) existentes entre as amostras solubilizada, tratada na condição H950 e H1000. O exame das microestruturas sugere que há uma maior quantidade de precipitados no material na condição H950. A Figura 35, realizada com maior aumento, realça a diferença na quantidade de precipitados observados entre as amostras H950 e $\mathrm{H} 1000$.

Conforme já citado anteriormente, a análise por EDS revelou que os precipitados são fases ricas em Mo e Ti (Figura 36). Considerando que o material da Figura 36 passou por processos de solubilização (austenitização - Figura 22), envelhecimento e nova solubilização a $982{ }^{\circ} \mathrm{C}$ (item 4.2) pode-se ter que, inicialmente, a fase observada tenha sido formada com maior teor de Ti. Lembra-se que a fase de Laves pode apresentar a estequiometria $\mathrm{Ti}_{21} \mathrm{Mog}$, em aços austeníticos aquecidos entre $600^{\circ} \mathrm{C}$ e $1100^{\circ} \mathrm{C}$. (VOORT et al., 1985).

Por sua vez, as análises por difração de raios $X$ e as análises por Thermo-Calc confirmaram a presença de fase chi, a qual é rica em Mo e Cr. Dessa forma, apesar de terem sido encontradas partículas ricas em Mo e $\mathrm{Ti}$, conclui-se que os precipitados encontrados na forma de partículas relativamente grosseiras, tanto transgranulares quanto intergranulares, são principalmente fase chi. Os resultados da análise por Thermo-calc (Tabela 9) confirmaram tal observação, mostrando que a fase chi está presente em uma maior porcentagem na condição de tratamento H950 (2,6\% para $\mathrm{H} 950$ e 2,0\% para H1000). Esta diminuição de 2,6\% para 2,0\% pode ter contribuido para a diminuição da resistência à tração observada para o material na condição H1000.

Em resumo, os resultados evidenciam e sugerem que os tratamentos $\mathrm{H} 950$ e $\mathrm{H} 1000$ alteram as propriedades à tração devido ao aumento da fração de austenita, coalescimento e tamanho dos precipitados $\mathrm{Ni}_{3} \mathrm{Ti}$, e, talvez diminuição da fração de fase chi. 


\section{Resistência à corrosão por pite}

A determinação da resistência à corrosão por pite do aço Custom $465 \AA$ foi realizada através do levantamento dos valores de Ep em função dos tratamentos de envelhecimento $\mathrm{H} 950$ e H1000 em meio contendo cloreto com adições de sulfato.

Observa-se na Figura 41a que, considerando cada eletrólito individualmente, o Ep das condições avaliadas apresentou valores que não diferem muito, se forem consideradas as barras de dispersão. Isto é, os valores de Ep obtidos não permitem afirmar que os tratamentos térmicos originaram uma diferença significativa de resistência à corrosão por pite em cada eletrólito.

Os estudos de Wegrelius e Olejford (1995), sugerem que maior quantidade de fase chi prejudica a resistência à corrosão por pite, uma vez que menor quantidade de cromo e molibdênio estariam em solução sólida. Deste modo, considerado os microconstituintes observados nos resultados de MO, MEV, EDS, difração de raios $X$ e Thermo-Calc, este seria o caso da condição H950, que apresentou maior quantidade de fase chi $(2,6 \%$, contra $2,0 \%$ para $\mathrm{H} 1000)$. No entanto, conforme citado, as duas condições de envelhecimento, H950 e H1000, apresentaram praticamente a mesma resistência à corrosão por pite: a dispersão obtida não permite afirmar que há uma tendência com o tratamento térmico (Figura 41a). Embora a afirmação de Wegrelius e Olejford (1995) esteja correta, os resultados do presente trabalho indicam que é necessária uma diferença nas porcentagens de fase chi maior do que as apresentadas pelos tratamentos H950 e H1000, para que ocorra a alteração da resistência à corrosão por pite.

Apesar de não ter sido observada influência do tratamento térmico sobre a resistência à corrosão em cada eletrólito individualmente, os resultados (Figura 41a) mostram que o efeito inibidor do íon $\mathrm{SO}_{4}{ }^{-2}$ é mais acentuado para o tratamento $\mathrm{H} 1000$. De fato, a Tabela 12 apresenta a regressão linear para a dependência do Ep com o teor de íon $\mathrm{SO}_{4}{ }^{-2}$ para cada tratamento térmico, onde se observa claramente que a inclinação é maior para o tratamento $\mathrm{H} 1000$, sendo, portanto, uma evidência do maior poder inibidor do $\mathrm{SO}_{4}^{-2}$ quando o material está nessa condição de tratamento térmico. 
Tabela 12: Regressão linear do Ep (y) em função do teor de $\mathrm{SO}_{4}^{-2}(x)$ - dados da Figura 41.

\begin{tabular}{|l|l|c|}
\hline \multicolumn{1}{|c|}{ Amostras } & \multicolumn{1}{c|}{ Regressão linear } & $\mathbf{R}^{\mathbf{2}}$ \\
\hline Solubilizada & $y=458 x+231$ & 0,913 \\
\hline H950 & $y=409 x+278$ & 0,977 \\
\hline H1000 & $y=590 x+218$ & 0,963 \\
\hline 304L & $y=174 x+341$ & 0,922 \\
\hline
\end{tabular}

A maior capacidade de inibição do sulfato na condição H1000 é difícil de explicar. No entanto, as causas devem estar contidas nas variações microestruturais.

De modo geral, considera-se que, o mecanismo da inibição da nucleação de pite por sulfato, depende da adsorção deste íon em sítios ativos que seriam inicialmente ocupados pelo íon cloreto, levando a formação de pites. Portanto, deve-se buscar os fatores que levariam à adsorção preferencial de $\mathrm{SO}_{4}{ }^{-2}$. Raciocínio semelhante foi apresentado por Calderón-Hernández (2012) que considerou a afinidade entre os elementos de liga do aço, $\mathrm{Cl}^{-}$e $\mathrm{SO}_{4}{ }^{-2}$ para discutir diferentes valores de $\mathrm{Ep}$. Buscando-se na literatura, encontram-se valores de energia livre de formação $\left(\Delta G^{\circ}\right)$ para compostos de $\mathrm{NiCl}_{2}$ e $\mathrm{NiSO}_{4}$ de -259.4 e $-760.9 \mathrm{~kJ} / \mathrm{mol}$ (WEAST, 1988), que mostram a intensidade da afinidade química entre essas espécies. O maior potencial termodinâmico para formação de sulfato de níquel comparativamente ao cloreto de níquel sugere que a adsorção de sulfato será mais intensa na medida em que se têm maiores teores de níquel.

Uma das diferenças entre as microestruturas das condições H950 e H1000 é o teor de austenita retida (0,8\% para H950 e 2,9\% para H1000). Na condição H950 ela é praticamente inexistente e na condição H1000, provavelmente, está finamente dispersa pela matriz (foram feitas tentativas de visualização dessa fase por MO e MEV e não foram encontradas evidências de sua precipitação até o nível de resolução que essas técnicas permitem).

Sendo a austenita uma fase rica em $\mathrm{Ni}$ e estando finamente dispersa pela matriz, pode-se propor que a adsorção de $\mathrm{SO}_{4}{ }^{-2}$ tenha ocorrido de forma uniforme pela superfície, acentuando, assim, o efeito inibidor na condição H1000.

Pode-se pensar também no empobrecimento e enriquecimento de outros elementos, como Fe, Cr, Mo e Ti. No entanto, não são encontrados dados termodinâmicos que 
permitam a comparação da afinidade desses elementos com $\mathrm{Cl}^{-}$e $\mathrm{SO}_{4}^{-2}$, o que provavelmente se deve a própria falta de afinidade química.

O comportamento do aço 304L (Figura 41b) reforça a hipótese do efeito do Ni. O teor de $\mathrm{Ni}$ nesse aço é de $8 \% \mathrm{Ni}$, enquanto que o aço Custom $465 \AA$ apresenta $11 \%$ $\mathrm{Ni}$. Desse modo o efeito inibidor do íon $\mathrm{SO}_{4}{ }^{-2}$ é mais acentuado para o Custom $465 \AA$, sendo que a Figura 41 b e a Tabela 12 mostram isso claramente. Inclusive, para o máximo teor de $\mathrm{SO}_{4}{ }^{-2}$ examinado, obteve-se que o aço Custom $465 \AA$ apresenta melhor resistência à corrosão por pite do que o aço 304L.

Um detalhe observado durante a realização dos ensaios de polarização potenciodinâmica está relacionado com o tamanho dos pites obtidos ao término da polarização. As Figuras 42 e 43 mostram que com a adição de $\mathrm{SO}_{4}^{-2}$ são obtidos pites maiores. Esse comportamento pode ser entendido a partir do próprio aumento do Ep. Os pites nucleados durante o ensaio de polarização potenciodinâmica, estão submetidos a uma sobretensão que é tanto maior quanto maior o Ep do material. Por isso, quando é nucleado um pite em alto potencial, sua velocidade de crescimento é maior do que aquela de um pite nucleado em Ep mais baixo. Convém ressaltar, que isso não significa um pior desempenho do aço, pois o objetivo do ensaio é quantificar a resistência à nucleação de pite. Em princípio, o fator determinante do desempenho é o valor de Ep, e não a velocidade com que o pite cresce.

Por fim, os resultados mostraram que o critério na escolha do tratamento térmico pode ser o das propriedades mecânicas almejadas, uma vez que a resistência à corrosão por pite permaneceu em mesmo nível. 


\section{CONCLUSÕES}

Este trabalho permite listar as seguintes conclusões:

1. O aço Custom $465 \AA$, após envelhecimento, apresenta microestrutura constituída por martensita, austenita, fase chi e precipitados de $\mathrm{Ni}_{3} \mathrm{Ti}$.

2. O tratamento de envelhecimento $\mathrm{H} 950$, que ocorre em menor temperatura que o $\mathrm{H} 1000$, apresenta maiores limites de resistência, escoamento e dureza, devido a presença de menor quantidade de austenita e maior quantidade de fase chi.

3. As duas condições de envelhecimento, H950 e H1000, apresentam praticamente a mesma resistência à corrosão por pite.

4. O aço Custom $465 \AA$ apresenta ótima resposta à inibição da nucleação de pite com adições crescentes de sulfato em meio de $0,6 \mathrm{M}$ de cloreto de sódio, sendo que a condição $\mathrm{H} 1000$ se sobressai sobre a condição H950 nesse quesito.

5. Através da adição de sulfato é possível obter maior resistência à corrosão por pite do aço Custom $465 \AA$ comparativamente ao aço $304 \mathrm{~L}$. Isso se deve a maior afinidade química entre níquel e sulfato, comparativamente àquela entre níquel e cloreto, levando a um maior potencial de pite quando o aço contém maior teor de níquel (aço Custom $465 \AA$ ), devido ao favorecimento da adsorção de sulfato pelo níquel.

6. O critério na escolha do tratamento térmico do aço Custom $465 \AA$ deve ser o das propriedades mecânicas almejadas, uma vez que a resistência à corrosão por pite mostrou-se praticamente independente do tratamento térmico. 


\section{SUGESTÕES PARA TRABALHOS FUTUROS}

Considerando os resultados obtidos, apresentam-se as seguintes sugestões para trabalhos futuros:

1. Estudar o efeito de maiores concentrações de sulfato $\left(0,8 \mathrm{M}, 1 \mathrm{M} \mathrm{Na} \mathrm{SO}_{4} \mathrm{e}\right.$ outras) em solução contendo $0,6 \mathrm{M} \mathrm{NaCl}$, para verificar se, com eletrólitos menos agressivos, é possível quantificar alguma diferença de resistência à corrosão por pite entre os tratamentos de envelhecimento.

2. Estudar o efeito de outros tipos de inibidores sobre a resistência à corrosão por pite, por exemplo, $\mathrm{ClO}_{4}{ }^{-}, \mathrm{SO}_{4}^{-2}, \mathrm{NO}_{3}{ }^{-}$e $\mathrm{OH}^{-}$.

3. Estudar 0 efeito de longos tempos de tratamento térmico (maiores que 4 horas) sobre a resistência à corrosão por pite, objetivando encontrar a relação entre as fases precipitadas e a resistência à corrosão, particularmente o efeito do empobrecimento em $\mathrm{Cr}$ e Mo devido à fase chi.

4. Avaliar o efeito dos tratamentos de envelhecimento sobre a resistência à corrosão sob tensão, a qual é uma das preocupações da indústria aeronáutica.

5. Estudar por microscopia eletrônica de transmissão a microestrutura do aço Custom $465 \AA$ visando o entendimento, principalmente, da formação da fase austenita e dos precipitados $\mathrm{Ni}_{3} \mathrm{Ti}$. 


\section{REFERÊNCIAS BIBLIOGRÁFICAS}

AMS 5963. SAE AEROSPACE. Steel, Corrosion-Resistant, Bars, Wire, and Forgings UNS S46500 Vacuum Induction plus Vacuum Consumable Electrode Remelted Solution Heat Treated, Precipitation Hardnable (Composition similar to UNS S46500). United States, 2007. 8p.

ASTM A370. AMS INTERNATIONAL - Standard Test Method and Definitions for Mechanical Testing of Steel Products. United States. 48p, 2012.

ASTM E8/E8M. AMS INTERNATIONAL - Standard Test Method for Tension of Metallic Materials. United States, 2011. 27p.

BECHTOLDT, C. J.; VACHER, H. C. Phase-diagram study of alloys in the ironchromium-molybdenum-nickel system. Journal of Research of National Bureau of Standards, v.58, 1957. p.7-19.

BENSCOTER, A. O. AMS HANDBOOK - Metallography and Microstructure. Ohio, AMS, 1985. v.9, p.285-286.

CALDERÓN-HERNÁNDEZ, J. W. Efeito da Temperatura de Solubilização e da Concentração de ĺons Cloreto e Sulfato sobre a Resistência à Corrosão por Pite dos Aços Inoxidáveis Austeníticos 17Cr-6Mn-5Ni e UNS S30403. $2012.115 \mathrm{p}$. Dissertação (Mestrado) - Escola Politécnica, Universidade de São Paulo, 2012.

CORDEIRO, D. B. Influência de Tratamentos Superficiais de Nitretação e Nitrocarbonetação, Obtidos por Plasma Pulsado, sobre a Resistência à Corrosão do Aço UNS G10350. 2001. 108p. Dissertação (Mestrado) - Escola Politécnica, Universidade de São Paulo, São Paulo, 2001.

CRAIG, B. D.; LANE, R. A; ROSE, D. H. Corrosion Prevention and Control: A Program Management Guide for Selecting Materials. 2nd ed. New York: Advanced Materials, Manufacturing, and Testing Information Analysis Center (AMMTIAC), 2006. 296p.

DEPARTMENT OF DEFENSE. MIL-HDBK-5J-Metallic Materials and Elements for Aerospace Vehicle Structures, 2003. cap. 2.6. 
ECHA. Candidate List of Substances of Very High Concern for Authorisation. Disponível em <http://echa.europa.eu/web/guest/candidate-list-table> acesso em 20 Nov. 2013.

ERICSSON, T. AMS HANDBOOK - Heat treating. Metals Park, AMS, 1991. v.4, p.23.

Euro Inox. Alloying Elements in Stainless Steel and Other Chromium-Containing Alloys. Disponível em <http://www.euro-inox.org/pdf/map/AlloyingElements EN.pdf> acesso em: 5 Jan. 2013.

European Commission. Part 1: List of chemicals subject to export notification procedure. Disponível em <http://edexim.jrc.ec.europa.eu/list annex i chemicals .php?id.part=1 > acesso em 10 Jul.2012.

EVANS, U. R. Corrosion, v.7, N²38, 1951 apud DAVISON; DEBOLD; JOHNSON, 1987 DAVISON, R. M.; DEBOLD, T.; JOHNSON, M. J. AMS HANDBOOK. Corrosion. 9. ed. Metals Park, AMS, 1987. v.13. p.1327-1339.

FAROOQUE, M. et al. The formation of reverted austenite in 18\% Ni 350 grade maraging steel. Journal of Materials Science, v.33, p.2927-2930, 1998.

GARRISON J. W. M.. Stainless Steels: Martensitic. In: Encyclopedia of Materials: Science and Technology, p.8804- 8810, 2008.

GATES, J. D.; JAGO, R. A. Effect of nitrogen contamination on intergranular corrosion of stabilized ferritic stainless steel. Material Science and Technology, v.3, p.450-454, 1987.

GORDON, W.; BENNEKOM, A. van. Review of stabilization of ferritic stainless steels. Material Science and Technology, v.12, p.126-131, 1996.

HERBSLEB, G. Werskt. U. korros. (1982) 33, PP.334-40 apud ALFONSSON, E. e QVAFORT, R. Investigation of the applicability of some PRE expressions for austenitic stainless steels. ACOM, Avesta Corrosion Management, Avesta, 1-1992, p.1-6. ISSN 1101-0681.

HOAR, T. P. and JACOB, W. R. Breakdown of Passivity of Stainless Steel by Halide lons. Nature, v.216, p.1299-1301, 1967. 
HOAR, T. P.; MEARS, D. C.; ROTHWELL, G. P. The relationships between anodic passivity, brightening and pitting. London: Corrosion Science, v.5, p.279-289, 1965.

IBGE. PIB varia 0,2\% em relação ao $4^{\circ}$ tri de 2011 e chega a $R \$ 1,03$ trilhões. Disponível em <http://www.ibge.gov.br/home/presidencia/noticias/noticiavisualiza .php?id noticia=2144\&id pagina=1 > acesso em: 20 Jan. 2013.

KARAMINEZHAAD M.; SHARAFI S.; DALILI K. Effect of molybdenum on SCC of 17$4 \mathrm{PH}$ stainless steel under different aging conditions in chloride solutions. Journal Material Science, v.41, p.3329-3333, 2006.

KIM, S. J.; WAYMAN, C. M. Material Science Engineering A, v.128, p.217-230, 1990.

KITADA, T. et al. Nippon Kokan Technical Report Oversas, n.51 (1987), p. 37-45 apud ALFONSSON, E.; QVAFORT, R. Investigation of the applicability of some PRE expressions for austenitic stainless steels. ACOM, Avesta Corrosion Management, Avesta, 1-1992, p. 1-6.

KUEHMANN, C. J.; OLSON, G. B.; JOU, H. J. Nanocarbide Precipitation Strengthened Ultrahigh-strength, Corrosion Resistant, Structural Steels. EP1368 504 B1. 02Feb. 2010.

LECKIE, H. P.; UHLIG, H. H. Environmental Factors Affecting the Critical Potential for Pitting in 18-8 Stainless Steel. Journal of the Electrochemical Society, v.113, 1966. p.1262-1267.

LEE, E. U., GOSWAMI, R; JONES; VASUDEVAN, A. K. Environment-Assisted Cracking in Custom 465 Stainless Steel. Metallurgical and Materials Transactions A, v.42A, p.415-423, 2011.

LI X.; YIN Z. Reverted austenite during aging in 18Ni (350) maraging steel. Materials Letters, v.24, p.239-242, 1995.

LIN, C. K.; TSAI, W. J. Corrosion fatigue behavior of 15Cr-6Ni precipitation-hardening stainless steel in different tempers. Fatigue Fracture Engineering Material Structure, v.23, p.489-497, 2000. 
LORENZ, K.; MEDAWAR, G. Thyssen Forschung 1 (1969). p. 97-108, apud ALFONSSON, E.; QVAFORT, R. Investigation of the applicability of some PRE expressions for austenitic stainless steels. ACOM, Avesta Corrosion Management, Avesta, 1-1992, p.1-6. ISSN 1101-0681.

MARCUS, P.; OUDAR, J. Corrosion Mechanisms in Theory and Practice. $1^{\mathrm{a}}$ ed. New York, 1995.

MARTIN, J. W.; KOSA T.; DULMAINE, B. A. High Strength, Notch-Ductile Precipitation-Hardening Stainless Steel Alloy. US005681528A. 28 Oct. 1997.

MISCHLER, et al. The chemical composition of the passive film on Fe-24Cr and Fe24Cr-11Mo studied by AES, XPS and SIMS. Corrosion Science, v.32, n.9, p.925944, 1991.

MONKMAN, F. C.; CUFF, F. B.; GRANT, N. J. Computation of Ms for Stainless Steels. Metal Progress, v.71, p.94, 1957.

NAKAGAWA, H.; MIYAZAKI T. Effect of retained austenite on the microstructure and mechanical properties of martensitic precipitation hardening stainless steel. Journal of Materials Science, Japan, v.34, p.3901-3908, 1999.

NUNES, L. P. Fundamentos de Resistência à Corrosão. Rio de Janeiro, Interciência, 2007. p.4

RAGHAVAN, V. Phase Diagrams of Ternary Iron Alloys. United States of America: Indian Institute of Technology Delhi, 1987.p.43-54. AMS International.

RAYNOR, G. V; RIVLIN, V. G. Phase Equilibria in Iron Ternary Alloys. The Institute of Metals: London, 1988. p.316-331.

RENNER et al. Werkst. U. Korros. (1986) 37, pp183-190, apud ALFONSSON, E.; QVAFORT, R. Investigation of the applicability of some PRE expressions for austenitic stainless steels. ACOM, Avesta Corrosion Management, Avesta, 1-1992, p.1-6. ISSN 1101-0681. 
ROHRBACH, K.; SCHMIDT, M. AMS HANDBOOK - Properties and Selection: Irons, Steels, and High Performance Alloys. 10. ed. Metals Park, AMS, v.1. p.1225-1420, 1993.

SATO, N. A Theory for Breakdown of Anodic Oxide Films on Metals. Electrochimica Acta, v.16, p.1683-1692, 1971.

SATO, N; KUDO, K; NODA, T. The Anodic Oxide Film on Iron in Neutral Solution. Electrochimica Acta, v.16, p.1909-1921, 1971.

SCHNITZER et al. Reverted austenite in PH13-8Mo maraging steels. Materials Chemistry and Physics, v.122, p.138-145, 2010.

SCHNITZER el al. Influence of reverted austenite on static and dynamic mechanical properties of a $\mathrm{PH} 13-8$ Mo maraging steel. Materials Science and Engineering A, v.527, p.2065-2070, 2010.

SEDRIKS, A. J. Corrosion of stainless steel. 2. ed. New York, John Wiley.1996. p.62; 102-112; 124.

SINHA et al. Austenite Reversion in $18 \mathrm{NI} \mathrm{CO-FREE} \mathrm{Maraging} \mathrm{-} \mathrm{Steel.} \mathrm{Steel}$ Research, v.66, p.490-494, 1995.

SPEIDEL, M. O. Nitrogen Containing Austenitic Stainless Steel. Mat-wiss. U. Werkstoiftech, v.37, n.10, p.877, 2006.

STAVROS, A. J.; PAXTON, H. W. Effects of heat treatment on the potentiostatic polarization behavior of $18 \% N i$ maraging steel. Corrosion Science, v.12, p.739-748, 1972.

SUUTALA, N.; KUKELA, M. Proc. Stainless Steel-84, Gothenburg, Sep. 3-4 (1984), pp 20-47, apud ALFONSSON, E.; QVAFORT, R. Investigation of the applicability of some PRE expressions for austenitic stainless steels. ACOM, Avesta Corrosion Management, Avesta, 1-1992, p.1-6. ISSN 1101-0681.

SZLARSKA-SMIALOWSKA, Z. Review of Literature on Pitting Corrosion Published Since 1960. Corrosion-NACE, v.27, n.26, p.223-233, 1971. 
TRUMAN, J. E. Proc. U. K. Corrosion -87, Brighton, Oct. 26-28, pp. 111-29, apud ALFONSSON, E.; QVAFORT, R. Investigation of the applicability of some PRE expressions for austenitic stainless steels. ACOM, Avesta Corrosion Management, Avesta, 1-1992, p.1-6. ISSN 1101-0681.

VISWANATHAN, U. K.; BANERJEE, S.; KRISHNAN, R. Effects of aging on the microstructure of 17-4 PH stainless steel. Material Science Engineering A, v.104, p. 181-189, 1988.

VOORT et al., AMS HANDBOOK - Metallography and Microstructure. Ohio, AMS, 1985. v.9, p.681.

WASHKO, S. D.; AGGEN, G. AMS HANDBOOK - Properties and Selection: Irons, Steels, and High Performance Alloys. 10.ed. Metals Park, AMS, v.1. p.1303-1408, 1993.

WEAST, R. Handbook of chemistry and physics 1 st student edition. Florida, CRC. 1988. Section D. p.55-60.

WEGRELIUS, L; OLEFJORD, I. Dissolution and passivation of stainless steel exposed to hydrochloric acid. Materials Science, v.185-188, p.347-356, 1995.

WERT D. E., DiSabella R. P., Advanced Stainless Offers High Strength, Toughness and Corrosion Resistance Wherever Needed. Carpenter Technology Corp. Wyomissing, PA, USA. 2006. p.1-6.

WRIGHT, J.; JUNG, J-W. Martensitic Stainless Steel Strengthened by Ni3Ti n-Phase Precipitation. US0007879159B2. 01 Feb. 2011. 